Design Features and Technology Uncertainties for the Next Generation Nuclear Plant

Independent Technology Review Group

June 30, 2004

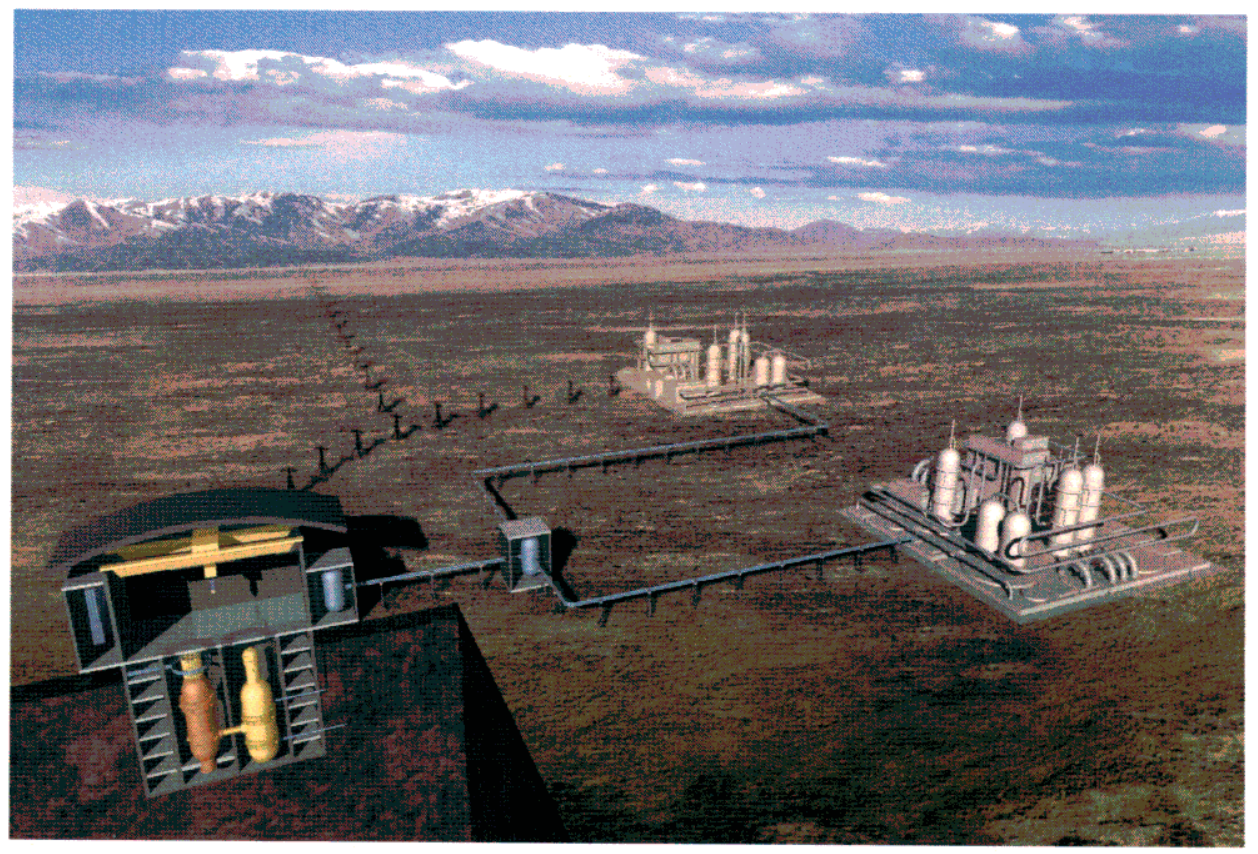

Idaho National Engineering and Environmental Laboratory Bechtel BWXT Idaho, LLC 


\section{Disclaimer of Endorsement}

Reference herein to any specific commercial product, process, or service by trade name, trademark, manufacturer, or otherwise, does not necessarily constitute or imply its endorsement, recommendation, or favoring by the United States Government, the Idaho National Engineering and Fnvironmental I ahoratory, or Bechtel BWXT Idaho, LLC. The views and opinions of authors expressed herein do not necessarily state or reflect those of the United States Government, the Idaho National Engineering and Environmental Laboratory, or Bechtel BWXT Idaho, LLC, and shall not be used for advertising or product endorsement purposes. 


\title{
Design Features and Technology Uncertainties for the Next Generation Nuclear Plant
}

\author{
Independent Technology Review Group \\ Phil Hildebrandt, Chairman; Engineering, Management and Technology, Inc. \\ Osamu Baba, Co-Chair; Oarai Research Establishment, JAERI, Japan \\ Ron Ballinger; Massachusctts Institute of Technology \\ Robert Brodsky; Nuclear Power Technology, Inc. \\ Hans-Wolfgang Chi; Independent Consultant \\ Dennis Crutchfield; Independent Consultant \\ Herb Estrada; Independent Consultant \\ Jean-Claude Garnier; CEA/DEN/Cadarache, France \\ Gerald Gordon; Materials and Corrosion Performance \\ Richard Hobbins; Independent Consultant \\ Dan Keuter; Entergy Nuclear, Inc. \\ Marilyn Kray; Exelon Corporation \\ Philippe Martin, Co-Chair; CEA/DEN/Cadarache, France \\ Steve Melancon; Entergy Nuclear, Inc. \\ Christian Simon; Universite P\&M Curie, France \\ Henry Stone; Independent Consultant \\ Robert Varrin; Dominion Engineering, Inc. \\ Werner von Lensa; Forschungszentrum Juelich $\mathrm{GmbH}$, Germany
}

\section{Advisors}

Jeff Hedges; ChevronTexaco

Shigeru Kato; Nuclear Fuel Industries, Japan

Kazahisa Nishimura; Nuclear Fuel Industries, Japan

Masuro Ogawa; Japan Atomic Energy Research Institute, Japan

Kazuhiro Sawa; Japan Atomic Energy Research Institute, Japan

Alice Tang; ChevronTexaco

Masahido Umaya; Mitsubishi Heavy Industries, Japan

INEEL Project Coordinator

John M. Ryskamp; Idaho National Engineering and Environmental Laboratory

June 30, 2004

\section{Idaho National Engineering and Environmental Laboratory Idaho Falls, Idaho 83415}

\author{
Prepared for the \\ U.S. Department of Energy \\ Office of Nuclear Energy, Science and Technology \\ Under DOE/NE Idaho Operations Office \\ Contract DE-AC07-99ID13727
}





\section{ABSTRACT}

This report presents the conclusions, observations, and recommendations of the Independent Technology Review Group (ITRG) regarding design features and important technology uncertainties associated with very-high-temperature nuclear system concepts for the Next Generation Nuclear Plant (NGNP). The ITRG performed its reviews during the period November 2003 through April 2004.

The report includes an Executive Summary and selected discussions on focus areas important to fulfilling the high-level functional objectives for NGNP. These focus areas include:

- Commercial Viability

- Fuel Development

- Materials Development

- Power Conversion

- $\quad$ Process Energy Utilization

- Major Components

- Systems Design

- Safety and Licensing.

The report also includes conclusions regarding the comparative risks and advantages in addressing technology uncertainties of the nuclear system concepts that were considered, including the helium-cooled prismatic reactor, the heliumcooled pebble bed reactor, and the molten-salt-cooled prismatic reactor.

The ITRG observations and recommendations focus on the most important of the design features and technology uncertainties. Mitigation of the risks associated with these uncertainties requires the coordinated application of technical talent, strong management structure and appropriate resources, and careful weighing of alternatives. Recommendations are made for those considerations important to mitigating the technology and design risks. 


\section{EXECUTIVE SUMMARY}

\section{Background}

The United States Department of Energy (DOE) authorized the Idaho National Engineering and Environmental Laboratory (INEEL) to have the Independent Technology Review Group (ITRG) conduct a review of technology alternatives for meeting the functional objectives for the Next Generation Nuclear Plant (NGNP). The ITRG membership is broadly experienced in the design, construction, and operation of nuclear systems and represents an international perspective with selected specific expertise spanning the range of nuclear reactor applications. Selected advisors from the nuclear, heavy equipment, and petrochemical industries assisted in the review, as requested.

The ITRG activities include reviewing (1) the design features and important technology uncertainties of a very-high-temperature reactor (VHTR) concept for the Next Generation Nuclear Plant represented by the helium-cooled prismatic reactor, and (2) the advantages that may be provided by the helium-cooled pebble bed reactor and the molten-salt-cooled prismatic reactor concepts in addressing technology uncertainties associated with the representative concept. Technology and design uncertainties are characterized in terms of performance benefits and programmatic risks to assist in focusing the necessary research and development (R\&D) activities.

The high-level functions and requirements defined in the Idaho National Engineering and Environmental Laboratory report INEEL/EXT-03-01163, dated September 2003, ${ }^{1}$ for the NGNP are used as a starting point. However, the appropriateness of these functions and requirements is scrutinized as well.

This report presents the ITRG conclusions, observations, and recommendations based on (1) discussions with selected proponents of nuclear system concepts that potentially fulfill many of these high-level functions and requirements, (2) review of a comprehensive range of technical reports prepared in support of development of the Generation IV Nuclear Energy Systems Technology Roadmap, ${ }^{2}$ and related documents. The discussions with the proponents were supported by extensive public as well as limited-distribution documentation, as shown in the references and bibliography. Additional information was provided by informal responses to ITRG members' questions. The concepts discussed with the proponents were at varying levels of development and detail, and all were preconceptual from a design standpoint for the NGNP functional objectives. The ITRG approached these concept discussions with the proponents with the understanding that plant design configurations are conceptual in nature, any design analyses are preliminary, and descriptive quantities are based primarily on indicative analyses and judgment.

The ITRG observations and recommendations focus on overall design features and important technology uncertainties of a very-high-temperature nuclear system concept for the NGNP. The observations and recommendations may apply to one or more of the nuclear system concepts described above; concept-specific observations and recommendations are identified as appropriate. However, most of the observations and recommendations apply independently of the specific nuclear system configuration.

This report also considers alternative and developmental means of producing hydrogen using the high-temperature process energy available in the NGNP concept. The ITRG observations and recommendations focus on the nuclear system requirements necessary to support these alternative concepts for producing hydrogen, and on the means for transferring the energy from the nuclear reactor system to a hydrogen production facility. This report also touches bricfly on the types of technologies and relative advantages of various hydrogen production concepts. The ITRG further suggests broadening 
the process energy considerations beyond hydrogen production to include such considerations as cogeneration of heat and power $(\mathrm{CHP})$ for refineries and petrochemical complexes, including steam reforming and hybrid hydrogen production processes.

\section{High-Level Functional Objectives}

The conclusions, observations, and recommendations summarized below are based on achicving an appropriate balance between development risks and the broadly defined high-level functional objectives for the NGNP. Thesc objectives include demonstrating an economically viable nuclear system, licensable in the United States, with important commercially attractive production capabilities including highefficiency power conversion, effective utilization of process heat (e.g., for production of hydrogen), and intrinsic safety, allowing greater freedom of choice in locating the plant. The NGNP is to be designed, constructed, licensed, and operating by no later than 2020, with a target date for initial operations of 2017. These high-level functional objectives are taken as inviolable in assessing the design features and technology uncertainties.

Selection of the technology and design configuration for the NGNP must consider both the cost and risk profiles to ensure that the NGNP establishes a sound foundation for future commercial deployment. If the technology stretch is excessive, the NGNP may become solely an exercise in research and development, and fail to accomplish the high-level functional objectives needed to achieve its broader demonstration mission. The NGNP challenge is to achieve a significant advancement in nuclear technology while at the same time setting the stage for deployment of the new tcchnology in the commercial sector soon after 2020.

\section{Overall Conclusions}

The ITRG reviewed several nuclear system concepts for a very-high-temperature reactor for the NGNP including the helium-cooled prismatic reactor, the helium-cooled pebble bed reactor, and the molten-salt-cooled prismatic reactor, together with the associated power conversion system and process energy utilization concepts. The review was performed from November 2003 through April 2004 and included meetings and discussions with the proponents that were supported by extensive public as well as limited-distribution documentation as shown in the references and bibliography. Additional information was provided by informal responses to ITRG members' questions. The ITRG has reached the following overall conclusions regarding these concepts:

- There are specific differences in the technology and design uncertainties for the two helium-cooled reactor concepts, especially with regard to fuel features and specifications. Also, the reactor vessel design, materials, and dimensions of either the prismatic or pebble bed reactor may vary depending on the design concept. However, there are no developmental technology or design uncertainties that suggest either the prismatic block or the pebble bed concept is more likely to be a successful candidate for the NGNP application. The most important technology and design development areas are common to both. The most important uncertainties appear manageable, and the highlevel functional objectives for the NGNP appear achievable for these concepts.

- In comparison, the molten-salt-cooled concept is substantively less mature than the helium-cooled reactor concepts. The potential benefits of the molten-salt-cooled reactor compared to the heliumcooled concepts (e.g., potentially increased cycle efficiency, low primary system pressure, passive safety achieved at higher power levels, improved heat transfer, and smaller equipment size for comparable power ratings) were weighed against the greater range of developmental risks (e.g., coolant choice, coolant effects on materials, irradiation effects on the coolant, maintenance and 
refueling practicalities, licensing uncertainties). The ITRG judges that the extent of the risks makes it impractical for the molten-salt-cooled reactor to be successfully developed and implemented to fulfill the NGNP high-level functional objectives by 2020. Accordingly, the characterization of the technology and design risks summarized below does not further consider the molten-salt-cooled reactor concept.

- The potential for using a molten salt as a low-pressure heat transfer medium in the intermediate loop between a helium-cooled nuclear system and the hydrogen production facility may be a desirable design approach, and is discussed further in the section on process energy utilization.

\section{Focus Area Summary}

The following paragraphs provide a brief, high-level summary of the focus areas discussed in this report. The ITRG observations and recommendations are included in the next section.

Commercial Viability. Selection of the technology and design configuration for the NGNP must consider both the cost and risk profiles to ensure that the demonstration plant establishes a sound foundation for future commercial deployments. The NGNP challenge is to achieve a significant advancement in nuclear technology while at the same time setting the stage for an economically viable deployment of the new technology in the commercial sector soon after 2020.

Fuel Development. Coated-particle fuel performance is central to the economic viability and potential commercial interest in the helium-cooled nuclear system concepts and directly establishes the operational and accident mitigation design features for the NGNP. The German TRISO fuel development previously used for the Arbeitsgemeinschaft Versuchsreaktor (AVR-Germany) has been the sole successful qualification of this fuel type. Those design and manufacturing techniques have been adopted for the fuel used in the operating demonstration reactors High Temperature Engineering Test Reactor (HTTR-Japan) and High Temperature Reactor-10 (HTR-10-China), and for the Pebble Bed Modular Reactor (PBMR-South Africa) currently under development. Qualification of coated-particle fuel technology is an important development task for the NGNP program.

Materials Development. Qualification of materials for successful and long-life application at the high-temperature conditions planned for the NGNP is a significant development task for the NGNP. Few choices exist for metals for use at NGNP conditions and also, the design lifetime considerations for the metallic components may restrict the maximum operating temperature. A time-consuming development of other material technologies (e.g., oxide dispersion strengthened or refractory metals, or ceramics and carbon-based materials) may be required to achieve practical component lifetimes for commercial deployments of a VHTR at temperatures higher than that recommended herein for the NGNP concept.

Power Conversion System. Development of power conversion systems based on the Joule-Brayton cycle is being considered for high-efficiency conversion of the high-temperature energy from a heliumcooled reactor to electrical power. This is an important technology development challenge for the NGNP. The proponents are considering both direct and indirect cycles. Each offers important design tradeoffs in application of materials and anticipated operational viability.

Process Energy Utilization. A high-level functional objective for the NGNP is the successful demonstration of the use of high-temperature process energy for the efficient generation of hydrogen. The developmental areas include (1) choosing and developing the specific hydrogen generation technology from the large number of candidate processes, (2) qualifying materials for use in the aggressive environments associated with these technologies, and (3) determining the most effective means of transferring the high-energy process heat from the helium-cooled reactor to the hydrogen 
production facility (e.g., alternative heat transfer media, including helium or molten salt). The various candidate processes impose different requirements on the NGNP and potentially affect the overall design, including critical components such as the intermediate heat exchanger.

Major Components. There are several undeveloped components or subcomponents for the NGNP, including the intermediate heat exchanger (necessary to isolate the nuclear system from the hydrogen production plant, and the power conversion system in the case of an indirect cycle), the hot gas isolation valves, the reactor pressure vessel, selected reactor internals, the reactor inlet/outlet pipes, the helium circulator, the insulation systems, and instrumentation for high-temperature application. The most challenging are the intermediate heat exchanger and associated isolation valves. Qualification of materials for the high-temperature and extended lifetime conditions is critical and alternatives must be carefully evaluated.

System Design. One of the most important system design issues is selection of the plant control concepts for coupling the two diverse processes (electric power generation and hydrogen production). The dynamic response of the plant (e.g., during startup, shutdown, sudden loss of electrical load or hydrogen production, and loss of secondary coolant pressure) must be carefully assessed and characterized.

Safety and Licensing. The licensing strategy for the NGNP has yet to be developed. Key issues include (1) definition of fuel performance characteristics, (2) definition of the design basis conditions for a helium-cooled reactor system, (3) the technical justification for the source term following design basis accidents, (4) the technical basis for the use of a confinement or a containment to retain inventories of radioactive contamination, including fission products, following a design basis accident, and (5) practical approaches to maintainability and inspectability to support continued economical operations.

\section{Observations and Recommendations}

The most important ITRG observations and recommendations for the success of the NGNP are included in this report and are summarized below. The ITRG concludes that there are promising technology alternatives for meeting the functional objectives for the NGNP, and considers it important to focus on the associated risks to help identify approaches to mitigating these risks. Mitigation of the risks requires the coordinated application of technical talent, strong management structure and appropriate resources, and careful weighing of alternatives.

An important backdrop for the ITRG's conclusions and associated recommendations includes the practicalities associated with the commercial licensing process. Considering the current preliminary nature of the potential nuclear system design concepts for the NGNP, and the extent of the regulatory infrastructure development necessary for licensing, the ITRG concludes that the practical course for licensing of the NGNP will be as prescribed in 10CFR50. This involves a two-part process requiring separate applications for a construction permit and an operating license. The schedule for submittal of these applications is critical to the extent of technology development that can be achieved. The milestones for this process, for an operational target of 2017, are anticipated to be:

- Construction Permit Application - 2008

- $\quad$ Construction Permit Issued - 2011

- $\quad$ Operating License Application - 2014

- $\quad$ Operating License Issued - 2016. 
The construction permit application milestone sets the initial timeframe during which sufficient confidence must be established that there are credible approaches for the development of the applicable technologies. Development and qualification of these technologies must in turn be completed by the milestone for submitting an application for an operating license.

\section{NGNP Fuel Development}

\section{The schedule for the DOE fuel development and qualification program (Advanced Gas Reactor (AGR) program) for the reactor concepts under consideration does not support the NGNP target completion schedule.}

Successful operational and accident performance of ceramic-coated-particle fuel (TRISO) is cssential to the safety casc. Adequate fucl performance is also central to the cconomic viability and potential commercial interest in this nuclear system concept, and is a fundamental requirement for all concepts under consideration. The operational and accident mitigation design features that must be included in the NGNP are directly determined by the anticipated performance of the coated-particle fuel.

Successfully qualified fuel fabrication processes were used for fuel in the German demonstration reactor Arbeitsgemeinschaft Versuchsreaktor (AVR), and these or somewhat modified processes are currently being used for fuel in the Japanese High Temperature Engineering Test Reactor (HTTR) and Chinese High Temperature Gas-Cooled Reactor (HTR-10) demonstration projects. Qualification of such fuel for the Pebble Bed Modular Reactor, which is planned to be built in South Africa, is also substantially further advanced than the DOE fuel development. The fuels for these programs were, and are, hased on use of TRISO fuel with a $\mathrm{UO}_{2}$ kernel, a SiC harrier layer, and a design burnup of less than $10 \%$ fissions per initial metal atom (FIMA) in a low power density design.

The AGR program goal is to develop fuel to meet the high power density $(6-10 \mathrm{~W} / \mathrm{cc})$, high burnup (15 25\% FIM $\Lambda$ ), and high outlet gas temperature parameters envisioned for a Generation IV very-hightemperature reactor. Because the successful use of $\mathrm{SiC}$ TRISO-coated $\mathrm{UO}_{2}$ fuel is limited to combinations of comparatively lower power density $(\sim 2-4 \mathrm{~W} / \mathrm{cc})$, lower burnup $(<10 \%$ FIMA) and mostly lower fuel temperatures $\left(\sim 1150^{\circ} \mathrm{C}\right)$, the AGR program is qualifying TRISO fuel with a uranium oxycarbide (UCO) fuel kernel, a SiC barrier layer, and a design burnup of 15-25\% FIMA. Although the AGR fuel development and qualification program is using the successful German coating process as its baseline, the more aggressive reactor design goals require a significant extrapolation and extension of the existing fuel development database.

These qualification goals, while desirable for the long term for NGNP, are more ambitious than necessary for initial operation of NGNP. A credible backup approach based on the previously successfully qualified fuel fabrication processes is judged important as a parallel activity in the event developmental problems are encountered in achieving these more aggressive reactor design goals.

In addition, the completion of work to provide a validated methodology for establishing mechanistic source terms is predicated on the basis of cost sharing participation by industry. Solidifying the funding and schedule for this work, which is a key element of the safety case, is required to provide timely support for licensing activities.

The ITRG recommends that:

1. U.S. fuel development for the NGNP should initially focus on successful fabrication, testing, and qualification of coated-particle designs and manufacturing processes that have the most extensive worldwide experience hase ( $\mathrm{UO}_{2}$ kernel), thereby reducing the risk for fuel qualification on the NGNP completion schedule. Once it is determined that a $\mathrm{UO}_{2}$ kernel will be successful up to a 
burnup of 10\% FIMA at appropriate reactor design conditions, then the UCO kernel, as part of the AGR development program, could be phased in as appropriate to provide the capability of increased burnup and increased power density to reduce fuel costs and increase plant power. The ITRG considers that this approach is acceptable for initial core loads, with the capability to achieve increased performance in subsequent core loads as the improved UCO fuel types are developed.

The reactor core design should be compatible with the demonstrated capabilities of the fuel used in the NGNP (e.g., in areas such as packing fraction, power density, temperature, and thermal gradients).

2. Alternatives such as licensing or purchasing similar and previously successful technology from an offshore vendor should be pursued and implemented as a necessary parallel path forward for the initial NGNP cores. It also may be possible to obtain commercial assistance to construct and operate a fuel fabrication pilot plant within the United States if required to meet U.S. Nuclear Regulatory Commission (NRC) licensing conditions.

3. The fuel development program should incorporate both $\mathrm{UO}_{2}$ and $\mathrm{UCO}$ and continue as planned to determine the influence on fuel quality of different manufacturing processes for producing fuel particle coatings and compacts. The program should continue to investigate the thermal hydraulics and neutronics of complete fuel elements, e.g., with regard to maximum fuel temperatures and power peaking, for both kernel types.

4. Means should be found to improve the overall schedule for fuel development to ensure successful qualification within the required timeframe and support the licensing milestones. Further, the ITRG recommends that means to fund the completion of the mechanistic source term work on a schedule to support licensing be established as soon as possible.

5. Scope and priority for activities within the fuel development program necessary for the success of the NGNP should be established by the NGNP project rather than by the fuel development program. (As discussed further below, the NGNP project management structure is essential to control of project-related development activities such as these.)

\section{NGNP Reactor Outlet Temperature}

\section{The reactor outlet temperature for the NGNP should be in the range of 900 to $950{ }^{\circ} \mathrm{C}$.}

While the fuel appears to support an outlet temperature of $1000^{\circ} \mathrm{C}$, high-temperature materials development that supports the $1000^{\circ} \mathrm{C}$ outlet temperature and a 60 -year design life and provides a licensable nuclear system is not achievable within the NGNP schedule. The maximum acceptable temperature for a practical design life and acceptable operational inspection schedule is about 900-950 ${ }^{\circ} \mathrm{C}$, based on available metallic materials that could be used for the reactor internal structures, power conversion system (in particular the hot pipe and high-pressure turbine), and the intermediate heat exchanger (IHX). An important consideration in drawing this conclusion is the need to effectively limit the extent of Class 1 pressure boundary metals subject to time-dependent deformation (creep) (see discussion below).

The ITRG considers that the power conversion efficiencies that can be achieved at this reduced outlet temperature continue to be economically and commercially viable and fulfill the high-level functional objectives for the NGNP and its potential commercial applications. Further, the process heat conditions at a reduced temperature are still expected to fulfill the high-level functional objectives for hydrogen production and other uses of nuclear process heat. 
Based on material development considerations, the ITRG recommends that the specified design requirement for the NGNP be revised to limit the maximum metal temperature to less than $900{ }^{\circ} \mathrm{C}$. This will require reducing the maximum core average outlet temperature to about $900-950{ }^{\circ} \mathrm{C}$. Note that even at this metal temperature some reactor core subassemblies might require replacement during the 60 -year design plant life. The outlet temperature could be acceptably increased if the plant is designed for significantly more frequent replacement of selected components or by reducing design life. However, such an approach should carefully weigh whether an operationally viable plant results. It is likely that increasing the metal temperature beyond $900^{\circ} \mathrm{C}$ will result in allowable stresses that make the use of metallic matcrials impractical. Proposals for designing the NGNP should be required to fulfill the functional objectives for economic power production and process heat usage at a reactor outlet temperature of $900-950{ }^{\circ} \mathrm{C}$, and limit metal temperatures to less than $900{ }^{\circ} \mathrm{C}$.

As requested by INEEL, Appendix A summarizes a possible path forward and a parallel development approach to pursue an increased reactor outlet temperature (e.g., $1000^{\circ} \mathrm{C}$ ) once a successful commercial demonstration of NGNP has been achieved at the recommended maximum metal temperature limit of $900^{\circ} \mathrm{C}$. However, consistent with these observations and conclusions, the ITRG considers that the need to achieve higher outlet temperatures in a gas-cooled reactor must be justified (e.g., on an economic basis) before embarking on the extensive research and development program requiring many years and extensive resources. Lacking this justification, the ITRG does not recommend attempting to achieve a gas outlet temperature of $1000^{\circ} \mathrm{C}$ for the NGNP, but this operating temperature could be a long-term VHTR goal.

\section{Power Conversion Concept}

\section{An indirect cycle power conversion concept fulfills the high-level functional objectives with reasonable development risk.}

The alternative vertical single-shaft and multi-shaft direct-cycle (Joule-Brayton cycle) power conversion systems suggested by two direct-cycle proponents, while anticipated to be thermodynamically more efficient than a similar indirect cycle, introduce risks both in development and in operational practicality that threaten the success of the NGNP. Access for maintenance to critical systems and components, and the level of effort necessary for required inspections and repairs are important considerations for commercial owner/operators. The vertically oriented direct cycle power conversion system concept, particularly the integrated shaft arrangement, involves more development risk and safety issues than the indirect cycle and represents greater risk in achieving a successful maintenance approach.

The ITRG recommends that the design configuration for the NGNP proceed on the basis of an indirect cycle for power conversion. This reduces and focuses the development risk on the intermediate heat exchanger(s) required for the indirect cycle and for utilization of process heat. It also allows combining two or more reactor modules with one larger power conversion system to improve the economics. The recommended approach does not foreclose the possible use of direct cycle power conversion systems in Generation IV plants beyond the NGNP, particularly if the secondary circuit of the NGNP is also used as a test loop for direct cycle components. In addition to their small advantage in cycle efficiency, the direct cycles appear to offer advantages in plant simplicity and may allow for further increase of the reactor outlet temperature, even beyond $1000^{\circ} \mathrm{C}$, once the materials problems related to the increased temperatures are resolved.

However, as noted above, a still-to-be-defined reactor outlet temperature that limits the temperature in the metallic components in the primary circuit to about $900{ }^{\circ} \mathrm{C}$ is the maximum that should be pursued within the time frame specified for NGNP. It is recognized that the development of an intermediate heat exchanger capable of prolonged and reliable operation at material temperatures in the $900{ }^{\circ} \mathrm{C}$ range is 
itself a developmental challenge, particularly in the metallurgy of the heat exchanger materials and the development of a code-acceptable approach to the heat exchanger design. However, these challenges must also be overcome if NGNP is to be used for the thermochemical production of hydrogen. Moreover, similar metallurgical challenges confront the turbomachinery design of the direct cycles, in addition to several other difficult and diverse challenges of comparable magnitude. The radial and axial bearing systems and the design of low leakage turbine-compressor machinery for the helium working fluid are examples.

\section{Hydrogen Production Capability}

The development of a high-temperature hydrogen production capability for the NGNP should be accelerated.

A high-level functional objective for the NGNP is demonstrating effective utilization of process energy for production of hydrogen. Functional and design decisions for the NGNP that must be made include: (1) quantity and rate of heat to be transported, (2) need for an intermediate heat transfer loop to provide isolation between the nuclear and hydrogen production portions of the plant, (3) hydrogen production temperature requirements, (4) effect of loss of load to the hydrogen plant, and (5) effect of loss of reactor power. Each of the candidate hydrogen production processes potentially would impose different system and component requirements on the NGNP.

The ITRG recommends that DOE implement an accelerated plan for the hydrogen production concept development that is compatible with and supportive of the NGNP schedule. This plan should promote strong international cooperation, e g., with the Japan Atomic Energy Research Institute (JAERI), to ensure a better understanding of the technical issues with the sulfur-iodine (SI) and related processes. This may permit narrowing the number of candidate processes being pursued. Further, detailed recommendations in this regard are provided in Section 5, Process Energy Utilization.

\section{Design Uncertainties}

- The greatest equipment development risks are the intermediate heat exchanger between the reactor and secondary coolant system, and the hot gas valves that isolate the nuclear side from the power conversion system (for an indirect cycle) or the hydrogen production plant in case of disturbances.

The ITRG recommends that a specific development task be implemented by DOE, irrespective of the specific nuclear system design configuration that is chosen for NGNP, to initiate evaluation of current technologies and approaches (e.g., HTTR; former German PNP) to get an early start on the design and material concepts appropriate for this equipment.

- $\quad$ One of the concepts for the NGNP that was reviewed included operating conditions that subject the pressure boundary to time-dependent deformation (creep).

The ITRG considers that this design approach is not appropriate and recommends that the temperature of the irreplaceable primary reactor coolant pressure boundary be limited such that time-dependent deformation is insignificant.

- Preliminary evaluations suggest that a single plant that is designed for both electric power generation and hydrogen production may have design and operations challenges not present in plants designed for a single purpose. 
The challenges associated with co-generation of electricity and hydrogen are primarily due to the differences in the thermodynamic requirements for the power conversion system concept and hydrogen production plant, particularly with regard to the pressure. For example, direct-cycle plants tend toward higher pressures (70-90 bar) whereas most nuclear process heat applications perform better at moderate pressures (10-40 bar). Additional problems might occur during upset conditions (e.g., hydrogen production plant trip). Initial indications are that using an indirect cycle such as recommended above may be more compatible with use of the nuclear system for simultaneous electrical power generation and for hydrogen production.

The ITRG recommends that an early task in the conceptual design for the NGNP should be to perform additional design and analytical studies to investigate possible configurations and control schemes for electric power generation and hydrogen production to confirm or deny these preliminary evaluations. Special attention should be put on the integration of a nuclear heat source with petrochemical facilities that may be the main consumers of hydrogen and nuclear process heat in the future.

- The high-level requirements defined in INEEL/EXT-03-01163, September 2003, should not over specify the desired capability.

The most obvious example of over-specification is specifying the required reactor outlet temperature rather than the functional capability to achieve electric power generation or hydrogen production with a range of acceptable efficiencies based on economic considerations. The result is that the design can be driven to a more technically risky position than may be warranted.

The I'TRG recommends that the functional specification should be reviewed to remove other instances of potential over specification.

\section{Other Related Issues}

- $\quad$ The Licensing Strategy for the NGNP needs to be developed.

Licensing by the U.S. Nuclear Regulatory Commission (NRC) and other regulatory agencies in the United States is a high-level functional objective and necessary to ensure commercial viability of the NGNP. There are several technical and regulatory challenges that have the potential to delay timely licensing of the NGNP (e.g., mechanistic source term, design basis definition, confinement concept, bases for site selection).

The ITRG recommends that a comprehensive licensing strategy, which includes early involvement of the NRC, be developed within the next two years with the assistance of power generating companies that are potential owners of the commercial application of the NGNP. Benefit could be taken from recent licensing activities of the Pebble Bed Modular Reactor (PBMR) in South Africa because of many common generic issues.

- Direct and timely participation in designing, building and operating the NGNP by companies that are potential owners of the commercial application of the NGNP is essential at the earliest opportunity.

This may include power generating companies and companies that may be end-users of process energy. The experience and perspectives of these commercial entities are essential to ensure that the NGNP remains commercially viable. As a result of extensive operating experience in the commercial nuclear industry, many design modifications were made to enhance safety, maintainability, reliability, and overall operational economics. Involving commercial nuclear industry entities during the design and development phases of the NGNP effort should ensure that 
the lessons learned from Light Water Reactor (LWR) operations are incorporated into the NGNP. Similarly, engagement of entities with experience in petrochemical operations will ensure that industry experience in chemical plant operations and processes are incorporated during the design, development, and integration of the hydrogen production and other process heat applications. In addition, industry participation during the development phases should facilitate the licensing process for the NGNP and perhaps establish a precedent or model for future deployments in the commercial sector. Still another benefit of early industry participation in the NGNP is the direct access to commercial industry economic analyses that could alter or become important considerations in NGNP and chemical process selection and related design decisions.

The ITRG recommends, therefore, that an ongoing joint commercial and government structure be implemented at the earliest opportunity. Such a collaborative effort could take the form of a consortium, including direct participation by the potential future operator and license holder for the NGNP. This recommendation relates to the need to provide an integrated project structure as discussed below, in that it provides an entity for involving interested utilities and end-users.

- There are many high-risk resource-intensive development issues associated with the NGNP that could benefit from direct participation of the international community, drawing on its previous and ongoing experience.

The ITRG supports the DOE's ongoing efforts to involve the international community in the NGNP program and recommends that the DOE investigate specific and formal methods of achieving timely, long-term international participation in selected areas. A potential starting point for such an arrangement could be based on the ongoing Generation IV International Forum (GIF) VHTR related R\&D activities. The objective should be direct participation by selected international participants in research activities supporting the NGNP design and development (e.g., as an international project and/or via contracting).

A provision for direct input from former and actual high temperature reactor projects (e.g., HTTR, HTR-10, PNP, EVO, PBMR) should be implemented into the NGNP R\&D Plan. Particular benefit can be taken from the ongoing Japanese test capabilities for the coupling of a nuclear heat source with hydrogen production processes at HTTR. Direct involvement of current ongoing commercial projects (e.g., PBMR team) could accelerate the NGNP development by exploiting generically applicable information. With this approach, R\&D can more readily focus on actual needs, eliminating unnecessary duplication.

- Credible cost estimates for the design, construction and operation of the NGNP are needed.

The ITRG recommends early development of a cost baseline (based on completion of the conceptual design), including accounting for uncertainties in the research and development costs as a project risk. This cost baseline, with research and development costs removed, provides an important basis for evaluations by potential owners of the commercial version of NGNP. The cost baseline should be tightly coupled to the integrated project structure recommended below, so that design and development tradcoff studics can be conducted as the NGNP design detail evolves, including the tradeoffs of potential cogeneration of electricity and process heat.

- An integrated project management structure is necessary for the NGNP at the earliest opportunity, not only to ensure successful design, construction, and startup, but also to ensure successful and timely completion of multiple development activities.

The ITRG recommends that an integrated project management structure should be implemented as soon as practical. Development activities for which this is particularly important include (1) fuel 
development and qualification, (2) high-temperature materials development, (3) practical fabrication and inspection considerations for the large reactor pressure vessel, (4) implementation of a licensing strategy, (5) evaluations of practical means for startup, shutdown, control, and transient response of the nuclear system, including the power conversion systems, and (6) integration of hydrogen development and production facilities. 


\section{CONTENTS}

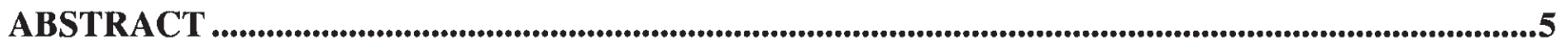

EXECUTIVE SUMMARY .......................................................................................................................................7

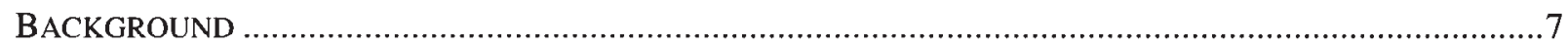

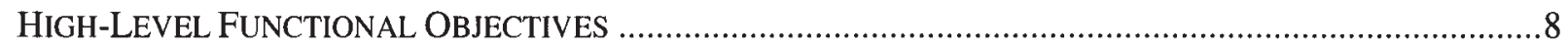

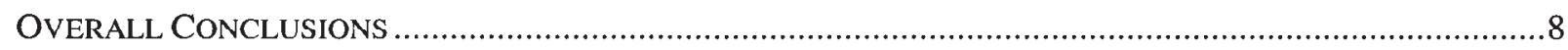

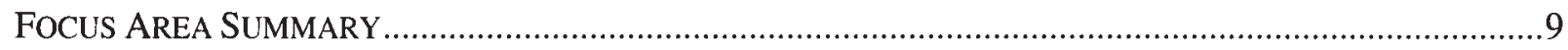

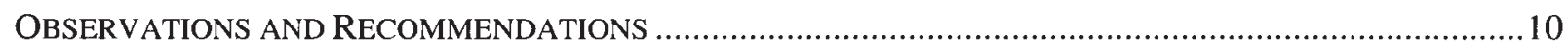

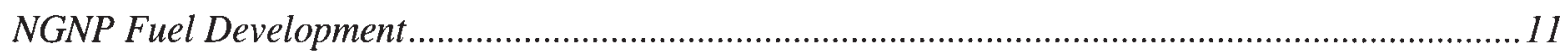

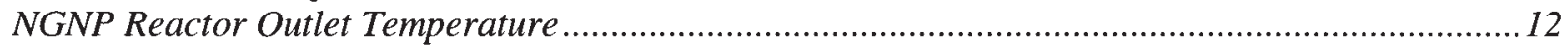

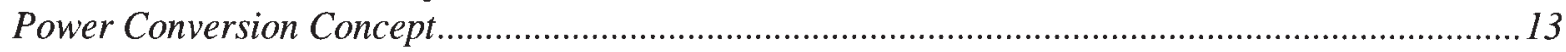

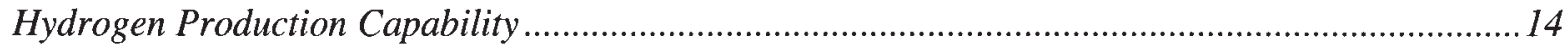

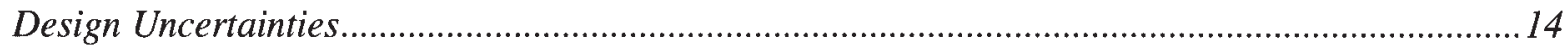

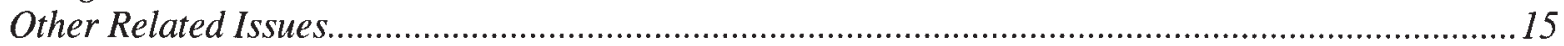

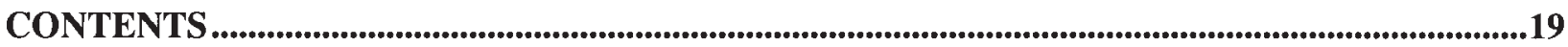

1. COMMERCIAL VIABILITY

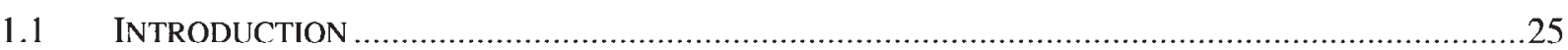

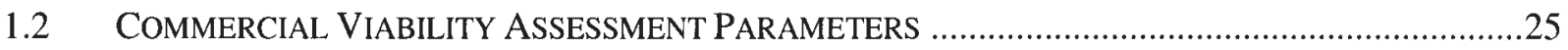

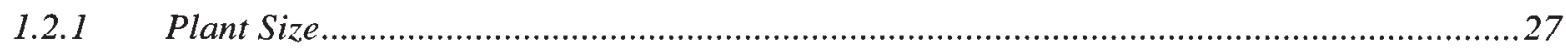

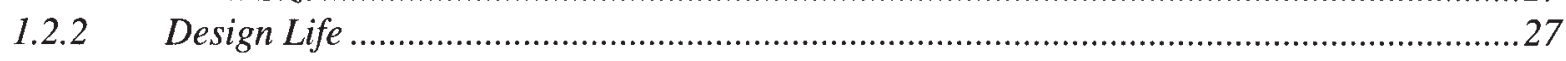

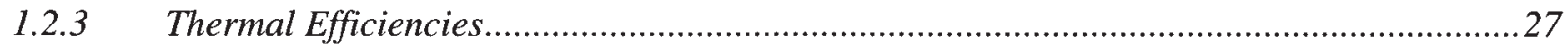

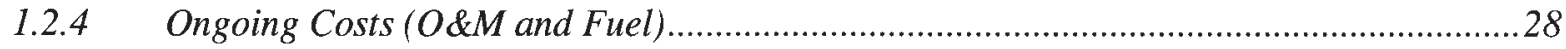

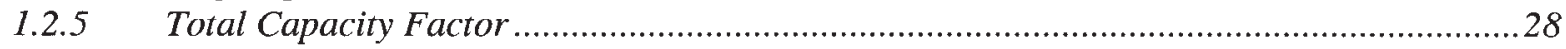

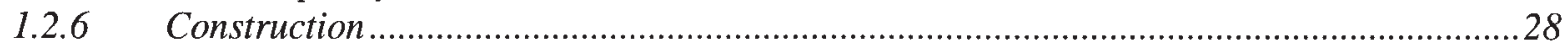

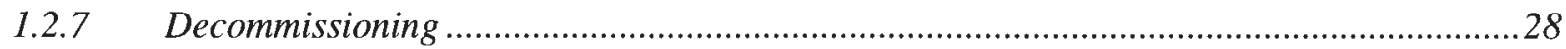

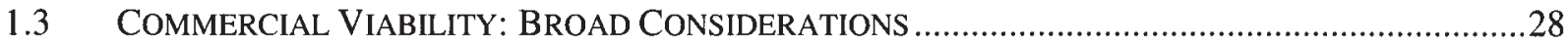

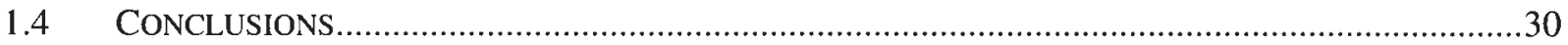

2. FUEL DEVELOPMENT ..................................................................................................................33

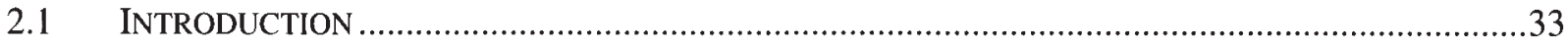

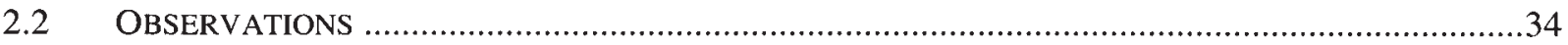

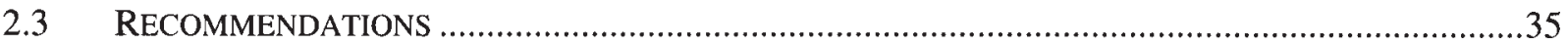

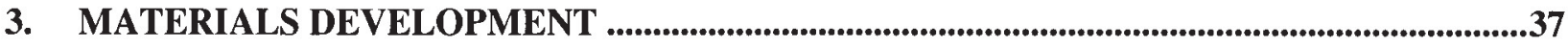

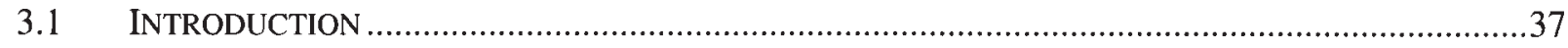

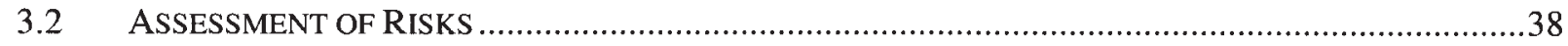

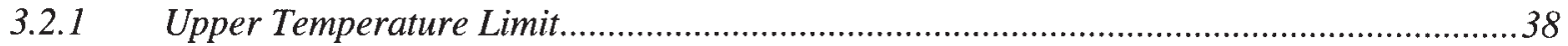

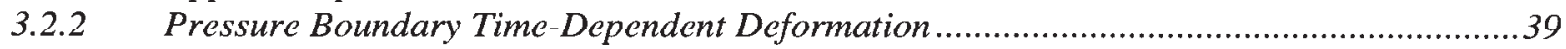

3.2.3 Fabrication, Welding, Inspection, and Monitoring ...................................................... 41

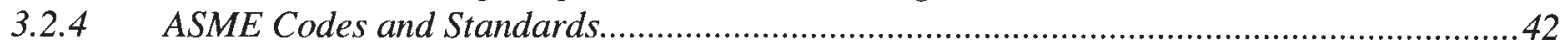

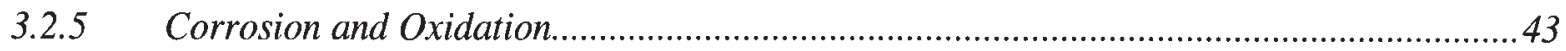

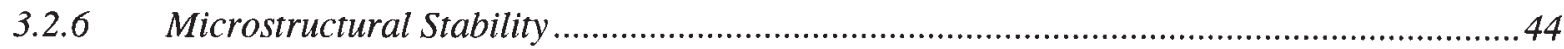

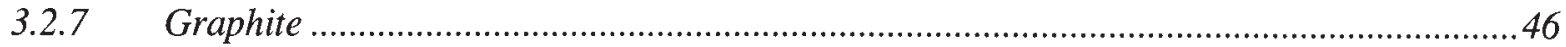

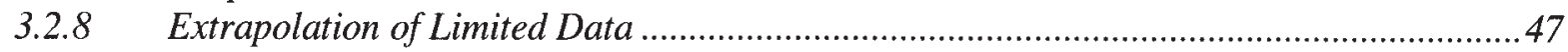

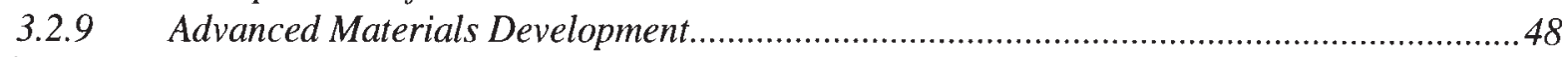

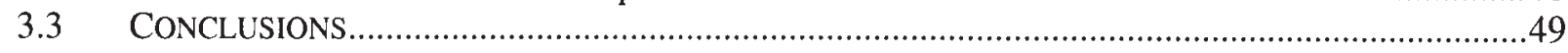




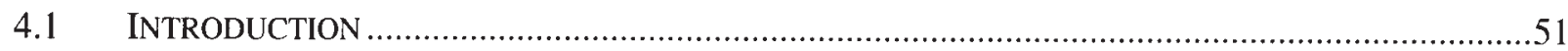

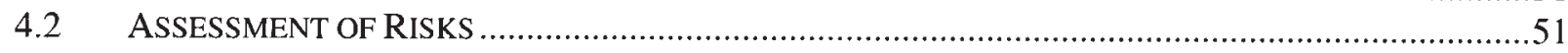

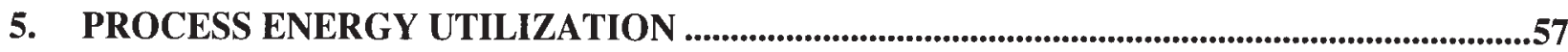

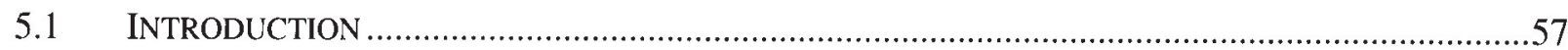

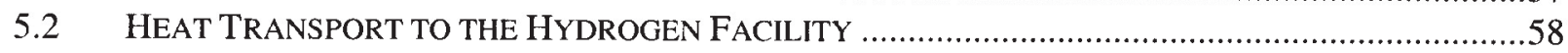

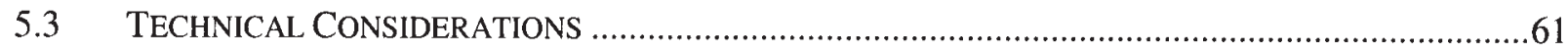

5.3.1 Process Selection and Effect on NGNP Design and Schedule .........................................61

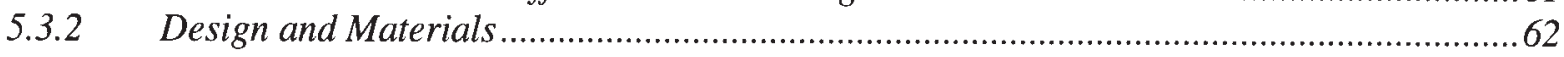

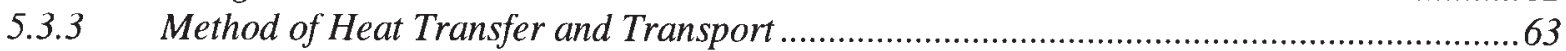

5.4 COLLOCATION OF THE NGNP AND THE HYDROGEN PRODUCTION PLANT ...............................65

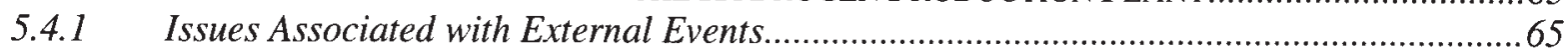

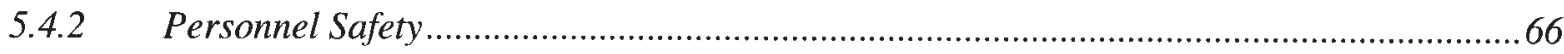

5.4.3 Process Control and Plant System Interactions.......................................................67

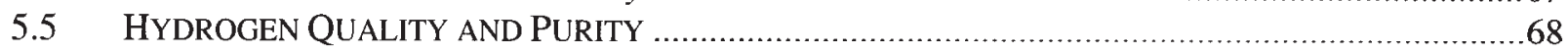

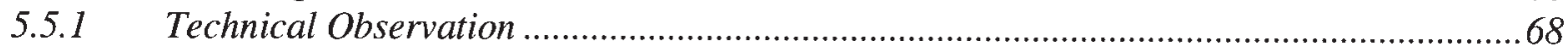

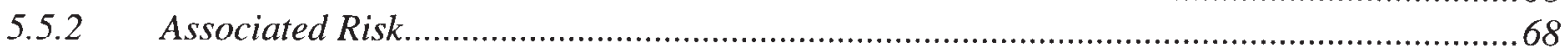

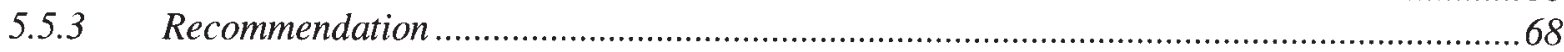

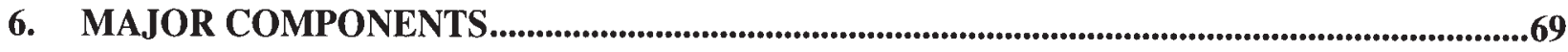

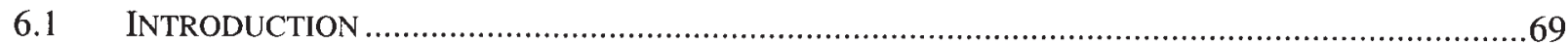

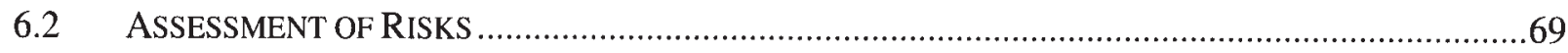

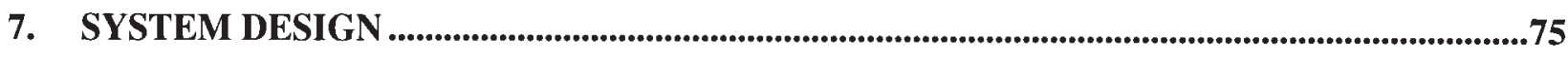

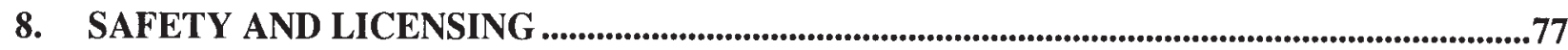

8.1 DECISIONS RELATIVE TO CONFINEMENT VERSUS CONTAINMENT …...................................77

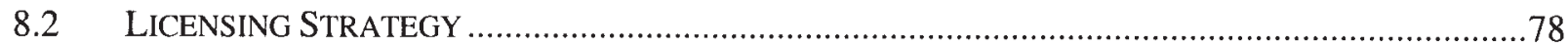

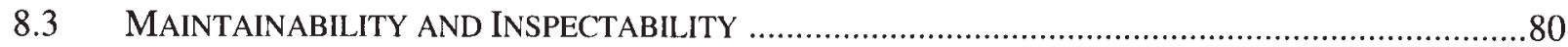

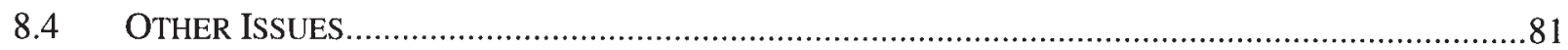

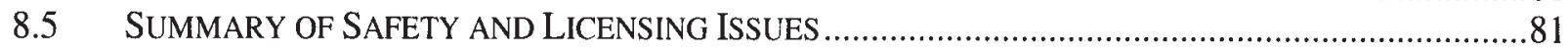

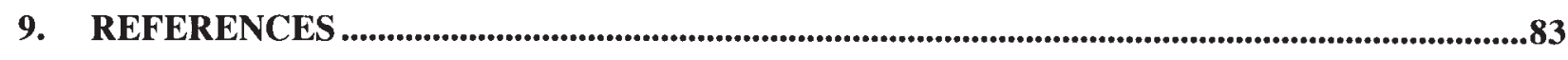

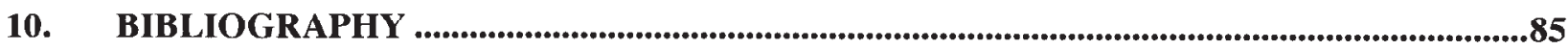

APPENDIX A - ACHIEVING A REACTOR OUTLET TEMPERATURE OF $1000^{\circ} \mathrm{C}-\mathrm{AN}$ APPROACH FOR FURTHER DEVELOPING THE NGNP ............................................................93

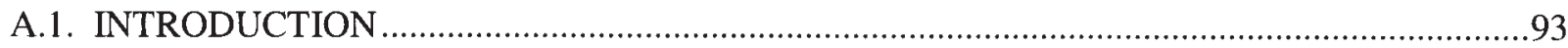

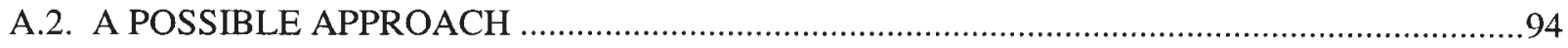

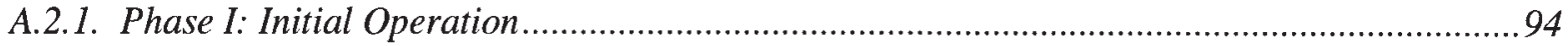

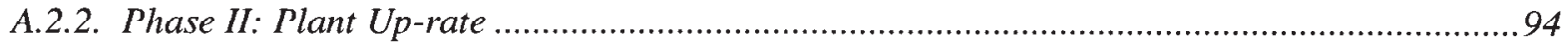

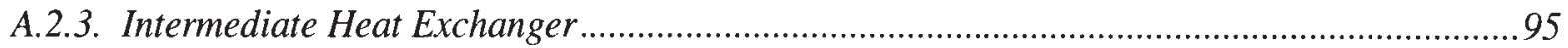

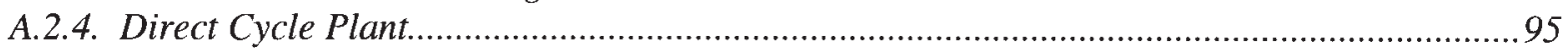

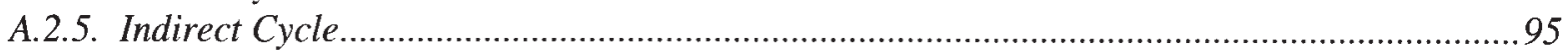

A.2.6. Alternative Pressure Vessel Material ...........................................................................96

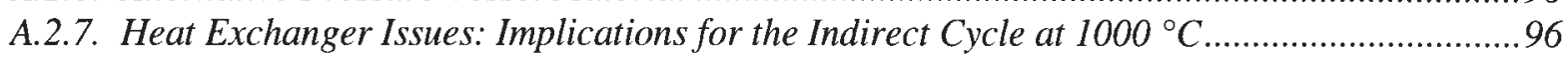

A.2.8. Is the $1000^{\circ} \mathrm{C}$ Gas Outlet Temperature Needed?...........................................................98

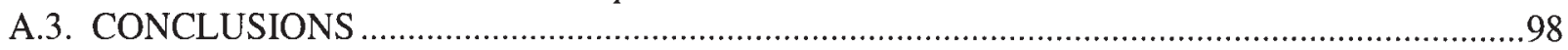

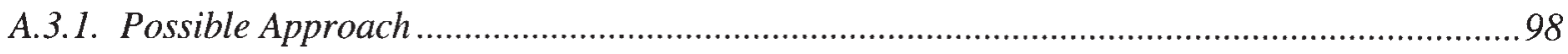


A.3.2. Direct versus Indirect Cycle

A.3.3. Further Consideration: PV Steel Material C'hoice ............................................................99

A.3.4. Beyond the Initial NGNP Demonstration

\section{FIGURES}

1. Schematic illustrating the level of risk as the degree of materials development complexity

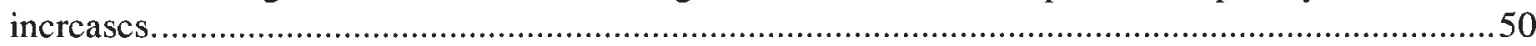

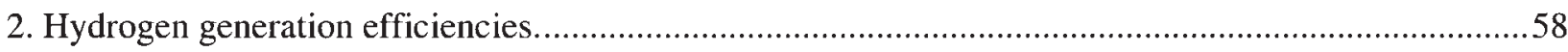

3. Direct cycle power conversion unit with helium main heat transfer loop.......................................60

4. Direct cycle power conversion unit with intermediate heat transfer loop......................................60

5. Indirect cycle power conversion unit with helium main heat transter loop. ......................................60

6. Indirect cycle power conversion unit with high-temperature electrolysis.....................................61

7. Key issues related to licensing NGNP with thermochemical hydrogen production. …......................65

\section{TABLES}

1. Data collected from various concept proponents.

2. Risk Summary for Direct-Cycle Power Conversion Systems.

3. Risk Summary, Major Components 


\section{ACRONYMS}

\begin{tabular}{|c|c|}
\hline $\mathrm{AE}$ & architect/engineer \\
\hline AGR & Advanced Gas Reactor \\
\hline AHTR & Advanced High-Temperature Reaclor \\
\hline ALWR & Advanced Light Water Reactor \\
\hline ASME & American Society of Mechanical Engineers \\
\hline AVR & Arbeitsgemeinschaft Versuchsreaktor \\
\hline BWR & boiling water reactor \\
\hline $\mathrm{C} / \mathrm{C}$ & carbon/carbon-fiber composite \\
\hline CCGT & combined-cycle gas turbine \\
\hline CEA & Atomic Energy Commission (France) \\
\hline $\mathrm{CFC}$ & carbon-fiber composite \\
\hline CFR & Code of Federal Regulations \\
\hline $\mathrm{CHP}$ & cogeneration of heat and power \\
\hline $\mathrm{CP}$ & Construction Permit \\
\hline DOE & U. S. Department of Energy \\
\hline EPA & U.S. Environmental Protection Agency \\
\hline EPRI & Electric Power Research Institute \\
\hline EVO & Energieversorgung Oberhausen \\
\hline FBR & Fast Breeder Reactor \\
\hline FIMA & fissions per initial metal atom \\
\hline FSAR & Final Safety Analysis Report \\
\hline FTE & full-time equivalent \\
\hline FY & fiscal year \\
\hline GDC & General Design Criteria \\
\hline GIF & Generation IV International Forum \\
\hline GSI & Generic Safety Issue \\
\hline GT-MHR & Gas Turbine-Modular Helium Reactor \\
\hline GTHTR & Gas Turbine High Temperalure Reactor \\
\hline HC\&SCC & Hydrogen Codes and Standards Coordinating Committee \\
\hline HENDEL & Helium Engineering Demonstration Loop \\
\hline HFIR & High Flux Isotope Reactor \\
\hline HFR & High Flux Reactor \\
\hline $\mathrm{HHV}$ & Hochtemperatur Helium Versuchanlage (High Temperature Helium Test loop) \\
\hline HIP & hot isostatic pressing \\
\hline HTE & high-temperature electrolysis \\
\hline HTGR & High Temperature Gas Reactor \\
\hline HTR-10 & Chinese High Temperature Gas-Cooled Reactor \\
\hline HTR & high-temperature reactor \\
\hline HTTR & High Temperature Engineering Test Reactor \\
\hline IEC & International Electrotechnical Commission \\
\hline IHX & intermediate heat exchanger \\
\hline
\end{tabular}


INEEL Idaho National Engineering and Environmental Laboratory

INSRI International Nuclear Energy Research Initiative

ISPRA Institute for Environment and Sustainability

ITRG Independent Technology Review Group

JAERI Japan Atomic Energy Research Institute

JMTR Japan Materials Test Reactor

KVK Komponentenversuchskreislauf (German test facility)

LWR light water reactor

MWe megawatts-electrical

MWt megawatts-thermal

NFI Nuclear Fuel Industries

NFPA National Fire Protection Association

NGNP Next Generation Nuclear Plant

NOAK nth-of-a-kind

NRC U.S. Nuclear Regulatory Commission

O\&M operations and maintenance

ODS Oxide Dispersion Strengthened

OKBM Experimental Designing Bureau of Machine Building (Russia)

OL Operating License

PBMR Pebble-Bed Modular Reactor

PCHEs Printed Circuit Heat Exchangers

PCU Power Conversion Unit

PNP Prototypanlage Nukleare Prozesswaerme (Prototype plant Nuclear Process heat)

PRA Probabilistic Risk Analysis

PSAR Preliminary Safety Analysis Report

PV pressure vessel

PWR Pressurized Water Reactor

R\&D Research and Development

RPM revolutions per minute

RPV Reactor Pressure Vessel

SI sulfur-iodine

SMR steam methane reforming

SR stress relief

SSC structures, systems, and components

TID Technical Information Document

TRISO ceramic-coated-particle fuel

UCO uranium oxycarbide

UL Underwriters Laboratories

USI Unresolved Safety Issue

$\mathrm{V} \& \mathrm{~V} \quad$ verification and validation

VHTR very high temperature reactor 


\section{Design Features and Technology Uncertainties for the Next Generation Nuclear Plant}

\section{COMMERCIAL VIABILITY}

\subsection{Introduction}

It is recognized that the cost and operational performance of the NGNP will not directly represent the later $\mathrm{n}^{\text {th }}$-of-a-kind (NOAK) deployments of the technology in the commercial sector. First-of-a-kind design, construction, and testing activities, the research and development nature of the NGNP facility, and the post-startup optimization efforts that will probably arise, will all contribute to schedules and costs that deviate considerably from future $\mathrm{n}^{\text {th }}$-of-a-kind deployments. Accordingly, the cost and performance data used by the ITRG in evaluating commercial viability of the NGNP technologies are those projected for the $n^{\text {th }}$ plant.

Given the current stage of development, definitive cost values related to the construction, operations and maintenance (O\&M), and decommissioning for an $\mathrm{n}^{\text {th }}$-of-a-kind NGNP are not available. Furthermore, because of the lack of design definition and the considerable leap in technology from current Light Water Reactors (LWRs), it is difficult to extrapolate future plant economics with any degree of certainty. That notwithstanding, the ITRG used results from recent high-temperature gas reactor cost studies performed by the commercial industry [Electric Power Research Institute (EPRI), architectural engineer (AE), nuclear utility], considered current best-guess projections of NGNP future costs offered by proponent organizations, and reviewed projected costs for advanced light water reactors (AI WRs) as a comparison reference, in order to make judgments regarding the viability of the various NGNP options.

The observations and comments that follow, therefore, are largely subjective in nature because of the lack of design definition and because of the risks and uncertainties yet to be addressed, assessed, and quantified as part of the NGNP.

\subsection{Commercial Viability Assessment Parameters}

Investment decisions in the commercial sector consider both cost and risk profiles in the evaluation process. The basic elements of the cost profile for new nuclear generation include construction costs, operating and maintenance (O\&M) costs, and decommissioning costs. Integral to these major cost categories are the construction schedule, component and system reliability, maintainability (access to components and effort required to inspect, investigate, and perform repairs), overall plant availability and capacity factor, cost and schedule for major component replacements (ongoing capital expenditures), and any regulatory or external influence that might affect plant operations. Risks are largely subjective in nature and essentially include any issues or considerations that could ultimately impact costs or shareholder return on investment.

Table 1 shows specific data collected from the various concept proponents. These data, in addition to other descriptive information on the different concepts, were reviewed by the ITRG to make judgments regarding the commercial viability of the designs. No alterations or liberties were taken with the proponent-supplied information and, consequently, the data merely reflect projections (potentially optimistic projections) by the individual proponents. Recognize that the data are very preliminary by the developmental nature of the technologies and concepts. As indicated in the table, PBMR proponents furnished two estimates for some of the requested parameters. The first estimates are designated as the "base" and represent estimates whose bases are the current PBMR development activities. The second set of estimates is projections anticipated for a future or "NGNP" deployment at VHTR conditions. Although 
caution should be exercised in drawing any definitive conclusions from Table 1, the data are, nevertheless, the best starting point available for commercial viability assessments of the proposed nuclear system concepts.

Table 1. Data collected from various concept proponents.

\begin{tabular}{|c|c|c|c|c|c|}
\hline Parameter & Target & $\begin{array}{c}\text { Direct } \\
\text { Cycle } \\
\text { Prismatic } \\
\end{array}$ & $\begin{array}{l}\text { Indirect } \\
\text { Cycle } \\
\text { Prismatic } \\
\end{array}$ & $\begin{array}{c}\text { Direct Cycle } \\
\text { PBMR }\end{array}$ & AHTR \\
\hline Plant Size (Unit/Plant; MWe) & $\begin{array}{l}1000 \\
1500\end{array}$ & $286 / 1144$ & $286 / 1144$ & $\begin{array}{l}\text { 165/1320 Base } \\
275 / 1100 \\
\text { NGNP }\end{array}$ & $1250 / 1250$ \\
\hline Plant Design Life (Years) & 60 & 60 & 60 & $\begin{array}{l}40 \text { Base } \\
60 \text { NGNP }\end{array}$ & 60 \\
\hline Thermal Efficiencies (\%) & $>50$ & 48 & 46 & $\begin{array}{l}45 \text { Base } \\
55 \text { NGNP }\end{array}$ & 52 \\
\hline \multicolumn{6}{|l|}{ Ongoing Costs } \\
\hline Staffing levels/plant (FTEs) & $<250$ & & $\sim 250$ & 131 & \\
\hline$O \& M \operatorname{cost}(\$ / M W \cdot h)$ & $<5$ & & $\sim 6$ & 5.30 & \\
\hline Fuel $\operatorname{cost}(\$ / \mathrm{MW} \cdot \mathrm{h})$ & 5.00 & 6.40 & 6.40 & $4.40-5.20$ & 6.40 \\
\hline Fuel disposal cost $(\$ / M W \cdot h)$ & 1.00 & 1.00 & 1.00 & 1.00 & 1.00 \\
\hline Misc owner costs $(\$ / M W \cdot h)$ & & & & 1.30 & \\
\hline Fuel enrichment (\%) & $<20$ & 15 & 19.9 & $\begin{array}{l}\text { 9.6 Base } \\
19.5 \text { NGNP }\end{array}$ & 15 \\
\hline Fuel burnup (MWd/ton) & $>100,000$ & 140,000 & 120,000 & $\begin{array}{l}92,000 \text { Base } \\
200,000 \text { NGNP }\end{array}$ & 140,000 \\
\hline Total Capacity Factor (\%) & $>95$ & $>90$ & $>90$ & 97.5 NGNP & $>90$ \\
\hline Fuel cycle (months) & 24 & 18 & 18 & Continuous & \\
\hline Refueling length (days) & $<20$ & 22 & 21 & N/A & \\
\hline $\begin{array}{l}\text { Major maintenance outage } \\
\text { (days/yrs) }\end{array}$ & None & $30 \mathrm{~d} / 7 \mathrm{yrs}$ & $30 \mathrm{~d} / 3 \mathrm{yrs}$ & $30 \mathrm{~d} / 6 \mathrm{yrs}$ & \\
\hline \multicolumn{6}{|l|}{ Construction } \\
\hline NOAK cost $(\$ / \mathrm{kWe})$ & $<1000$ & 975 & 1300 & $\begin{array}{l}1100-1225 \\
\text { Base } \\
<1000 \text { NGNP }\end{array}$ & \\
\hline NOAK Sch., $1 \mathrm{st} / 2^{\text {nd }}$ (months) & $24-36 / 12$ & $24-36 / 12$ & $24-32 / 12$ & $24 / 3$ & 36 \\
\hline Decommissioning cost (\$M/unit) & $<100$ & & 200 & $<148$ & \\
\hline
\end{tabular}


The first column in Table 1 presents values projected by commercial operators to be economically viable (given acceptable risk profiles). Subsequent columns represent data obtained for the helium-cooled direct cycle prismatic concept, the helium-cooled indirect cycle prismatic concept, the helium-cooled direct-cycle pebble-bed (PBMR) concept, and the molten-salt-cooled prismatic Advanced High Temperature Reactor (AHTR) concept.

\subsubsection{Plant Size}

Current commercial nuclear industry analyses suggest that target plant sizes in the range of 1000 $1500 \mathrm{MWe}$ are required to be competitive with other electric power generation technologies. Although smaller units, such as a single module, may well be deployed economically in some scenarios, it is likely that the range above will normally be required to cover the fixed and variable operating costs and the investment recovery costs and still generate power competitively within the location's market pricing structure. The data supplied by the proponents indicate the MWe capacity for individual units as well as the multiple units required to achieve the target range. A review of these data indicates that to achieve the target range specified, four modules of the prismatic concepts are required, eight modules of the pebble bed "base" concept are required, four modules of the pebble bed "NGNP" concept are required, and one unit of the AHTR is necessary. Although moderate economies of scale will certainly be realized with multiple modules, additional costs will accompany the additional modules. As the designs mature, and cost and performance data become more refined, the economics of multiple modules should be carefully reviewed. Although the AHTR requires only one unit to achieve the target generation capacity, its design is much less mature than the gas-cooled designs, and this technology embodies many uncertainties or risks that must be addressed before considering deployment in the commercial sector.

Providing high-temperature process energy for hydrogen production and petrochemical uses is an important capability for commercial applications of the NGNP concept. When deployed in the production of hydrogen, plant sizes have not been analyzed definitively-primarily because of the immaturity of the associated technologies. Several efforts, however, were undertaken within the commercial industry to model hydrogen production feasibility and costs with a nuclear heat source. In these efforts, the economic modcling was based on a four-module prismatic core design (600 MWt each). Under various scenarios with this four-module configuration, the economic modeling indicates that hydrogen produced by emissions-free thermochemical water-splitting processes and a nuclear heat source could be competitive with natural-gas-fired steam methane reformation when natural gas prices are in the range of $\$ 5.00 / \mathrm{MMBTU}$ or higher. Although the studies focused on a four-module configuration, it is anticipated that smaller deployments may also be competitive, particularly if carbon sequestration costs are applied to natural-gas-fired steam methane reformation or if the prices of natural gas increase appreciably beyond current-day market prices.

\subsubsection{Design Life}

Current LWR fleet life extensions from 40 to 60 years have driven the establishment of the 60 -year design life target for next-generation technologies. A review of the data supplied by proponents indicates 60 -year design life projections. These design life projections are tempered with the provisions for replacement of life-limiting components. Notwithstanding the commercial industry expectations, economic models indicate that the difference between a design life of 40 years and 60 years actually represents only a modest benefit.

\subsubsection{Thermal Efficiencies}

Target thermal efficiencies are greater than $50 \%$. Efficiencies in this range are more achievable at higher reactor outlet temperatures $\left(\sim 1000^{\circ} \mathrm{C}\right)$. At the reduced, more realistically achievable temperatures 
$\left(850^{\circ} \mathrm{C}-900{ }^{\circ} \mathrm{C}\right)$, efficiencies in the $45-47 \%$ range are anticipated. The concepts reviewed are all in this range.

\subsubsection{Ongoing Costs (O\&M and Fuel)}

Target values for fixed and variable costs are based on economic competitiveness with other technologies. Although shifts in one or the other parameter values may be acceptable, the combined fixed (O\&M) and variable (fuel) costs must be consistent with target value totals for overall ongoing costs in order to be economically competitive. A review of the proponent-supplied data (albeit incomplete in some cases) indicates general consistency with targets. However, some variance does exist between proponent concepts. With substantial development remaining, the ITRG believes it is premature to draw any definitive conclusions regarding ongoing costs for any particular concept. Of interest, however, are the differences between proponent projections for fuel enrichment and burnup.

\subsubsection{Total Capacity Factor}

The U.S. commercial industry average capacity factor in 2002 exceeded $90 \%$. Well-run commercial facilities are achieving annual capacity factors of $95 \%$ or greater - even with refueling outages. This level of performance has dictated capacity factor targets for next generation technologies of at least $95 \%$. Many LWRs have gone to a 24-month fuel cycle with refueling outages every two years.

The PBMR concept with continuous refueling projects the highest capacity factor of any design. Note that the theoretical advantages of online refueling have not been realized over the long term in commercial applications. Furthermore, proprietary industry studies suggest that the variance in capacity factor between continuous and batch-refueling configurations is actually quite small. It is anticipated that extending the 18-month fuel cycles to 24 months will render the actual capacity factor variance between the two concepts negligible.

\subsubsection{Construction}

Construction schedules and capital investment costs are key considerations in commercial viability assessments. Target values for construction schedules vary with technology and configuration. Capital investment costs are targeted at $\sim \$ 1000$ per $\mathrm{kWe}$. The developmental nature of the designs does not allow accurate projection of either schedules or capital investment costs. Proponent projections are based largcly on past industry experience with other nuclear and fossil technologies. Despite the multi-module arrangement, the footprint remains comparable to a single unit Pressurized Water Reactor (PWR) of the same total power and does nol pose additional sile requirements.

\subsubsection{Decommissioning}

Just as in the case of ongoing and initial construction costs, the developmental nature of the proponent designs makes accurate projections of decommissioning difficult. The target value of $<\$ 100 \mathrm{M} /$ per unit is based on current LWR decommissioning estimates.

\subsection{Commercial Viability: Broad Considerations}

In addition to the specific parameters delineated above, commercial viability is also influenced by a variety of broader issues and considerations.

To be commercially viable, the selected NGNP design must meet with regulatory approval. From a commercial viability standpoint, the significant regulatory risks associated with the proponent concepts include (1) fuel testing and qualification, (2) use of a confinement structure in lieu of a conventional 
containment, and (3) overall quality assurance, including verification and validation of computer codes and models. Regulatory risks and recommendations are captured in other report sections, but it is important to note that commercial viability and future deployments of the selected design will be enhanced by early regulatory (NRC) involvement in the project.

Several technical issues or challenges must be overcome to achieve the NGNP objectives. A variety of challenges in materials, components, and fuel must be overcome in order to deploy the NGNP successfully and effectively set the stage for future commercial deployments. Although these challenges and issues are the subject of other report sections, it is important to consider the expectations of the commercial nuclear industry (utility sector) when investing in new or advanced technologies. Risks, real or perceived, are given very careful consideration, particularly with investments of this magnitude and with any investments involving nuclear technologies. Utility executives will give special consideration to what they believe will be the Wall Street analysts' view of the investment. Any lingering uncertainties or risks (technical or otherwise) inherent in the NGNP product after a nominal period of demonstration plant operation that might negatively impact the economics may well be cause for investor retreat. This critical or perhaps overcritical skepticism on the part of the decision makers in the commercial industry should not be viewed as an impossible hurdle to overcome but rather a reminder that NGNP design selections and demonstration plant operations must provide definitive assurances that the new technologies will perform satisfactorily to commercial industry standards.

Specific design features and deployment options can impact the cost/risk profiles and, as a result, the commercial viability of the NGNP.

Modular Deployment Economics-Preliminary industry studies indicate that the vertical singleshaft direct-cycle Gas Turbine-Modular Helium Reactor (GT-MHR) 4-pack can be deployed in three to four years, with the first unit operational in approximately two years. The economic impact of the revenue stream derived as units become operational, even at initially reduced capacity factors, offers substantial cconomic advantage over deployment of a single large unit (e.g., ALWR) requiring a three to four year construction period. From a commercial viability standpoint, therefore, consideration should be given to modular or incremental deployment capability.

Indirect Cycle Economics - To compensate for the higher fuel costs associated with TRISO particle fuel, gas-cooled reactors must offer economic benefits in other areas to remain competitive with alternative technologies. Greater fuel burnup, the higher Brayton cycle efficiencies, and less overall plant equipment appear to provide this economic edge. Preliminary indications suggest that an indirect Brayton cycle arrangement with an intermediate heat exchanger $(\mathrm{IHX})$ results in only a modest $(<2 \%)$ penalty in efficiency when compared to a direct Brayton cycle arrangement. The indirect cycle permits combining two or more modules with one larger power conversion unit. This may compensate for the loss of thermal efficiency. A more efficient supercritical steam cycle could also be used.

Furthermore, this indirect configuration offers the added assurances in reliability and maintainability from the significant experience base associated with combined-cycle gas turbine (CCGT) applications currently deployed in the commercial sector. Indirect cycle proponents estimate operational and maintenance costs consistent with commercial CCGT facilities. Whether or not these projections will prove to be realistic with a nuclear heat source remains to be determined. If, on the other hand, use of the indirect cycle configuration, including the bottoming cycle (steam turbine and associated equipment), requires staffing and O\&M costs similar to current LWRs, commercially viability will be affected. At this stage of development, it is premature to draw definitive conclusions in either direction.

Vertical Single-Shaft Direct Cycle Power Conversion Unit (PCU)-Although the vertical singleshaft direct-cycle (Joule-Brayton cycle) arrangement is more thermodynamically efficient and offers 
potential cost benefits in plant area layout requirements; it entails additional developmental risks and uncertainties in operational practicality. Developmental risks may cause research and development delays before deployment of the NGNP and/or delays in providing the reliability assurances required by the commercial industry once the NGNP is operational. The vertical single-shaft arrangement is quite appealing if the PCU performs as proponents claim. If, however, unanticipated monitoring, maintenance, or inspections are required, it is likely that access to and repair of the targeted components will require substantial time and effort (i.e., extra costs). Establishing commercial viability under these conditions will be difficult, at best. Given (1) the marginal improvement in projected efficiencies/performance, (2) the higher risk profile, (3) the development efforts ongoing in Russia at OKBM (Experimental Designing Bureau of Machine Building) on this vertical single-shaft design, and (4) the need to develop an IHX for extracting process heat for $\mathrm{H}_{2}$ production, deployment of an indirect cycle power conversion arrangement for the NGNP may be the most practical course of action. Innovative components for a direct cycle may be tested at full scale in the secondary circuit of an indirecl cycle NGNP.

Confinement versus containment-A more detailed discussion of the confinement versus containment issue is presented in a later section of this report; however, it is important to note that should containment (similar to current LWRs) be required, the incremental capital investment costs coupled with the associate incremental O\&M costs may be an adverse impact on the commercial viability of any of the proposed NGNP designs.

Maintenance Considerations-Maintenance requirements, maintainability, and reliability of structures, systems, and components (SSCs) are important considerations in commercial viability assessments. Ease of access to critical SSCs as well as the subsequent level of effort required for periodic monitoring, inspection, and repair of these SSCs are key factors in investment evaluations. As a general rule, simple and robust designs are favored.

\subsection{Conclusions}

Although very preliminary in nature, cost and performance estimates provided by the proponents were in the range of the "target" values provided by the commercial sector. Note that the "very preliminary" nature of the cost and performance data as well as the uncertainty in market pricing and financing metrics for a period beginning ten years into the future render any economic modeling for the NGNP to be "ballpark" at best. The ITRG did access and review commercial economic models utilizing the "target" values, as delineated in Table 1. The conclusion is that the cost and performance data at this stage of development of the NGNP technologies suggest that the technologies could be commercially viable and competitive. Cost and performance projections, however, are not the only criteria used in commercial viability determinations. The most important consideration is reducing the real and perceived risks associated with deploying the new technologies.

Companies deploying new nuclear plants in the merchant sector will weigh risks very carefully. What does this mean for the NGNP deployment? Although selection of the technology, materials and component arrangements for the NGNP must indeed stretch the envelope in technology development, this goal should be tempered with the necd to offer the ultimate user the foundation for deploying a product that is economically competitive, and one that harbors a minimum of inherent economic risks, if any. In the current fleet of LWRs, costly plant modifications required to remedy design deficiencies were somewhat commonplace in years past. Commercial buyers, particularly those in merchant markets, are now much more skeptical and much more diligent in investment assessments. Risks will be better identified and subsequently mitigated through financial instruments or through selection of alternative, proven technologies. 
The NGNP must therefore offer a platform for testing and verifying the capabilities of the advanced technologies. It must also allow for a sufficient period of steady-state operations to simulate commercial industry application. This steady-state operation simulating a commercial facility will, as a minimum, be used to

1. Confirm operating and maintenance costs

2. Identify and resolve reliability and any unresolved safety issues

3. Familiarize and train operating and maintenance personnel

4. Formulate and refine operating procedures and practices

5. Confirm data and assumptions used in licensing submittals.

Selection of the technology and design configuration for the NGNP must consider both the cost and risk profiles to ensure that the demonstration plant establishes a sound foundation for future commercial deployments. If the technology stretch is excessive, the NGNP may become solely an exercise in research and development, and fail to accomplish the high-level functional objectives describing its broader mission. The NGNP challenge is to achieve a significant advancement in nuclear technology while at the same time setting the stage for deployment of the new technology in the commercial sector soon after 2020 . 


\section{FUEL DEVELOPMENT}

\subsection{Introduction}

Fucl devclopment for the reactor concepts being considered for the NGNP largely depends on the Advanced Gas Reactor Fuel Development and Qualification Program (AGR program) ${ }^{3}$ being conducted by the Department of Energy. The principal goal of the AGR program is to provide a baseline fuel qualification data set in support of the licensing and operation of the Generation IV very-high-temperature reactor (VHTR). The NGNP is basically an early demonstration of the Generation IV VHTR. The Advanced Gas Reactor (AGR) program assumed that the VHTR would demand more severe service conditions (an increase in the peak fuel temperature $\left(\sim 1250^{\circ} \mathrm{C}\right.$ peak), high power density $(6-9 \mathrm{~W} / \mathrm{cc})$, and high burnup (15-25\% FIMA) than those in the successful Arbeitsgemeinschaft Versuchsreaktor (AVR) reactor in Germany. In AVR, SiC TRISO-coated-particle fuel with a $\mathrm{UO}_{2}$ kernel was irradiated to a burnup of $10 \%$ fissions of initial metal atoms (FIMA) at a power density of 2-3 W/cc and peak fuel temperatures generally below $1150^{\circ} \mathrm{C}$. Therefore, SiC TRISO-coated-particle fuel with a UCO kernel and a burnup goal of 15-25\% FIMA was sclccted as the starting point for fuel development work. The program also assumed adequate DOE funding and no significant difficulties during the development, irradiation testing, and subsequent experiments that could impact the completion schedule significantly.

Subsequent to the issuance of the AGR program plan, ${ }^{3}$ the high-level functions and requirements for the NGNP were published. ${ }^{1}$ This document allows TRISO-coated-particles with either UCO or $\mathrm{UO}_{2}$ fuel kernels and does not specify a required level of core burnup or power density. Therefore, $\mathrm{SiC}$ TRISO-coated fuel particles with $\mathrm{UO}_{2}$ kernels operating within the range of burnup successfully tested (under irradiation and through post-irradiation heating tests to accident temperatures) in Germany and Japan, $\leq 10 \%$ FIMA, are permissible. The German fuel was developed and tested in the form of spherical pebbles at lower power densities $(2-3 \mathrm{~W} / \mathrm{cc})$ with a very specific manufacturing process and lower packing fraction compared to that for the cylindrical compact typically used in a prismatic core concept. It is apparent that either UCO or $\mathrm{UO}_{2} \mathrm{SiC}$ TRISO-coated fuel particles can be used to meet the high-level functions and requirements of the NGNP.

- The $\mathrm{UO}_{2}$ kemel is a much more mature technolugy intermationally and its excellent performance has been demonstrated at lower temperatures, lower burnup and lower power density compared to the performance objectives of the AGR program. .

- The UCO kernel is being developed in the AGR program to prevent CO formation, which is advantageous for high burnup, and to limit kernel migration that is expected at high power densitics. However, UCO presents grcater development risk given its lack of maturity compared to $\mathrm{UO}_{2}$.

Although SiC TRISO-coated-particle fuels in cylindrical compact shapes have undergone development and testing for many years in the United States, the failure rate during irradiation of these fuels (both $\mathrm{UCO}$ and $\mathrm{UO}_{2}$ ) has been three orders of magnitude greater than that of the German fuel, ${ }^{4}$ on the basis of fission gas release measurements. Key differences in fuel fabrication methods have been identified that are thought to be responsible for the poorer performance of the U.S. fuel relative to the German fuel, ${ }^{4}$ and improved methods based on German practices are incorporated into preliminary fuel specifications in the AGR program. ${ }^{5}$ 


\subsection{Observations}

The German TRISO fuel development activities, primarily based on spherical pebble bed type fuel compacts, have resulted in a great deal of potentially applicable data for high-temperature reactors. Further fuel development work in Japan, South Africa, and China has been based on this relatively mature technology. The resulting core designs have largely been based on this existing fuel design experience. The more aggressive AGR program includes a significant cxtrapolation and extension of the existing fuel development database. The AGR program has been under way for only one year, but the DOE funding has been half of that planned, so the schedule has already slipped two years. ${ }^{6}$ As currently scheduled, ${ }^{6}$ fuel qualification would be complete in 2014, two years after the start of construction and at about the time the NGNP operating license application would need to be submitted to the NRC to support the target of 2017 for reactor operation. Source term code validation would also be completed in 2014, although uncertainties in funding fission product plateout and liftoff measurements, both out-of-pile and in an inpile loop, need to be resolved earlier to have confidence in the schedule for the completion of this work. At this time, two assumptions of the AGR plan are inconsistent with the NGNP requirements and schedule: the need for a high-performance UCO kernel and adequate funding. The third assumption, that there be no experimental difficulties encountered causing significant schedule disruption, is now very risky.

There are ways to reduce the risk of not having qualified fuel and validated mechanistic sourceterm methods available to support design and licensing activities. One could then select and follow the most promising paths. For example, the fuel development risk could be lowered by qualifying $\mathrm{SiC}$ TRISO-coated-particle fuel compacts to $10 \%$ FIMA, representative neutron fluence, and $1200^{\circ} \mathrm{C}$ for the initial core of the NGNP, operating at power densities typical of AVR $(2-3 \mathrm{~W} / \mathrm{cc})$. Higher burnup, neutron fluence, power density and fuel operating temperature could be a parallel or future development, to be pursued by the AGR program and demonstrated when mature, using lead test fuel blocks or pebbles in the NGNP. The above actions can partially reduce the risk of not having qualified fuel in time for NGNP licensing applications. The first recommendation below incorporates this concept.

One of the stated goals of the AGR program is to utilize international collaboration mechanisms to extend the value of DOE resources. Ways need to be established to formalize and institute this collaboration to realize its potential benefits. One collaboration that should be explored is an agreement to obtain rights to the German process for fabricating $\mathrm{SiC}$-coated $\mathrm{UO}_{2}$ fuel particles and compacting them (licensing may be required). To supplement current activities in the AGR program, the collaboration could focus on compacting techniques in the geometry used in the NGNP that will minimize damage to particles during fabrication. Other possibilities should be investigated, such as obtaining TRISO-coated $\mathrm{UO}_{2}$ fuel particles from the South Africans, the Japanese, or the Chincse. Bencfit could also be derived from the ongoing European program on particle fuel, which includes several irradiations currently scheduled in the High Flux Reactor (HFR) at Petten.

The South Africans have licensed the German process for fabricating SiC TRISO-coated fuel particles within the graphite matrix of fuel pebbles, but they have not begun irradiation testing to confirm fuel performance. Nuclear Fuel Industries $(\mathrm{NHI})$ in Japan is currently the only commercial manufacturer of $\mathrm{SiC}$ TRISO-coated $\mathrm{UO}_{2}$ fuel, although the fuel compacts they supply for the HTTR are annular in geometry. The Japanese irradiation program in HTTR is currently at very low burnup, but the Japanese have irradiated compacts with good results to 7\% FIMA in the High Flux Isotope Reactor (HFIR) at ORNL and to 10\% FIMA in the Japan Materials Test Reactor (JMTR) at Japan Atomic Energy Research Institute (JAERI). The Japanese have found that as-fabricated SiC defects occur in the compaction process mainly by the direct contact between neighboring particles, suggesting that the packing fraction of particles in compacts is an important parameter. The Chinese have fabricated $\mathrm{UO}_{2}$ TRISO-coated fuel particles with equipment obtained from Germany. Several of their pebbles are currently undergoing 
irradiation in Russia, and the HTR-10 pebble bed reactor in China has begun operation. Thus, it is recognized that the South African, Japanese, and Chinese fuel development programs are in varying states of maturity, but they are proceeding along the lines of the successful German program.

Fuel manufactured in the United States by German processes or fuel particles obtained from foreign sources and compacted in the United States will need to be irradiated and safety-tested to qualify the fuel for operation in the NGNP. Schedule improvements might be made in support of NGNP licensing by initially importing fuel fabrication technology, fuel particles, or complete compacts proven by irradiation and safety testing in South Africa, Japan, or China, followed by qualification testing in the United States. Representatives from NFI in Japan have expressed to the ITRG a willingness to provide fuel on a timely basis to support the NGNP. This fuel would be $10 \%$ enriched $\mathrm{UO}_{2}$ and could be made available in the form of TRISO-coated particles or compacts of either solid cylinders or pebbles.

The U.S. manufacturers have not as yet been successful in producing pebble bed or prismatic fuel compacts to the required specifications. Much work has been planned and is in progress to develop the necessary capability in the United States; however, this will take a long time and will require extensive resources. It is essential therefore to employ proven and very intensive quality control procedures to ensure early successes, in order to support the design and licensing of NGNP. Additional considerations include:

- Confidence that fuel manufactured for the NGNP will be of the same quality as pre-production fuel (qualified by irradiation and safety testing) can be enhanced by applying the same product and process specifications used to fabricate the qualified fuel, including specifications for component materials such as graphite.

- $\quad$ Past experience has shown that an important factor in fuel failure is neutron fluence-induced coating failures, primarily in the pyrocarbon layers. An important aspect of the chosen fuel manufacturing process is the ability to achieve a suitable coating process.

- As mentioned above, packing fraction is one important parameter to be considered in determining the influence of different compact manufacturing processes on fuel quality in the planned AGR research on compacting.

- Initial results on maximum fuel temperatures and power peaking provided in the INEEL assessments of neutronics and thermal hydraulics in the NGNP point design study are important and this work should be completed.

- $\quad$ The reactor core design should be compatible with the demonstrated capabilities of the fuel used in NGNP (e.g., in areas such as packing fraction, power density, temperature and thermal gradients).

The AGR program states that industrial funding is required to complete the fission product transport and source term research, leading to validated methods for calculating mechanistic source terms. ${ }^{3}$ The completion of this work by 2014 is essential to support the licensing process, but a schedule and funding to complete this work do not exist. In addition to industry participation, substantial participation by international researchers and research facilities could lead to timely completion of this work.

\subsection{Recommendations}

Based on the above discussion, the ITRG recommends the following:

1. U.S. fuel development for the NGNP should initially focus on successful fabrication, testing, and qualification of coated-particle designs and manufacturing processes that have the most extensive 
worldwide experience base ( $\mathrm{UO}_{2}$ kernel), thereby reducing the risk for fuel qualification on the NGNP completion schedule. Once it is determined that a $\mathrm{UO}_{2}$ kernel will be successful up to a burnup of 10\% FIMA at appropriate reactor design conditions, then the UCO kernel,as part of the AGR development program, could be phased-in as appropriate to provide the capability of increased burnup and increased power density to reduce fuel costs and increase plant power. The ITRG considers that this approach is acceptable for initial core loads, with the capability to achieve increased performance in subsequent core loads as the improved UCO fuel types are developed.

The reactor core design should be compatible with the demonstrated capabilities of the fuel used in the NGNP (e.g., in areas such as packing fraction, power density, temperature, and thermal gradients).

2. Alternatives such as licensing or purchasing similar and previously successful technology from an offshore vendor should be pursued and implemented as a necessary parallel path forward for the initial NGNP cores. It also may be possible to obtain commercial assistance to construct and operate a fuel fabrication pilot plant within the United States if required to meet U.S. Nuclear Regulatory Commission (NRC) licensing conditions.

3. The fuel development program should incorporate both $\mathrm{UO}_{2}$ and $\mathrm{UCO}$ and continue as planned to determine the influence on fuel quality of different manufacturing processes for producing fuel particle coatings and compacts. The program should continue to investigate the thermal hydraulics and neutronics of complete fuel elements, e.g., with regard to maximum fuel temperatures and power peaking, for both kernel types.

4. Means should be found to improve the overall schedule for fuel development to ensure successful qualification within the required timeframe and support the licensing milestones. Further, the ITRG recommends that means to fund the completion of the mechanistic source term work on a schedule to support licensing be established as soon as possible.

5. Scope and priority for activities within the fuel development program nccessary for the success of the NGNP should be established by the NGNP project rather than by the fuel development program. 


\section{MATERIALS DEVELOPMENT \\ 3.1 Introduction}

This section presents the key risk factors identified by the ITRG during its review of potential materials development requirements. During the initial discussions, the ITRG identified following areas of potential concern:

- Materials properties

- Contamination

- $\quad$ Core/vessel internals

- $\quad$ Pressure boundary materials

- Materials characterization (creep fatigue)

- ASME code issues

- Corrosion (environmental effects such as stress corrosion cracking)

- $\quad$ Erosion

- $\quad$ Pipes, piping materials

- $\quad$ Fabrication issues

- Welding

- $\quad$ Resource supply (e.g., graphite, helium)

- $\quad$ Sliding seals

- Inspection program

- Qualification of materials and procedures. follows:

During subsequent discussion, the above list was reduced to a smaller list of key risk areas, as

1. Upper temperature limit

2. Pressure boundary time-dependent deformation

3. Fabrication, welding, inspection, and monitoring

4. ASME Codes and Standards

5. Corrosion/oxidation

6. Microstructural stability

7. Graphite

8. Extrapolation of limited data

9. Advanced materials development.

For this discussion, the ITRG judged materials development against a goal of being able to initiate operation of the NGNP by the year 2020 with a plant life of 60 years. However, with respect to materialsrelated issues, any new material development or qualification "...must be fully qualified for the final 
design process, which is expected to begin late in FY-09."8 This earlier date effectively restricts the materials selection process to those materials that could be qualified with the immediate initiation of a very extensive and high-intensity program.

The following comments are applicable to all of the plant designs being considered unless otherwise stated.

\subsection{Assessment of Risks}

\subsubsection{Upper Temperature Limit}

Technical Observation. The specified NGNP gas outlet temperature of $1000^{\circ} \mathrm{C}$ is beyond the current capability of metallic materials. The requirement of a gas outlet temperature of $1000^{\circ} \mathrm{C}$ will result in operating temperatures for metallic core components (core barrel, upper shroud, control rod drive assemblies), and intermediate heat exchanger (IHX) components that will approach $1200{ }^{\circ} \mathrm{C}$ in some cases. Metallic materials that are capable of withstanding this temperature for the anticipated plant life will not be available on the NGNP schedule, if they can be developed at all. Nonmetallic materials capable of this temperature will require a development program that cannot support the NGNP schedule.

Associated Risk. The requirement for a gas outlet temperature of $1000{ }^{\circ} \mathrm{C}$ represents a significant risk that ITRG judges cannot be resolved consistent with the schedule for the NGNP.

Recommendation. It is recommend that the required gas outlet temperature be reduced such that metallic components are not exposed to more than $900^{\circ} \mathrm{C}$ for the base NGNP design. Raising the gas outlet temperature to $950^{\circ} \mathrm{C}$ may be considered but at the potential expense of a reduced life ( $<60$ year) for key components, e.g., the IHX.

\section{Technical Justification.}

Physical Temperature Limitation. One of the most significant physical limitations will be the upper temperature for materials of construction. The currently specified gas outlet temperature of $1000^{\circ} \mathrm{C}$ will place physical limitations on metallic materials that effectively eliminate the use of these materials in a design in which a 60 -year life is specified. While gas turbine systems are currently operated in this temperature range (and above) in commercial and military aircraft engine applications, the inspection interval for these systems is less than 1000 hours. Replacement of these components occurs on an interval of several thousand hours. Even with a planned replacement of selected components at earlier times, metallic materials will be effectively precluded, if not cooled to within acceptable limits. To provide perspective with respect to materials in common use for high-temperature components, Ni-base alloys (Ni-Cr-Fe plus additions of $\mathrm{W}, \mathrm{Mo}, \mathrm{Co}, \mathrm{Ti}, \mathrm{Al}, \mathrm{Nb}, \mathrm{Al}, \mathrm{Hf}$, and other minor elements) will have upper temperature limits bounded by (1) approximately $1300{ }^{\circ} \mathrm{C}$, where the matrix melting point is reached, and (2) a still lower upper temperature limit of approximately $1150^{\circ} \mathrm{C}$, where the solvus of most of the strengthening phases $\left[\mathrm{Ni}_{3}(\mathrm{Al}, \mathrm{Ti})\right.$, etc. $]$ will be exceeded. With a gas outlet temperature of $1000{ }^{\circ} \mathrm{C}$, one can expect that still higher temperatures will be possible for materials during upset or accident conditions. Off-normal coolant temperatures of as high as $1200^{\circ} \mathrm{C}$ are predicted for some accident scenarios, with core barrel temperatures reaching $1070^{\circ} \mathrm{C}$ and upper shroud temperatures exceeding $1200^{\circ} \mathrm{C} .{ }^{8} \mathrm{The}$ above temperatures are physical limitations. The use of metallic materials where temperatures can approach these physical limitations represents an unacceptable risk.

With metallic materials excluded for a $100{ }^{\circ} \mathrm{C}$ temperature level, the options are then to (1) reduce the operating temperature, or (2) use nonmetallic materials. With respect to nonmetallic materials, the general consensus is that to meet the $1000^{\circ} \mathrm{C}$ gas outlet temperature, a very significant materials 
development program for non-metallic materials will be needed. The risk associated with this will be very high if the NGNP schedule is to be met.

Practical Upper Temperature Limit for Core Structural Materials. During the presentations by the various proponents, each was asked to provide a "yes" or "no" answer on the possibility of meeting the $1000{ }^{\circ} \mathrm{C}$ temperature criterion by 2020 . If the answer was "no" then each was asked to identify the maximum practical upper temperature that would ensure a plant by 2020 . In every case, the answer was "no" with regard to the $1000^{\circ} \mathrm{C}$ gas outlet temperature. With respect to the maximum upper temperature limit, the unanimous answer was $900^{\circ} \mathrm{C}$. This was in spite of the fact that there have been, and are, gas reactors that have, and are, operated at higher temperatures-up to $950^{\circ} \mathrm{C}$. It was clear from the discussions that the requirement of a 60 -ycar life at $1000^{\circ} \mathrm{C}$, even with allowance for intermediate inspections and replacement of components, represents a significant challenge for the design teams and that this temperature is simply not feasible at this time.

Intended Operation at $1000{ }^{\circ} \mathrm{C}$ but Initial Operation at a Lower Temperature. Design of a system with an intended operating temperature higher than the initial operating temperature followed by a gradual increase in temperature as required performance or materials properties data are acquired is predicated, from a materials perspective, on the assumption that the operative deformation mechanisms governing behavior are the same over the entire temperature range of intended operation. Thus, for this case, the increase in operating temperature represents an extrapolation of an existing database. As an example of this method, the creep strain rate at a particular temperature may be needed in the design but may not be currently available. It simply remains to obtain the data. In this case, the designer simply allows for additional clearances, etc., during the design. However, if the intended upper temperature results in a change in operating regime to a regime in which new deformation mechanisms come into play or, even worse, there is a requirement for an entirely new material-the extension is no longer an extrapolation. In this case, it is possible for the higher-temperature design to be significantly different from the lower-temperature design. In the case of the NGNP, the $1000{ }^{\circ} \mathrm{C}$ intended operating temperature would possibly require significantly different materials/systems than would be used for the lower temperature design. The expectation that a plant can be designed for a lower temperature and then extended to a higher operating temperature by "sharpening the pencil using better data" or replacing a component with an identical one using a new material should thus be approached with care. However, having said this, a practical approach to the achievement of $1000^{\circ} \mathrm{C}$ gas outlet temperature would be to design the plant so that components can be replaced as new materials are qualified without requiring a wholesale redesign of the plant.

\subsubsection{Pressure Boundary Time-Dependent Deformation}

Technical Observation. Several of the NGNP concepts that were reviewed require many of the irreplaceable Class I boundary components (pressure vessel, piping, etc.) to operate at temperature and stress combinations that will result in significant time-dependent deformation (creep) during the component life. While there is allowance [American Society of Mcchanical Engineers (ASME) Code Case] for the inclusion of time-dependent deformation in pressure vessel designs, this has not been a part of commercial nuclear pressure vessel and piping systems in the past and represents a very significant departure from current practice. Moreover, it is likely that creep as well as fatigue-related time-dependent deformation will be present. Creep-fatigue interaction represents the most complex form of high temperature behavior, often requiring component-specific design rules. In addition, the regulatory infrastructure does not have experience with including significant time-dependent deformation in the licensing and safety evaluation process.

Associated Risk. The allowance of time-dependent deformation in the irreplaceable Class I boundary represents an unacceptable risk for the NGNP program. 
Recommendation. The ITRG recommends that time-dependent deformation be limited to "insignificant," as defined by the ASME Code, during the life of irreplaceable (60-year life) components for the NGNP. Time-dependent deformation for replaceable Class I components (portions of the IHX, interface heat exchanger for the hydrogen system, etc.) can be allowed, but only with the addition of significant additional levels of inspection and monitoring. However, the fraction of the Class I boundary that experiences significant creep deformation must be limited as much as possible.

\section{Technical Justification.}

A second, and still very significant, limitation for materials at operating temperatures above approximately one-half the melting point will be that related to creep deformation. While there is a high-temperature code case for Class I boundary materials, it has not been fully developed, approved, or applicd to the pressure boundary of any commercial plant that has actually been built. The Japanese HTTR was designed to operate in the creep range but only at the very bottom range, and the extent of creep deformation is limited to insignificant amounts. The application of time-dependent behavior to the design of the NGNP will thus represent a significant increase in risk with respect to the goal of a plant in 2020. The required inspection program for this mode of operation is judged to be an order of magnitude more complex, and costly, than current practice.

Practical Upper Temperature Limit for Pressure Boundary Material. In the case of pressure boundary materials, while the physical upper temperature limit of approximately $550{ }^{\circ} \mathrm{C}$ (or the tempering temperature of the material during fabrication, whichever is higher) is based on not exceeding the microstructural stability of the material, there will be a lower temperature threshold that defines the boundary between requiring and not requiring the inclusion of creep deformation in the design. This "limit" is not a physical one but one which, when crossed, will greatly increase the level of effort necessary to achieve the operational goals. For this reason, the ITRG concludes that the inclusion of crcep in the design of the pressure boundary represents a significant risk factor in the design. Current materials listed in Section II for Class I service (A508, A533 steels) have an upper continuous operating temperature limit of $347^{\circ} \mathrm{C}$. Austenitic stainless steels have an upper temperature limit of $427^{\circ} \mathrm{C}$. There are data for $9 \mathrm{Cr}-1 \mathrm{Mo}$ steels from the Fast Breeder Reactor (FBR) and Japanese reactor development programs for temperatures up to $500^{\circ} \mathrm{C}$. However, in the case of the Japanese designs, the life for components is limited to 10 years. In addition, for these components creep is limited to "insignificant" as defined by the ASME Code. For Section VIII service there are significantly more materials that are qualified for service. In addition, the upper temperature limit for some of these materials (Alloy $800 \mathrm{H}$ or Alloy 617 for example) is $800{ }^{\circ} \mathrm{C}$. However, in these cases, the allowable stresses are very low-of the order of 6-10 MPa. Such low allowable stresses will require very thick sections.

Intermediate Heat Exchanger. The intermediate heat exchanger in an indirect cycle plant and the interface heat exchanger between the primary system and the hydrogen generation system in the direct cycle will operate close to the core outlet helium temperature. Even with a reduced gas outlet temperature, as recommended in Section 2.1, metallic materials that can be qualified in time for the NGNP will all be operating within the creep regime. The intermediate heat exchanger required for the indirect cycle plant, and for thermochemical hydrogen generation for the direct cycle plant, has the largest surface area in the primary system, will be a part of the Class I boundary, and will be subject to the ASME Code, Section III, unless it is, itself, enclosed in a cooled-wall pressure vessel that acts as the Class I boundary. If the IHX is enclosed within a cooled pressure vessel, this design will probably require that the "secondary" system, or at least a part of it including the hot gas isolation valves), will also be subject to Class I rules. In the case of the direct cycle, the hydrogen interface heat exchanger will be a part of the Class I boundary and will be subject to ASME Section III as well, unless it is also enclosed in a cooled-wall pressure boundary with the same restrictions as the IHX in the direct cycle. In the case of the indirect cycle, the hydrogen interface heat exchanger will not be a part of the Class I boundary. In this case, the design will be in 
accordance with ASME Section VIII, which is less restrictive. In all of these cases, it will be very difficult to avoid having a portion of the Class I boundary being subjected to temperatures within the creep regime. However, this portion should be kept to an absolute minimum.

For operation at $1000^{\circ} \mathrm{C}$, the likelihood of a metallic material being an option for the heat exchanger will be extremely low. This will probably preclude the use of a heat exchanger for the NGNP at $1000{ }^{\circ} \mathrm{C}$. If this were the case, then, with the requirement of hydrogen generation for the NGNP (thus a heat exchanger), the maximum temperature would be limited to $900^{\circ} \mathrm{C}$. At this temperature, both the dircct and indircet cycles would be viable. At the higher temperature, only the direct cycle with turbine blade cooling would be viable, but without the capability for high-temperature hydrogen generation.

\subsubsection{Fabrication, Welding, Inspection, and Monitoring}

Technical Observation. The NGNP pressure vessel represents a significant increase in size over previous systems because of the $600-\mathrm{MWt}$ power rating and the relatively lower power density. The large size of the pressure vessel will require a significant amount of field fabrication, including welding, post-weld heat treatment, and machining. Fabrication, field welding, and post-weld heat treatment represent significant extensions of current technology. New inspection technology will have to be qualified for field inspection of welds.

Associated Risk. The risk is associated with the possibility that field-related fabrication and inspection of these large vessels, especially if advanced pressure vessel materials $(2.25 \mathrm{Cr}-1 \mathrm{Mo}, 9 \mathrm{Cr}-1 \mathrm{Mo}$ class) are employed, will be beyond the limits of current technology and will not be achievable within the NGNP time frame. The qualification of advanced matcrials represents a significant risk for the NGNP program.

Recommendation. The ITRG recommends that the pressure vessel and associated irreplaceable piping be fabricated using materials for which the current database now exists. If this is not possible, then the ITRG recommends that a focused $R \& D$ program be initiated at the earliest possible date to evaluate the key issues related to fabrication, welding and inspection to determine whether it will be possible to qualify advanced pressure vessel materials in time for NGNP service. Reduction in power rating might be an additional option to the vessel size within acceptable limits.

\section{Technical Justification.}

The fabrication of the NGNP pressure vessel, for the $~ 600-\mathrm{MWt}$ concepts reviewed, will exceed the capacity of all but a few facilities worldwide. Moreover, the thick sections required for some of the materials (e.g., $22 \mathrm{~cm}$ in the case of the high-system-pressure direct-cycle concept) will exceed the existing experience base for these materials. Maintaining physical and mechanical properties through these thick sections will thus be very difficult and will greatly magnify the effort necessary to qualify these materials for service. Welding of these thick sections will also require a significant qualification effort.

Steels of $2.25 \mathrm{Cr}$ or $9 \mathrm{Cr}$ class have been selected as the pressure boundary material of Class-I components for some NGNP concepts reviewed. Steels of $9 \mathrm{Cr}$ are, at present, widely used in coal/natural-gas-fired power plants at metal temperatures up to about $550{ }^{\circ} \mathrm{C}$ with a service life of about 10 years. Their mechanical properties have also been extensively studied in order to use them for liquid-metal-cooled fast breeder reactor applications. The $9 \mathrm{Cr}$ steels have also been used extensively in advanced gas reactor systems in Europe. The $9 \mathrm{Cr}$ class of materials is currently listed in the ASME Code but not qualified for the high temperatures called for in some concepts reviewed. From these experiences, the following issues are important to consider. 
Concerning the size of components with thick walls, the maximum size for which there is industrial experience is about $5.5-\mathrm{m}$ outer diameter, $100-\mathrm{mm}$ wall thickness, and $30-\mathrm{m}$ length. With respect to the NGNP concepts reviewed, the anticipated size of the reactor pressure vessel (RPV) is about 7.7-m diameter, 220-mm wall thickness, and 24-m length. Obtaining uniform properties in raw forging materials for the sidewalls and flange (8.2-m outer diameter) and development of proper inspection technology are key requirements for success. There is considerable experience with fabrication of components this large using A508/A533 materials, hut such experience does not exist for the high-chromium steels.

Welding technology has been well developed and used in sections up to $100 \mathrm{~mm}$ thick. The same method is basically available up to $220 \mathrm{~mm}$ without significant difficulty. Issues of concern are development of inspection technology, repair methods during and after welding, and stress relief heat treatment for very thick-section material. These technologies are not yet established, even in a factory environment. Although welding of this material at the site is very often applied in nonnuclear applications up to $100 \mathrm{~mm}$ thick, very careful development will be required for the RPV. Post-stress-relief machining of the RPV flange will likely be required in order to achieve adequate tolerance for helium system service.

\subsubsection{ASME Codes and Standards}

Technical Observation. Several of the NGNP concepts require either that existing materials be qualified for Section III service or that entirely new materials be developed. In addition, some of the NGNP designs allow for creep deformation in the Class I boundary.

Associated Risk. The risk is associated with the time that will be necessary for the qualification of existing or new materials for use in the Class I boundary. In addition, there will be risk associated with the allowance of creep deformation as a part of the Class I boundary design, both technical and regulatory. It is the judgment of the ITRG that the development and qualification of new materials for Section III, Class I service cannot be achieved in the time frame for the NGNP. Further, it is our judgment that the qualification of existing materials for Class I service where creep deformation is allowed represents an unacceptable risk for the program.

Recommendation. The ITRG recommends that the NGNP irreplaceable Class I boundary components be constructed using materials that are currently qualified for Class I service or that can be qualified without an appreciable data gathering program. The ITRG further recommends that qualification of new materials be limited to those that are either currently listed in Section II for Section VIII service or for which a database currently exists.

\section{Technical Justification.}

The prismatic NGNP, as well as other designs, will operate at temperatures that are not currently allowed by the ASME Code. The upper limits for materials defined in the ASME Code, Section II, are about $800^{\circ} \mathrm{C}$ for Section VIII applications and $427^{\circ} \mathrm{C}$ for Class I boundary materials used in designs governed by Section III. These temperatures are well below anticipated operating temperatures for many metallic components for the NGNP. Moreover, even if metallic materials were to be qualified for temperatures above $800^{\circ} \mathrm{C}$ for Section III, the allowable stresses would be extremely low. An alternative to the current "safe life" design, where time-dependent deformation is not allowed, is to relax this criterion. Subsection NH of the code allows for the inclusion of time-dependent behavior in a design. However, no actual Class III application has been licensed where significant time-dependent behavior is included in the design, and the number of materials qualified is limited to the $2.25 \mathrm{Cr}$, $1 \mathrm{Mo}$ grades. Higher-strength grades, typically the $9 \mathrm{Cr}$ and above classes of materials, will exhibit better performance but will still suffer from creep deformation at NGNP conditions. 
Some of the NGNP prismatic concepts reviewed require Class I boundary operation at temperatures above current code limits and/or use of materials that are currently not listed in the code. The significant risks associated with developing and/or qualifying existing materials for the ASME code are associated with (1) developing and/or qualifying existing materials for use where time-dependent behavior is still not allowed, and (2) allowing for creep behavior in the design. With respect to (1), the path is straightforward: acquiring the necessary data. Nonetheless, the time necessary to accomplish this will be significant and judged too long for design decisions to be made by 2009 . With respect to (2), the issues are much more significant. When time-dependent behavior is allowed, there will be a requirement for extensive inspection, possibly in real time or at least very frequently. Creep deformation, along with the likelihood of some fatigue component, will result in complex microstructural changes that are significantly more difficult to quantify than simple thermal aging phenomena. This will be especially true of welds. In the case of (2), the risks are thus significantly higher. The inclusion of creep deformation in the NGNP design is considered an impractical assumption from technical and licensing standpoints. The PBMR concept avoids this risk by using a reactor pressure vessel cooling system.

\subsubsection{Corrosion and Oxidation}

Technical Observation. High-temperature operation of metallic components for times up to 60 years will result in the possibility of corrosion damage. This damage will most likely be associated with coolant contamination within the primary system or air oxidation on external surfaces. In addition, the development of oxidized surfaces may affect the overall thermal resistance of the system as a result of changes in emissivity.

Associated Risk. The risk is associated with potential changes in material properties as a result of corrosion-induced embrittlement.

Recommendation. This risk is judged to be minimal assuming that adequate coolant contaminant control is exercised

\section{Technical Justification.}

From a corrosion standpoint, the reactor internals will operate in a helium atmosphere and the external reactor surfaces, including the reactor pressure vessel, will operate in air. With respect to past evaluations on the effects of operation at higher temperatures in helium, the range of helium impurity levels tested is summarized in INEEL/EXT-03-01128, Rev 0, ${ }^{7}$ Table 3-6, and Section 3.3.2.3. The main potential impurities that can persist in an NGNP helium environment are $\mathrm{H}_{2}, \mathrm{H}_{2} \mathrm{O}, \mathrm{CO}$, and $\mathrm{CH}_{4}$. The hot graphite core would react with any free oxygen present to form $\mathrm{CO}$ and with much of the water to form $\mathrm{CO}$ and $\mathrm{H}_{2}$. Small changes in impurity levels can have a significant effect on material performance, depending on concentration, temperature, and gas flow rate. Although unlikely under normal operating conditions with good helium impurity cleanup and long-term control, under off-normal conditions or with nonoptimum impurity control there is potential for carburization, decarburization, and surface or internal oxidation. Because of the low partial pressures of the impurities in the helium gas stream, the oxidation/carburization potentials at the metallic surfaces are established by the kinetics of the individual impurity-catalyzed reactions at the surface. The potential degradation mechanisms, depending on their reaction rates, can substantially affect such long-term mechanical properties as fracture toughness, fatigue, crack growth rate, IHX efficiency, etc. In the case of one of the proposed indirect cycle concepts for NGNP, although the primary system will contain pure helium, the secondary side system will contain a mixture of $80 \% \mathrm{~N}_{2} / 20 \% \mathrm{He}$ at temperatures up to $950{ }^{\circ} \mathrm{C}$, and similar effects of impurities on sccondary-side material performance would also be expected. However, impurity effects on very longterm materials performance under these mixed gas conditions are not as well defined. In the case of the RPV outer surface, air oxidation can alter long-term emissivity, and this effect must be quantified. An 
extensive helium environmental test program is planned to evaluate both the effects of impurities on mechanical properties and general corrosion response of candidate NGNP materials (INEEL/EXT-03-

01128, Rev 0, ${ }^{7}$ Section 3.3.2.3 and Appendix D). The successful completion of this program will provide a firmer basis for setting the key helium impurity concentration limits to ensure successful performance under the more aggressive thermal conditions and longer exposure times representative of the NGNP.

\subsubsection{Microstructural Stability}

Technical Observation. The exposure of metallic materials to high temperature for long periods of time may result in microstructural changes in pressure boundary materials that result in a degradation of material properties.

Associated Risk. The risk is associated with embrittlement of materials. However, with an adequate monitoring and inspection program, this risk is judged to be acceptable.

Recommendation. The ITRG recommends that the development program conducted for the NGNP include tests to identify thermal aging issues. Spccial consideration should be given to welds and heat-affected zones.

\section{Technical Justification.}

In addition to the potential for environmental degradation by helium gas impurities, very long-term exposure of the RPV and the other intermediate-to-high-temperature component materials has the potential to degrade material properties through various thermal aging mechanisms. In the case of the RPV steels, because of their significant wall thickness (e.g., $22 \mathrm{~cm}$ for the $2 \frac{1 / 4}{\mathrm{Cr}}-1 \mathrm{Mo}$ steel specified by GA), there is likely to be a range of carbide microstructures in the quenched and tempered condition or the normalized and tempered condition. The hardenability is insufficient to form a through-wall, fully martensitic structure or to prevent the formation of cementite (which has the potential to increase susceptibility to hydrogen attack under higher-pressure hydrogen gas conditions that are not likely to be relevant to the NGNP), even with accelerated cooling (ASM Metal Handbook, Volume $1,10^{\text {th }}$ edition, p. 621).

In contrast to the initial selection of the $21 / 4 \mathrm{Cr}$-1Mo steel for one concept, for another concept a high-chromium ferritic/martensitic steel, a $9 \mathrm{Cr}-1 \mathrm{MoVNb}$ type steel (Grade 91) was selected with a significantly thinner wall ( $13.5 \mathrm{~cm}$ in the RPV straight sections) because of the lower system pressure of the indirect cycle concept. This higher-alloy-content stccl has somewhat different carbide morphology than the $2 \frac{1 / 4}{\mathrm{Cr}}$ - $1 \mathrm{Mo}$ steel because fine $\mathrm{M}_{23} \mathrm{C}_{6}$ precipitate particles nucleate on $\mathrm{Nb}(\mathrm{C}, \mathrm{N})$, which first appears during heat treatment. The finer carbides add to the strength and tend to retard grain growth. Also, some vanadium dissolves in the $\mathrm{M}_{23} \mathrm{C}_{6}$, also retarding precipitate growth at higher temperatures.

For both potential RPV materials, the likely requirement for field fabrication of the vessel at the INEEL site by welding a series of thick-wall ring forgings and then performing a post-weld heat treatment (probably a local heat treatment in the vicinity of each field weld) may result in a somewhat different range of through-wall carbide microstructures than would be the case for shop fabrication and post-weld heat treatment of the entire vessel. There are data available in the literature that describe the effects of very long-term thermal aging without applied stress on subsequent mechanical properties (tensile properties and creep properties) for both materials, with some of these results described for thermal exposures up to $700{ }^{\circ} \mathrm{C}$ and for times up to 10,000 hours for $21 / 4 \mathrm{Cr}$-1Mo and for up to 100,000 hours for a 9Cr-1Mo steel in ASM Metals Handbook, Volume 1, 10 th edition, p. 622-629 and Figures 6 and 7. These results indicate an obvious effect of thermal aging on subsequent mechanical properties. For example, for the normalized and tempered $2 \frac{1}{4} \mathrm{Cr}-1 \mathrm{Mo}$ steel thermally aged for 10,000 hours at $500^{\circ} \mathrm{C}$, the subscquent 
$10,000 \mathrm{hr}$ stress rupture strength at $500{ }^{\circ} \mathrm{C}$ decreased from about $200 \mathrm{MPa}$ without previous exposure to about $165 \mathrm{MPa}$ with previous exposure. At the same temperature of $500^{\circ} \mathrm{C}$, the $9 \mathrm{Cr}-1 \mathrm{Mo}$ steel, at least in the annealed condition, was apparently also susceptible to thermal aging. For example, after 10,000 hr unstressed exposure at $500{ }^{\circ} \mathrm{C}$, the subsequent 100,000 -hr stress-rupture strength decreased from about $230 \mathrm{MPa}$ to about $150 \mathrm{MPa}$. Hardening in these steels at higher temperatures is a result of both solid solution strengthening and carbide precipitation hardening.

At higher exposure temperatures, one would expect transformation and coarsening of the carbides, changes in the matrix composition, and a concomitant reduction in strength. There is also the potential for a loss in notch toughness by temper embrittlement or the closely related creep embrittlement, which can occur over the temperature range of $425-595{ }^{\circ} \mathrm{C}$ in alloy steels having ferrite plus carbide microstructures. The latter mechanism appears to be closely associated with tempering reactions inside grains and at grain boundaries during the creep process. The formation of fine, needlelike precipitates in grain interiors, accompanied by the development of a denuded zone and elongated alloy carbides at grain boundaries, also appears to contribute to the embrittlement process (ASM Metals Handbook, Vol 1, p. 626-627). Because of the potential for undesirable mechanical property changes from long-term, higher temperature thermal exposure, it is critical that the planned RPV aged materials test program similar to that described in INEEL/EXT-03-01128, Rev 0, ${ }^{7}$ Section 3.3.3.1.2 be completed on an appropriate schedule to provide a defensible high-temperature exposure effects database for ASME Code qualification and for NRC review and licensing.

Thermal aging effects in the higher-temperature iron- and nickel-base austenitic alloys containing chromium, molybdenum, and tungsten are also a potential issue that must be quantified in the next few years to provide a defensible base for selection of materials. This class of alloys has the potential to form brittle, chromium-rich sigma phase and, for some of the candidate alloys, also brittle molybdenum and tungsten-rich $\mathrm{P}$ and $\mathrm{Mu}$ phases that tend to precipitate first at grain boundaries. In addition to creating the potential for embrittlement and degraded mechanical properties, these precipitated phases can denude the adjacent alloy matrix of beneficial alloying elements that provide corrosion resistance. $\Lambda \mathrm{n}$ example of such a potential nickel-base alloy that may have the requisite properties to serve as an IHX material at temperatures up to $1000^{\circ} \mathrm{C}$ is Inconel 617 [NO6617] ( $\left.\mathrm{Ni}-22 \mathrm{Cr}-12.5 \mathrm{Co}-9 \mathrm{Mo}-1 \mathrm{Al}\right)$. This alloy is further along toward qualification than many other potential NGNP high-temperature alloys in that it had a draft ASME Code case developed in the 1980 s for use up to $982^{\circ} \mathrm{C}$ with provision to treat very hightemperature time-dependent material property behavior. However, the draft Code case recognized that significant environmental effects could exist and that high-temperature thermal aging effects could lead to a significant reduction in fracture toughness and thus could require the treatment of potential brittle fracture.

A significant effort to develop the structural design technology as well as an extensive materials properties development test program would be required to complete the Inconel 617 code case. Similar materials performance problems are also likely to develop with other nickel-and iron-base alloys containing higher chromium, molybdenum, and tungsten that can form deleterious precipitate phases at higher temperatures. As described earlier, a materials qualification program that can lead to full code acceptance is given in INEEL/EXT-03-01128, Rev $0,{ }^{7}$ Section 3.4.3.2. It is essential that the elements of this program be completed in a timely manner if an NGNP operational date of about 2020 is to be accomplished.

The above potential issucs relatcd to corrosion and thermal aging can present a significant materials and thus NGNP risk, as stated above. However, the risk can be appreciably reduced, or at least minimized, if the following progress is achieved: obtain sufficient relevant materials-performance-related experimental test results from currently planned U.S. and international HTGR-related programs; development of defensible, benchmarked, relevant high-temperature, time-dependent materials 
performance modeling codes; and obtain parallel relevant HTGR experience, including the Japanese HTTR (once it attains a core outlet temperature $\geq 950^{\circ} \mathrm{C}$ ) and the Russian GT-MHR (if it is completed in the next few years).

\subsubsection{Graphite}

Technical Observation. The NGNP may require use of new sources of graphite, the source of graphite for earlier gas reactor systems no longer being available. The qualification of new sources of graphite will require an extensive $\mathrm{R} \& \mathrm{D}$ and qualification program.

Associated Risk. The risk is associated with the potential that graphite performance under irradiation at high temperatures may limit the life of key core structural components. In addition, radiation-damage-induced distortion of core structural materials may result in an increase in bypass flow.

The amount of bypass flow will have an important effect on fuel temperatures during operation. If excessive bypass flow is present, then the viability of a prismatic concept may be influenced. This risk is judged to be significant but not unacceptable with respect to safety.

However, cost risk associated with early replacement of core components may become significant and affect the overall economics (e.g., for structural components in a prismatic concept and reflector structures in the PBMR concept).

Recommendation. The ITRG recommends that additional work be done to quantify the expected evolution of bypass flow for a prismatic core concept more accurately. The relationship between graphite performance and bypass flow should be quantified. Radiation-induced graphite degradation generally increases with increased temperature and has to be investigated in detail with regard to maximum allowable coolant temperatures in the core region.

\section{Technical Justification.}

Graphite will he an essential material for NGNP core structural and fuel components. Graphite grade $\mathrm{H}-451$, which was the U.S. standard for nuclear service, may not be available. Moreover, the properties of graphite highly depend on the source and type of raw materials, as well as processing parameters. Thus, the NGNP must either rely on other qualified graphite sources or develop its own source of qualificd graphitc. Fortunately, there are a number of potential sources of graphite that either have been or are being developed for other gas reactor programs. These include Toyo Tanso IG-110, which is being used for both the Japanese HTTR and the Chinese HTR-10. Other grades of graphite, including UCAR-PCEA, SGL-HLM, and SGL-NBG-10 are available for use in structural applications.

While there are a number of sources of graphite available, the degree of qualification is variable though several programs are in progress to develop qualified databases. Therefore, much more work is needed in this area.

Graphite can be obtained that exhibits physical and mechanical properties that range from highly anisotropic to nearly isotropic. For structural and fuel block applications, nearly (or completely if possible) isotropic behavior is desired. However, even if this is achieved, radiation damage will result in some distortion of the graphite blocks used in the prismatic fuel, core structural, and reflector blocks. This is due to the temperature-dependence of the swelling and/or shrinkage of the graphite. Radiation damage gradients, in combination with temperature gradients, will result in a gradual distortion process that, while it can be minimized by design, cannot be eliminated. As a result of this process, there will be an increase in bypass flow in the core and reflector, which will affect both fuel temperatures and structural material tempcratures. In addition, an increasc in bypass flow will decrease plant efficiency. For the INEEL 
reference NGNP prismatic design, an assumption of a maximum of $10 \%$ bypass flow was assumed to be achievable. This was necessary to stay within the fuel temperature limits during operating conditions. Staying below $10 \%$ bypass flow will certainly be achievable during initial operation. However, Fort Saint Vrain experience indicates that a more realistic bypass flow maximum without interim replacement of graphite reflector blocks would be more like $20 \%$. Thus, the assumption of a maximum of $10 \%$ bypass flow may represent an important risk for the design.

As pointed out above, restriction of the design to less than $10 \%$ bypass flow will probably require the replacement of at least some of the reflector blocks during the 60-year life of the plant. The key question then is to determine the maximum exposure time allowable. Even if the H-451 graphite database were relevant to the NGNP design, the uncertainty in the data will make predictive behavior uncertain. This significant uncertainty, if not reduced, will result in a shorter replacement life. As an example, uncertainty in graphite behavior required the redesign of the PBMR reflector system for interim replacement. The reflector for the Pebble Bed Modular Reactor (PBMR) design is very similar to that of the prismatic design.

\subsubsection{Extrapolation of Limited Data}

Technical Observation. Use of advanced materials will require the development of an adequate database for materials used in the NGNP design. The current databases for advanced pressure boundary materials do not extend to the temperature ranges where some of the proposed NGNP concepts will operate. Use of materials at high temperatures may result in new deformation mechanisms (creep, creepfatigue) becoming issues. The extrapolation of time-dependent data where fatigue is present represents a very significant challenge to the design.

Associated Risk. The risk is associated with the uncertainty in extrapolation of existing data to higher temperatures.

Recommendation. The ITRG recommends that, where possible, minimal extrapolation be used. In addition, carc must be taken to ensure that cxtrapolation remains within the database deformation regime.

\section{Technical Justification.}

Regardless of the design chosen, or the materials used in construction, the high operating temperature will require that some tradeoff be made between cost and required data. The result will be the extrapolation of a limited database, primarily in time at temperature, stress and radiation dose, to the endof-life conditions. The uncertainty in the extrapolation will be determined by the uncertainty in the existing database and the extent of the extrapolation. Testing of materials at higher temperatures for shorter times is often used as a basis for extrapolation of lower temperature data to longer times. Higherstress data are often extrapolated to lower stresses. Radiation damage is often acquired at a faster rate and then extrapolated to lower dose rates at the same temperature. This being said, a fundamental assumption of the process is that the extrapolation actually represents an interpolation with respect to the operable mechanisms. In addition, with respect to radiation damage, the assumption is that the dynamics of the damage process in the base state are the same as at the extrapolated state. As pointed out in Section 2.1, extrapolation into the $1000^{\circ} \mathrm{C}$ temperature range from lower temperatures for metallic materials will have a substantive risk of violating the first of these assumptions. Great care will have to be taken in this area. In the case of irradiation damage, the dynamics of simultaneous damage and real-time annealing will have to be considered carefully for both metallic and ceramic components. As a result, it is likely that close-to-real-time testing will have to be done to ensure performance. 
As always, aside from the cost issues, the tradeoff will be between data veracity and inspection interval. Higher uncertainty will yield shorter inspection intervals. In the ITRG's judgment, the inclusion of creep deformation in the design will require real-time companion testing as well as sophisticated component monitoring. This will be true even at a reduced operating temperature of $900{ }^{\circ} \mathrm{C}$ because creep can still occur at this temperature.

\subsubsection{Advanced Materials Development}

Technical Observation. Operation at a gas outlet temperature of $1000{ }^{\circ} \mathrm{C}$ will require use of nonmetallic materials in core structural applications and will require development of new materials for heat exchanger designs.

Associated Risk. The risk is associated with the time it will take for the development and qualification of new materials. It is judged that sufficient new material development and qualification cannot be achieved in time to support the NGNP construction permit application (2009).

Recommendation. The ITRG recommends that NGNP materials be limited to those currently qualified or that can be qualified with minimal effort. As discussed in earlier sections, this will require that the gas outlet temperature be reduced.

\section{Technical Justification.}

As pointed out in the previous sections, achieving a continuous gas outlet temperature of $1000{ }^{\circ} \mathrm{C}$ with a 60 -year life, while supporting plant operation by 2020, is a goal that, in our opinion, is not achievable. The achievement of this goal will require the development or qualification of new metallic materials for pressure boundary applications and new classes of materials, $\mathrm{C} / \mathrm{C}$ and $\mathrm{SiC}$-based composite materials for structural applications. Achievement of $1000{ }^{\circ} \mathrm{C}$ continuous operation is expected to require the use of a completely ceramic/graphite/composite core system. In our opinion, the path forward for pressure boundary applications in the IHX will require a transition from Fe-based materials to other, likely Ni-based, materials for this application.

Three classes of advanced materials are proposed by concept proponents: carbon/carbon-fibcr composite $(\mathrm{C} / \mathrm{C})$ for control rod cladding material, $\mathrm{SiC}$ for use as a coating material on metallic components, and $\mathrm{Al}_{2} \mathrm{O}_{3} / \mathrm{SiO}_{2}$ fibcr as an insulation material. $\mathrm{C} / \mathrm{C}$ is already widely used as a structural material in nonnuclear applications. SiC-based or SiC-doped $\mathrm{C} / \mathrm{C}$ will allow for improved corrosion resistance. Key issues related to the use of $\mathrm{C} / \mathrm{C}$ as cladding material for control rod drives include

- Development of design criteria using an anisotropic material

- Investigation of neutron irradiation and corrosion behavior

- Development of quality control and acceptance criteria.

During early gas reactor development, an ASME code case was initiated. However, the case was never completed. The NGNP will require that the code case be completed.

Development of fabrication technologies for cylinders, plates, rods, and other shapes is a mature process for other industries, including the commercial aircraft industry. However, mechanical properties of $\mathrm{C} / \mathrm{C}$ composites depend on fabrication process and fiber arrangement and mechanical/dimensional response under multi-axial stress. These are difficult to predict and specific to a particular design. For this reason, design criteria for isotropic metallic materials cannot be simply applied to $\mathrm{C} / \mathrm{C}$ composite materials. Development of design criteria is, therefore, essential. 
Irradiation behavior of $\mathrm{C} / \mathrm{C}$ composites will be a strong function of individual component design and fabrication history. It is thus not sufficient to develop "generic" irradiation performance data and expect that these data will apply to specific applications. Each composite structure will have to have its own unique irradiation database.

$\mathrm{SiC}$ coating of metallic components is used in several high-temperature helium loops to prevent adhesion where two or more metallic parts contact each other. In these cases, the coating area is small. When the SiC coating area is large, development of a new technology is needed to accommodate differential thermal expansion between the metallic base and coating.

\subsection{Conclusions}

The previous sections discuss what the ITRG considers the key sources of materials-developmentrelated risk associated with the NGNP concepts that have been proposed.

Figure 1 shows the degree of risk as a function of materials-development-related "complexity." By increasing complexity we mean that the materials problem gradually becomes more significant with interdependent issues as the gas outlet temperature increases.

By far the most significant risk with respect to materials is associated with the requirement for a gas outlet temperature of $1000{ }^{\circ} \mathrm{C}$ or higher. Operation at $1000^{\circ} \mathrm{C}$ may eliminate the indirect cycle and hydrogen generation at this temperature. This requirement essentially eliminates metallic materials for an NGNP on the construction schedule identified. The high temperature would also greatly aggravate the risks associated with $\Lambda$ SME code qualification, welding, and processing, and essentially all of the other risk factors identified. As a result of this, it is our judgment that a gas outlet temperature of $1000{ }^{\circ} \mathrm{C}$ or higher represents a significant risk for successful completion of NGNP on the specified schedule. A more realistic, achievable, maximum temperature of $900{ }^{\circ} \mathrm{C}$ for metallic components was arrived at by general consensus.

The next most significant risk factor is that associated with the allowance of creep deformation in the Class I pressure boundary. The high gas outlet temperatures anticipated for the NGNP require use of materials for the pressure boundary that are at least capable of operating at temperatures above those of current pressurized water reactors, an attractive option from a plant efficiency point of view. However, while some (very few) of the current pressure vessel materials are capable of higher temperatures, operating at metal temperatures and stresses where creep or creep-fatigue mechanisms are significant represents a very substantial departure from current practice. The allowance in the design for creep during operations will also result in a very significant increase in the R\&D costs, as well as the required component inspection and monitoring. The judgment of the ITRG is that, while operating in the creep regime is possible, the achievement of this goal on the time frame of the NGNP will not be practical. The ITRG therefore recommends that creep deformation not be allowed to be significant for irreplaceable (60year life) components that are a part of the Class I boundary, such as the pressure vessel and primary system piping. For Class I components that could be replaced on a more frequent interval, such as the IHX, creep deformation may be allowed but at the expense of significant real-time monitoring and inspection. 


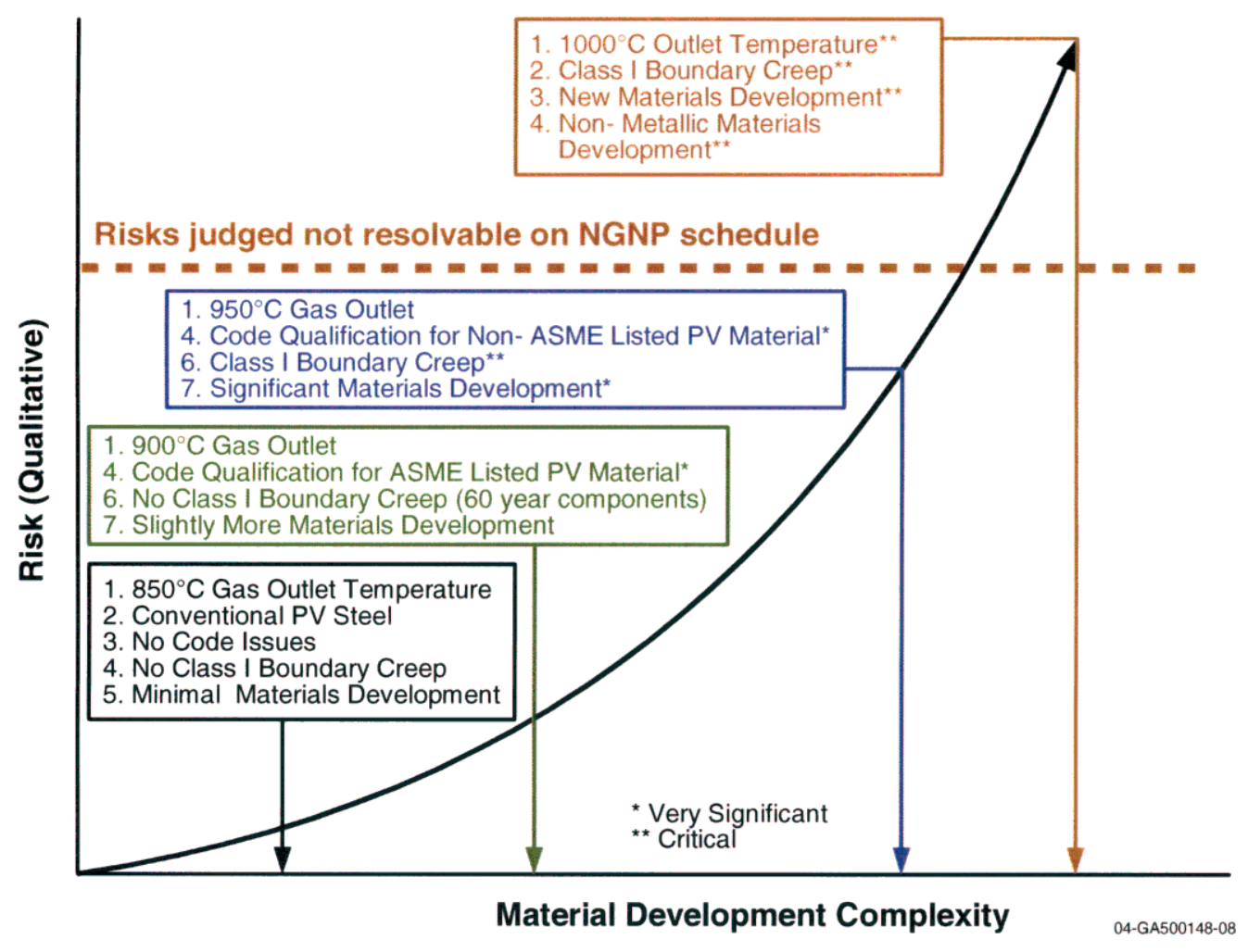

Figure 1. Schematic illustrating the level of risk as the degree of materials development complexity increases.

Issues associated with radiation-induced degradation and distortion of the graphite structure in the prismatic design also represent a very significant risk for the program. For a prismatic concept, the assumption of no more than $10 \%$ bypass flow, potentially necessary to ensure that fuel temperature limits are not exceeded during operation and transient conditions, is at variance with past experience where bypass flow levels of $20 \%$ were observed. Although it may be possible to implement core design improvements to limit core bypass, it is the judgment of the ITRG that this issue will need to be resolved. The existing uncertainties associated with this assumption represent a significant risk to the NGNP.

Other risk factors include those related to microstructural instability associated with aging, welding of thick metallic sections, and processing of thick sections. These risks are substantial and will require extensive R\&D to achieve acceptable levels. Once again, a reduction in gas outlet temperature and/or a reduction in Class I boundary metal temperatures would greatly reduce the extent and effect of this risk. 


\section{POWER CONVERSION SYSTEM}

\subsection{Introduction}

A review of the design, fabrication, and operation of the power conversion systems proposed by the proponents of prismatic gas-cooled reactor concepts and the PBMR concept was conducted with the objective of identifying the major risks associated with these systems. In addition, information was also obtained from background documents prepared by DOE and INEEL for the NGNP.

\subsection{Assessment of Risks}

In assessing risks, it has been assumed that the ITRG recommendation with respect to reducing the NGNP reactor outlet temperature will be adopted; specifically, that this temperature will be reduced from 1000 to $900-950^{\circ} \mathrm{C}$. As discussed in the materials section of this report, the metallurgical risks of the $1000^{\circ} \mathrm{C}$ outlct temperature are unacceptably high.

The reference power conversion cycle for the NGNP is direct; the helium circulating through the reactor core is also circulated through the power conversion system. One of the proponents of a prismatic gas-cooled reactor has proposed a direct-cycle power conversion system, and the designers of the PBMR are in the process of developing and testing hardware for a direct cycle. However, another prismatic reactor proponent has proposed an indirect cycle employing an intermediate heat exchanger to transfer heat to a closed secondary power conversion system.

The proponent of an advanced high-temperature (molten-salt-cooled reactor) proposed a compound indirect cycle: a secondary molten salt loop transfers heat through three salt-to-gas heat cxchangers in parallel. The transferred energy is used to power three turbine-compressors in cascade; each heat exchanger reheats the gas working fluid. This relatively complex arrangement is made necessary by the relatively small temperature difference across the primary side of the intermediate heat exchanger. Efficient heat transfer requires relatively small gas temperature rises across the secondary side of this heat exchanger.

The indirect power conversion cycle proponent proposes to use a mixture of nitrogen and helium for a working fluid. The mixture has thermodynamic properties closely resembling air and the combustion gas mixture employed in conventional gas turbine power plants. The single-shaft power conversion assembly is oriented horizontally. It resembles and uses much of the same technology as a conventional combined cycle (a gas turbine topping a steam turbine) power plant. Gas from the turbine exhaust is directed to a steam generator, where it is cooled to a temperature in the $50-100{ }^{\circ} \mathrm{C}$ range before entering the compressor. The steam from the steam generator is used to power a steam turbine, and the steam turbine exhaust is directed to a condenser, the ultimate heat sink for the cycle. Water from the condenser is directed back to the steam generator via condensate and feedwater pumps.

The cycle trades the recuperator, precooler and, for some designs, an intercooler of a Joule-Brayton cycle for the steam generator, condenser, feed pump, and steam turbine. About $80 \%$ of the power in this cycle is derived from the steam turbine and $20 \%$ from the gas turbine. Because of the highly efficient and fully developed Rankine steam cycle with superheater outlet temperatures of about $500{ }^{\circ} \mathrm{C}$, there is substantially less risk of this cycle failing to meet efficiency targets than with the direct Joule-Brayton cycle. In addition, the low return temperature from the secondary system leads to a low reactor inlet temperature and a high reactor coolant temperature difference. This in turn leads to a low coolant mass flow requirement-hence, a low coolant operating pressure (a high coolant density is not required to transport the energy). The low return temperature allows use of well-developed alloys for pressure bearing parts; the low pressure leads to moderate wall thickness for those parts. On the other side of the ledger, however, the cycle is significantly more complex than a direct Joule-Brayton cycle, as is any 
combined-cycle plant. Combining two or more reactor modules with one larger power conversion unit might compensate for this drawback.

Note that the indirect cycle need not be a combined cycle. An IHX will producc, conservatively, a secondary gas outlet temperature $50^{\circ} \mathrm{C}$ below the reactor outlet temperature. The loss in efficiency of a recuperated Joulc-Brayton cycle with a $50^{\circ} \mathrm{C}$ reduction in turbine inlet temperature is only about $1.5 \%$. However, the primary coolant pumping power required for the indirect cycle will impose an additional efficiency penalty of as much as $1.5 \%$, depending on coolant flow requirements. The indirect-combined cycle is expected to offset most of this penalty.

An important advantage of the direct cycle over the proposed combined cycle is its apparent simplicity. However, for the NGNP, the most significant drawback of the direct cycle is the large number and diversity of the development risks associated with it. These risks are described in Table 2.

An examination of the table shows risks of several kinds:

- Metallurgical. The front end of the turbine is $50{ }^{\circ} \mathrm{C}$ hotter for the direct cycle. Achieving 6-7 year component life (or better) at the higher temperatures is a development challenge.

- Maintenance/availability. The vertical and compact modular arrangements proposed make for very difficult access for maintenance. If component reliability is not high, lost time for maintenance outages will be large. In addition, the direct cycle is susceptible to contamination (e.g., by fissions products or activated silver) of the power conversion unit, which may result in high shutdown radiation levels.

- Design/development. The magnetic bearing systems required to minimize leakage from the direct cycles are in an early stage of development and will require full-scale prototype testing. The auxiliary (catcher) bearings likewise need development. These bearings prevent physical damage to the turbomachinery in the event of a failure of the magnetic bearing system.

- Operational. Control of the power conversion system during normal operations and during upsets involves components and concepts that are in an early stage of development and unfamiliar to utility operators. (In this regard, some aspects of indirect cycle control may also necd development.)

Given the large number and formidable nature of the risks associated with the direct cycle and their potential impact on the NGNP schedule, the ITRG concludes that the NGNP should procecd on the basis of a lower-risk indirect cycle (not necessarily the cycle proposed by the proponent of the indirect cycle). The indirect cycles necessitate use of an intermediatc heat exchanger-itself a component with significant developmental risks. However, the ITRG considers these risks-described in Section 6-to be more manageable than the aggregate of the risks associated with any of the direct cycle concepts.

The recommended approach is not intended to foreclose the future application of direct cycles to Generation IV power plants. The potential advantages of plant simplicity afforded by a direct cycle are great. Accordingly, the ITRG also recommends that the DOE actively participate in the several direct cycle developments currently under way: the PBMR power conversion system, the U.S. International Team power conversion system, and llıe Gass Turbine High Temperature Reactor (GTHTR-300) (JAERI) power conversion system. Further, the NGNP indirect secondary circuit can be used as a test platform for direct cycle components.

Finally, as notcd above, some of the control challenges of direct-cycle power conversion systems are also present in indirect-cycle power conversion systems. The ITRG considers that the selection of a control system design approach and the evaluation of its effectiveness would benefit from operating utility participation at an early stage. This will provide greater assurance that the control system design approach ultimately adopted will be operationally acceptable. 


\begin{tabular}{|c|c|c|c|c|c|c|}
\hline & & 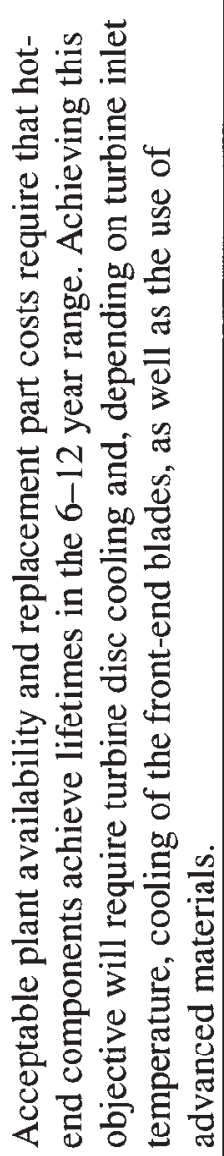 & 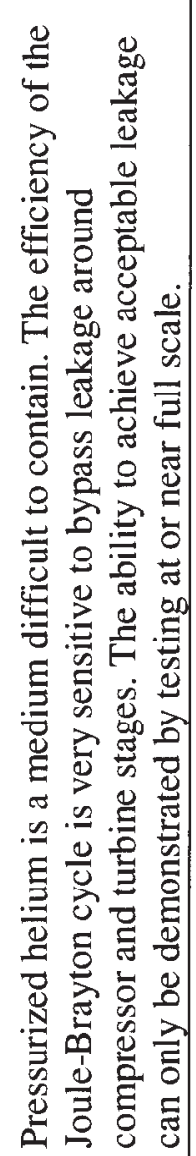 & 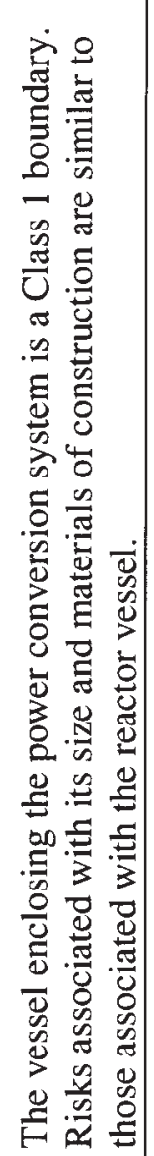 & 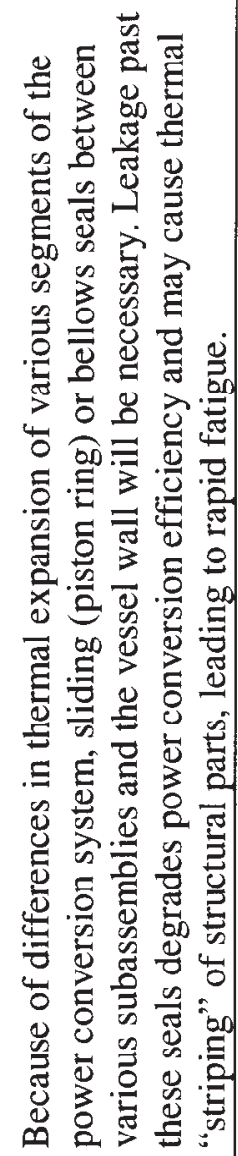 & 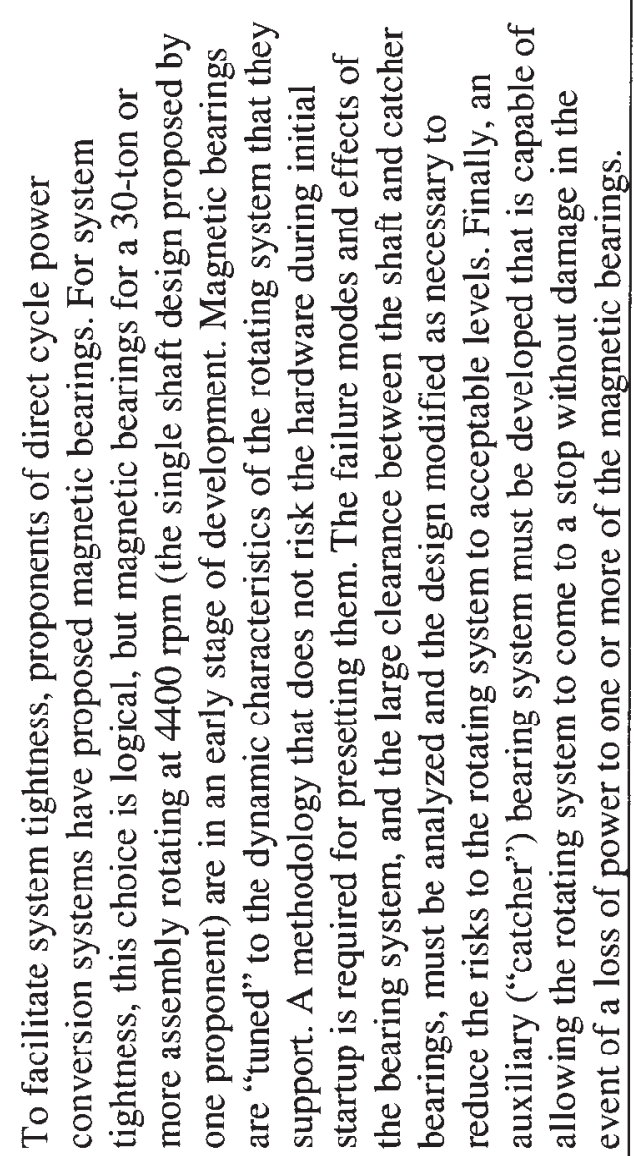 \\
\hline & 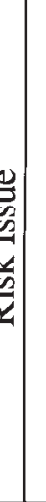 & 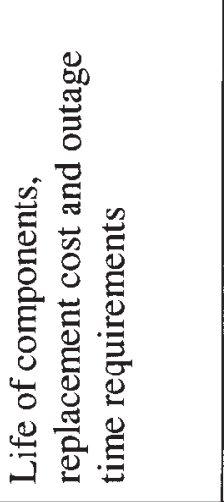 & 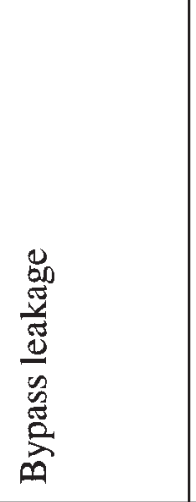 & 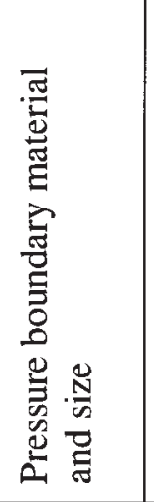 & 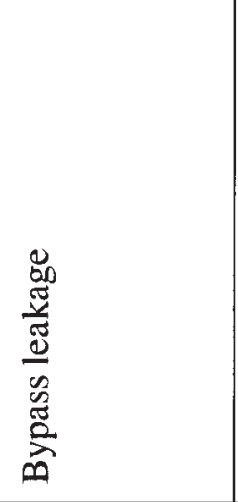 & 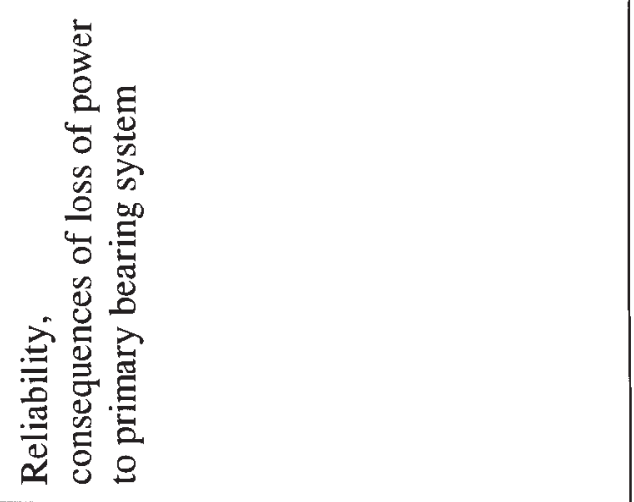 \\
\hline & 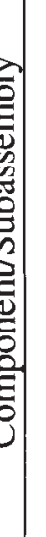 & 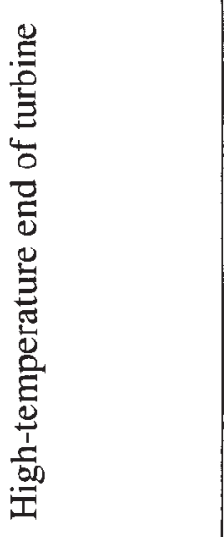 & 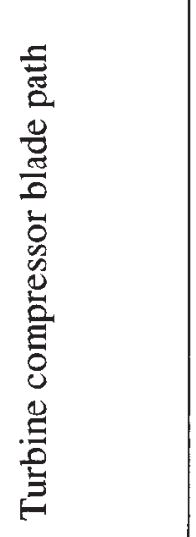 & 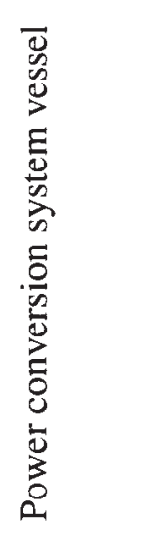 & & 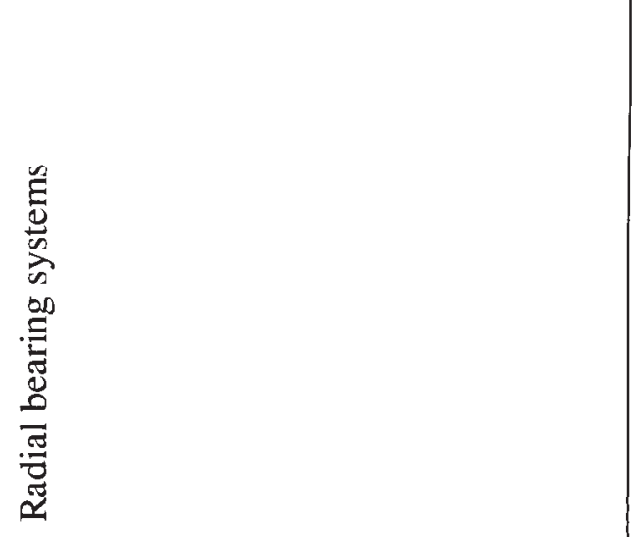 \\
\hline
\end{tabular}




\begin{tabular}{|c|c|c|c|c|}
\hline & 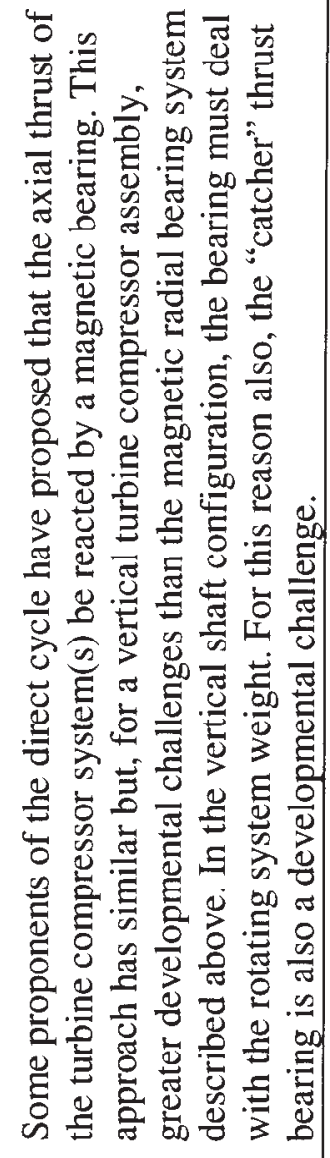 & 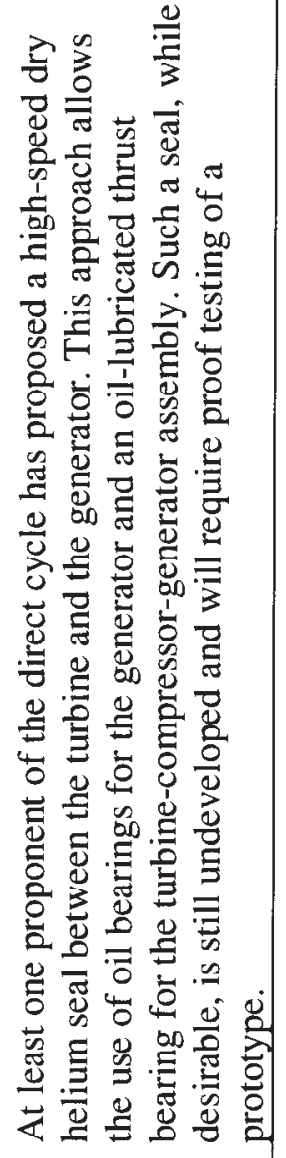 & 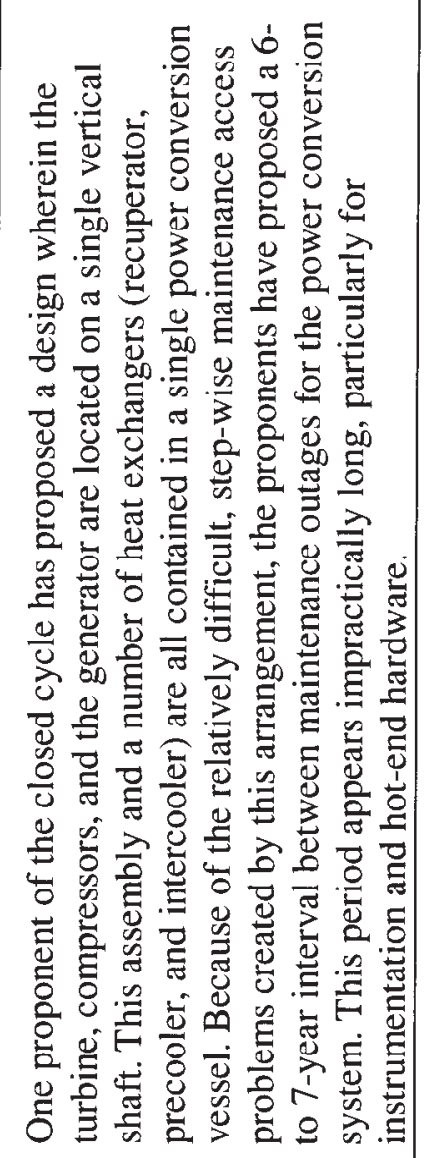 & 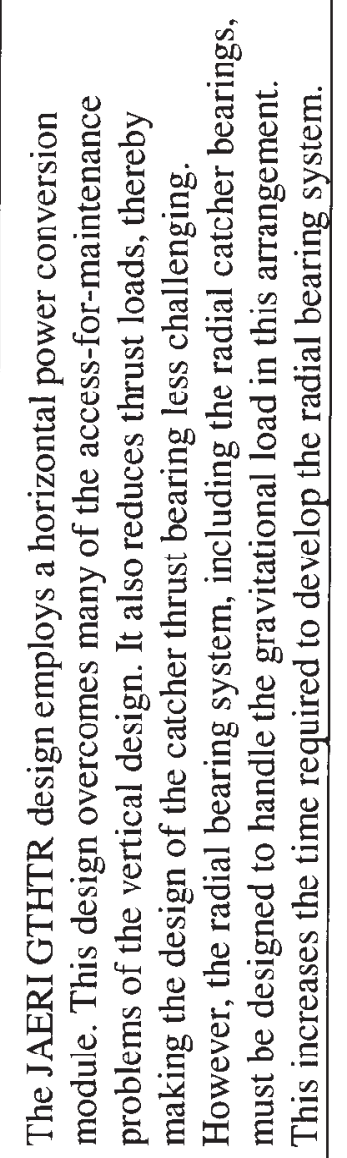 \\
\hline 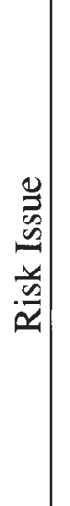 & 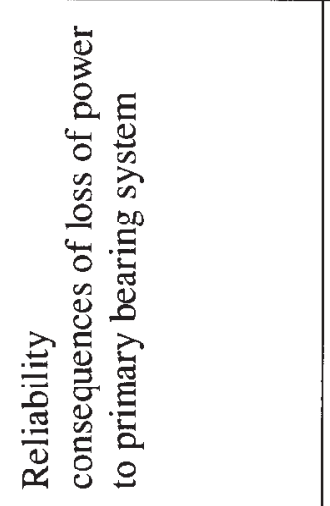 & 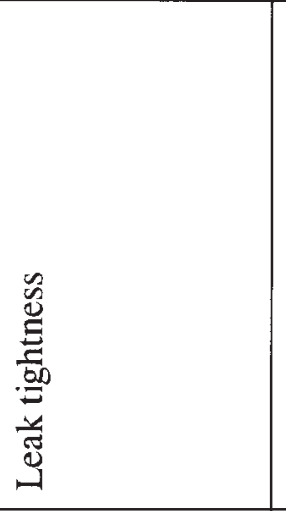 & 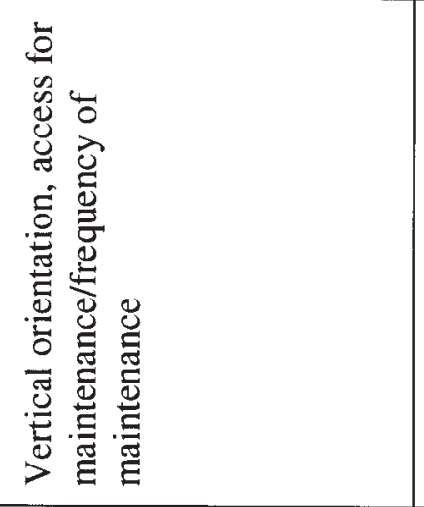 & 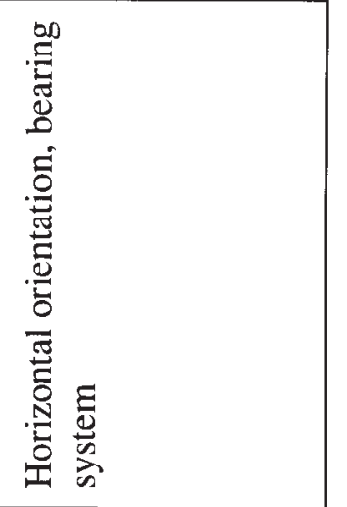 \\
\hline 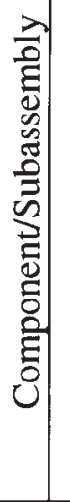 & 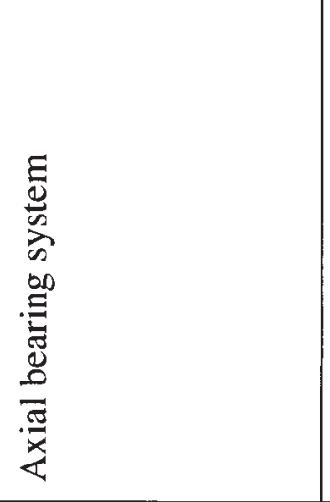 & 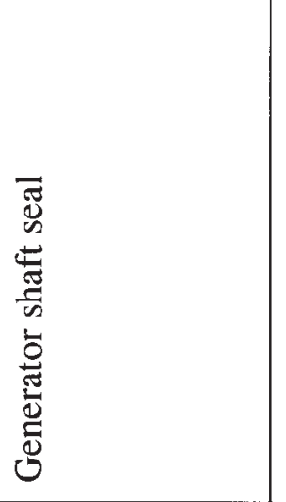 & 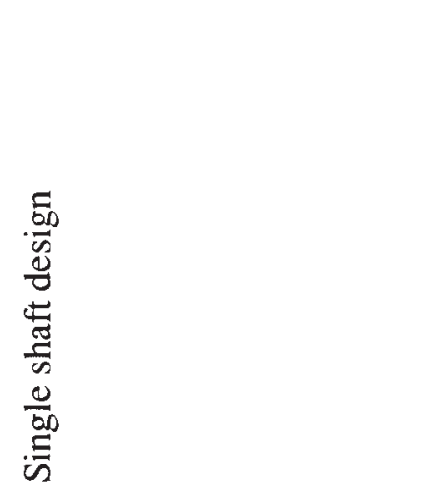 & \\
\hline
\end{tabular}




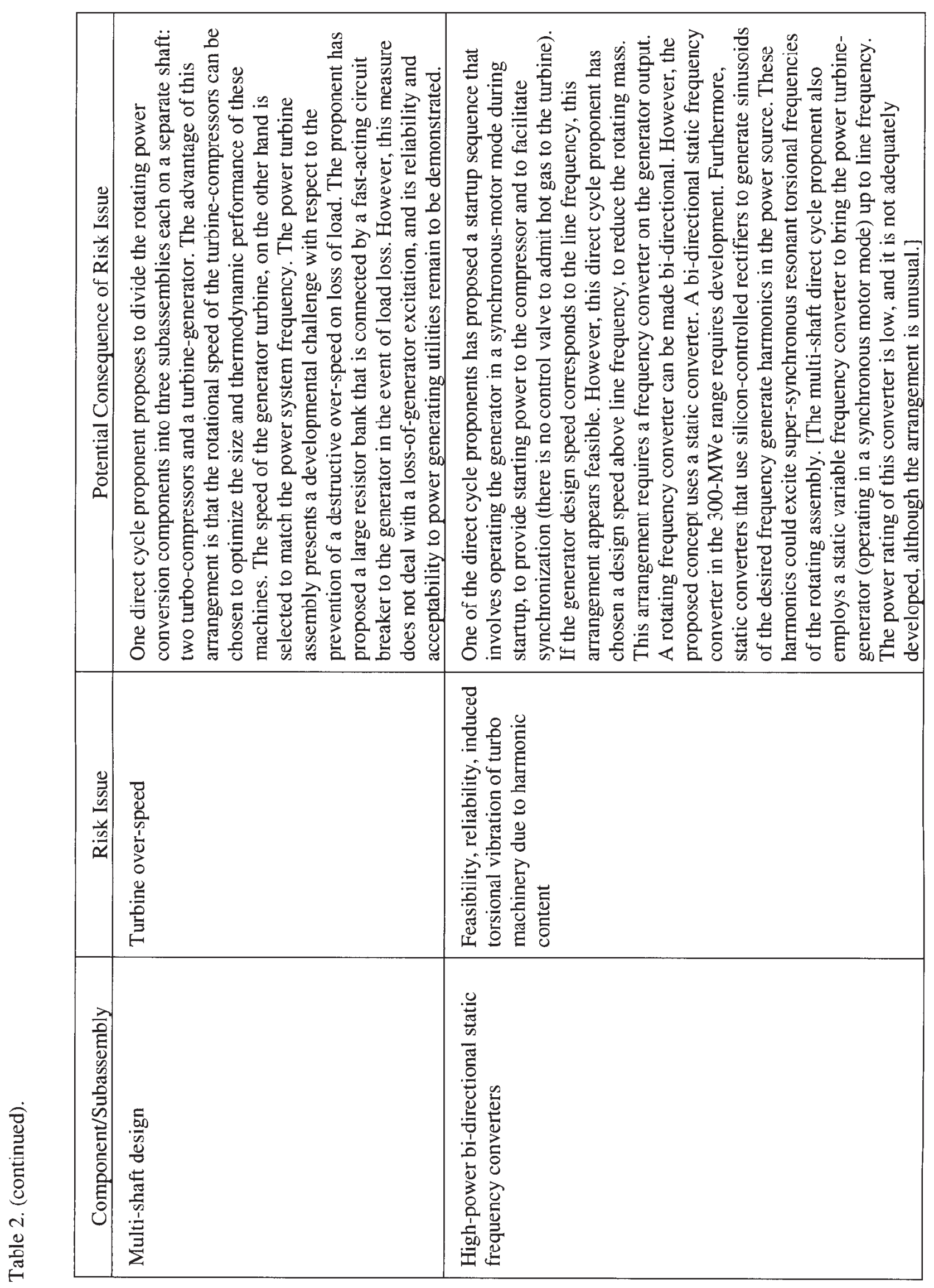




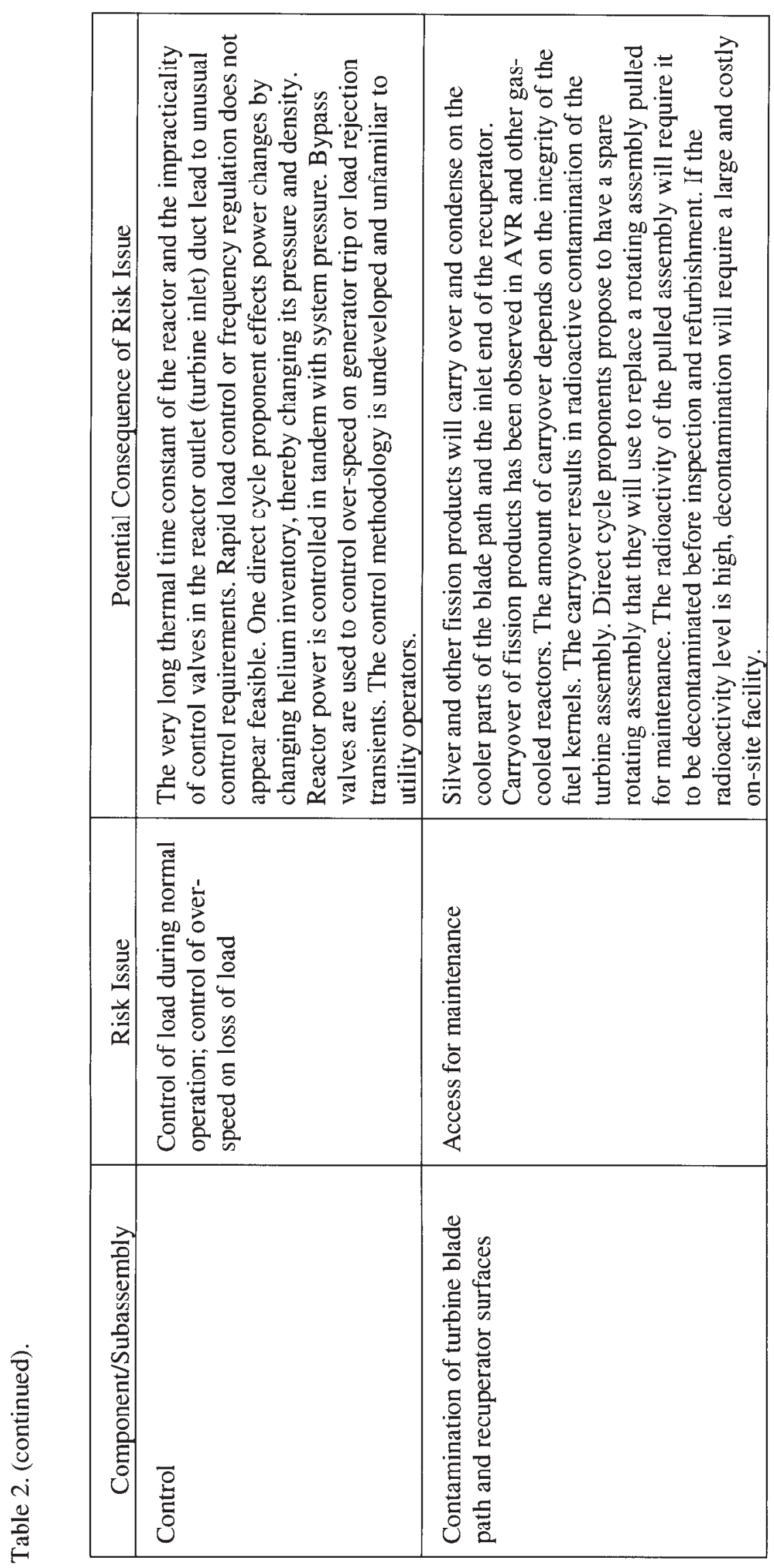




\section{PROCESS ENERGY UTILIZATION}

\subsection{Introduction}

This section assesses the effect of process energy facilities on reactor system design, operation, control, and safety for the NGNP and follow-on applications. The NGNP High-Level Functions and Requirements document sets forth requirements associated with use of the NGNP for the cogeneration of electricity and hydrogen. Up to $50 \mathrm{MWt}$ of the NGNP plant output is to be made available for hydrogen production by one or more processes, with a targeted production of up to $7000 \mathrm{~m}^{3}$ per hour of hydrogen. (This is compared to the $10 \mathrm{MWt}$ HTTR test loop that is currently available.) The NGNP hydrogen production capability is considered an engineering scale demonstration (pilot-plant scale), with full-scale commercial production eventually using up to $100 \%$ of the reactor thermal output $(600 \mathrm{MWt})$. The form and purity of the hydrogen are compatible with end-user needs including use in fuel cells and the chemical industry. The interface between the NGNP reactor and the hydrogen production plant must allow for safe transition from all-electric power production to the cogeneration mode. Upset conditions in either the NGNP systems or the hydrogen production plant must not affect the safe operation of either facility.

The current path forward for the NGNP is to demonstrate both a thermochemical process for high-temperature water splitting and high temperature electrolysis (HTE). The thermochemical process for the NGNP receiving the most attention is known as the sulfur-iodine (SI) process. General Atomics originally developed this process in the early 1980s, but most of the experimental research on this process since initial development has been performed overseas, particularly at JAERI. Currently, an International Nuclear Energy Research Initiative (INERI) project is underway, which includes design and construction of laboratory-scale reaction systems (the Bunsen reactor, the HI decomposer, and sulfuric acid concentrator/decomposer) at three facilities (CEA, Sandia National Laboratories, and General Atomics). The expectation is to combine the three subsystems into a small laboratory-scale closed loop by the end of FY 2005. Other work on high-temperature materials for the hydrogen facility is under way at the University of Nevada-Las Vegas and at University of California (UC) Berkeley. The specific HTE process for the NGNP has not been defined, but it is likely to be based on solid oxide fuel cell technology.

The thermochemical SI process requires thermal energy (heat) at temperatures up to $950^{\circ} \mathrm{C}$. The HTE process utilizes both electricity for electrolysis and thermal energy to generate steam-hydrogen feed mixture at $750-950{ }^{\circ} \mathrm{C}$. In either case, higher reactor operating temperature results in higher-efficiency generation of hydrogen. The trend for hydrogen generation efficiencies as a function of temperature for both the SI process and HTE are shown in Figure 2.

While there is a focus on the SI thermochemical process and HTE for demonstrations at the NGNP, other processes are being considered or developed in parallel. These include (1) alternative thermochemical processes such as the calcium-bromine (UT-3) process, and (2) "hybrid" processes, including the sulfur-based Westinghouse Ispra process, and the sulfur-bromine-based ISPRA (Mark 13) process. Such hybrid processes combine both thermochemical reactions as well as electrolysis and make use of the same chemical reaction (sulfur acid decomposition) as SI for coupling with the nuclear heat source. Recent work has also suggested that promising hydrogen production efficiencies may be achieved at lower temperatures using processes such as the copper-chlorine cycle. In addition, several studies have suggested that coupling a more conventional steam methane reforming (SMR) unit to a nuclear heat source is cost-effective even with carbon sequestration, and may entail lower risk. 


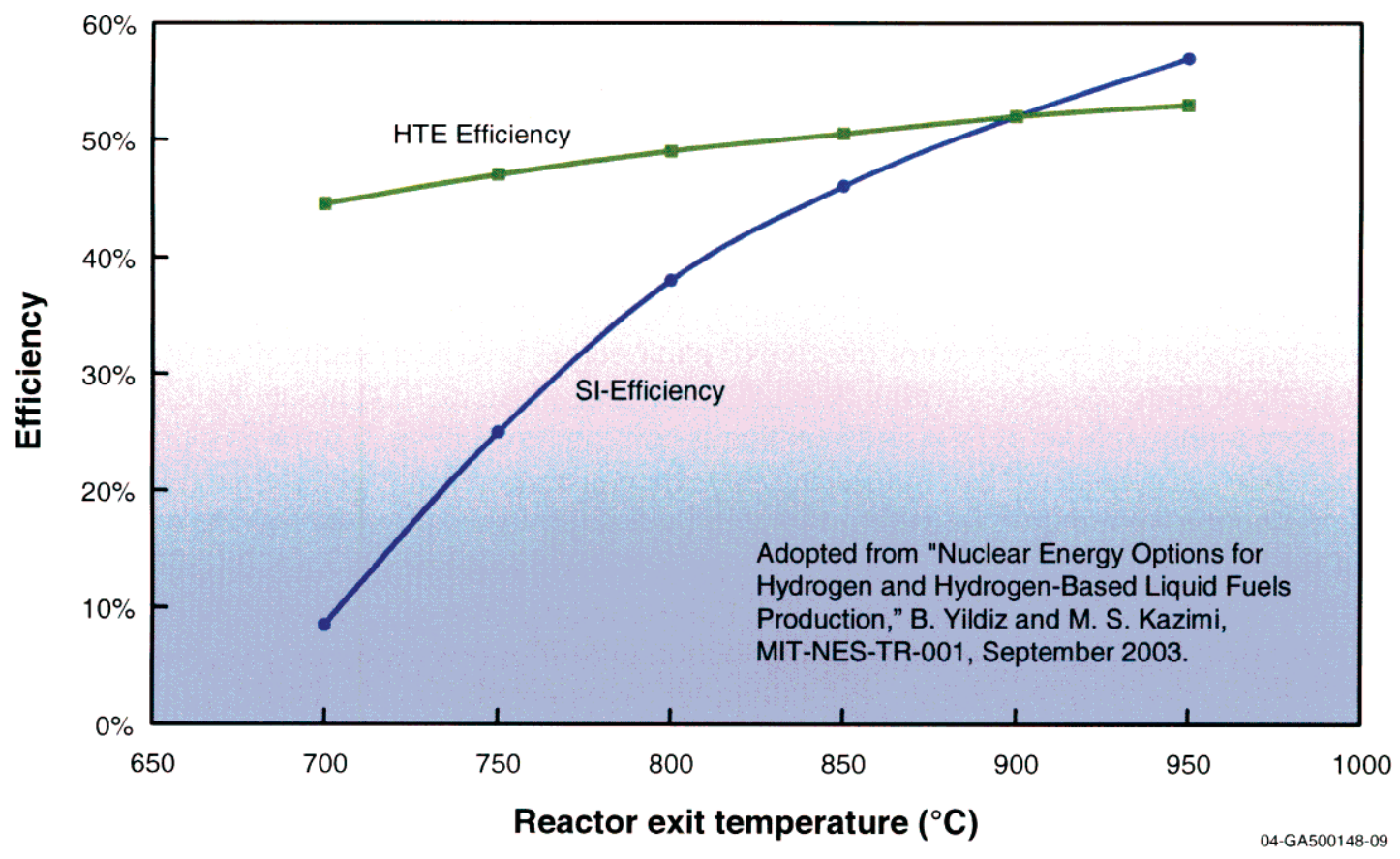

Figure 2. Hydrogen generation efficiencies.

The current NGNP nuclear hydrogen development plan calls for completing research and development, laboratory- and bench-scale testing of various processes, materials testing, final process selection, and preliminary pilot plant designs from FY 2004 through FY 2009 (or potentially as late as FY 2012), or about six years. This schedule is expected to support final-pilot plant design and construction by 2017 , the target date for commissioning the NGNP.

Outside of the United States, many of the candidate hydrogen production processes have already been studied extensively, but much work still remains. In Japan, JAERI recently demonstrated continuous production of $0.032 \mathrm{~m}^{3}$ per hour of hydrogen by the SI process. This laboratory-scale demonstration was the culmination of almost ten years of planning and research. Future research at JAERI will target commissioning a pilot-plant producing $30 \mathrm{~m}^{3}$ per hour by 2010 , and an engineering-scale plant producing $1000 \mathrm{~m}^{3}$ per hour by 2014 , supplied with 10 -MWt heat from the HTTR. This would represent the final step in a 20-year-long research and development effort.

\subsection{Heat Transport to the Hydrogen Facility}

All of the aforementioned processes share a common requirement that heat from the reactor must be transferred to a collocated hydrogen production plant. Even in the case of HTE, heat is required to produce steam.

For the purposes of the following discussions, it is worth clarifying that, in the context of discussions of hydrogen production, the functions and requirements for various heat exchangers in the system may vary, depending on whether they are part of direct or indirect cycle power conversion, or part of the hydrogen production facility. To aid in the following discussions, the following definitions are applicable:

NGNP IHX. The intermediate heat exchanger that serves as the heat transfer component between the reactor primary circuit and a secondary circuit that transports energy for power conversion or hydrogen 
production. This heat exchanger may or may not be part of the Class 1 pressure boundary, depending on plant design and the anticipated reliability of the hot gas isolation valves. In an indirect cycle, the NGNP IHX transfers all of the reactor heat to the secondary cycles, whether for power conversion or hydrogen production. In a direct cycle, only $50 \mathrm{MWt}$ would be transferred to the hydrogen production facility through the IHX. Materials and design considerations for the NGNP IHX are discussed elsewhere in this report.

Secondary IHX. An optional secondary intermediate heat exchanger that communicates with the NGNP IHX through an intermediate heat transfer loop. A secondary IHX may he inherent to the design of a power conversion unit that operates as an indirect cycle. It would be considered a design option in a direct cycle system. If this IHX were a helium-helium system, it would share many of the same materials and design challenges with the NGNP IHX.

Intermediate Heat Transfer Loop. An intermediate loop between the NGNP IHX and the secondary IHX. The intermediate loop would probably be operated at higher pressure than the NGNP primary circuit and would contain its own circulator in the event that the intermediate heat transfer loop contains helium as the working fluid. Valves may be used in the intermediate heat transfer loop to serve at the Class 1 boundary.

Main Heat Transfer Loop. The loop through which energy would be transported from the NGNP plant to the hydrogen production area. This loop may be several hundred meters long to satisfy separation requirements between the NGNP and the hydrogen production facility. The working fluid in this loop could be helium or a molten salt. If the main heat transfer loop uses molten salt, it could be operated at low pressure ( $<1 \mathrm{MPa})$. If helium were used as the heat transfer medium, then it would prohably operate at high pressure ( 5 to $7 \mathrm{MPa}$ ) to ensure any leakage through the NGNP IHX would be from the secondary to primary side and to ensure adequate heat transport. The main heat transfer loop could be operated at somewhat lower pressure helium if an intermediate heat transfer loop were used, albeit at the expense of larger pipe diameters and reduced heat transfer efficiency.

Process Heat Exchangers. The hydrogen production plant heat exchangers, which may be hightemperature process heat exchangers $\left(>900^{\circ} \mathrm{C}\right)$ or lower-temperature process heat exchangers $\left(<500^{\circ} \mathrm{C}\right)$. These may include (1) the steam generators for the HTE process, or (2) the sulfuric acid decomposer, the $\mathrm{HI}$ reactor, and various preheaters and reboilers for the SI process. Some of these components operate in corrosively aggressive environments and must be compatible with or protected from these conditions. Specific research and development efforts should be directed toward these components to reduce this substantial risk.

Figures 3 through 6 illustrate several candidate configurations for the design of the heat transfer interface between the NGNP and the hydrogen production facility. 


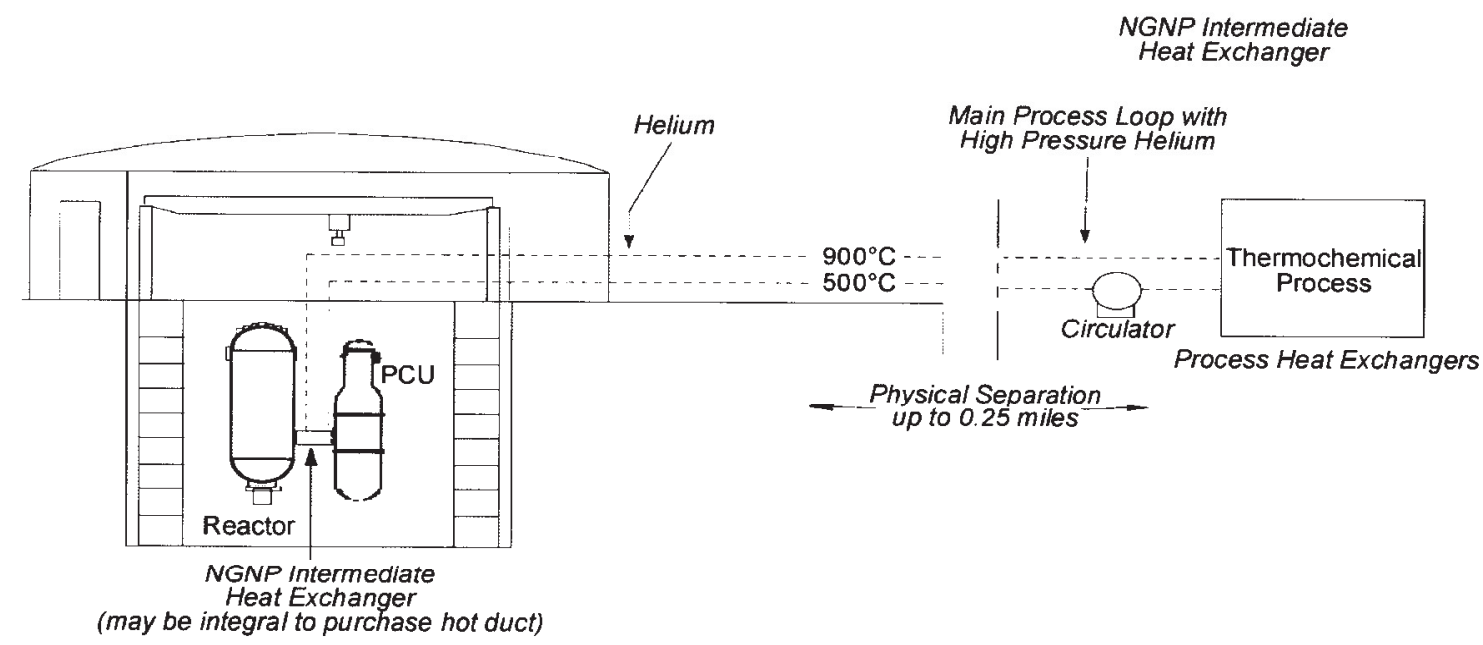

Figure 3. Direct cycle power conversion unit with helium main heat transfer loop.

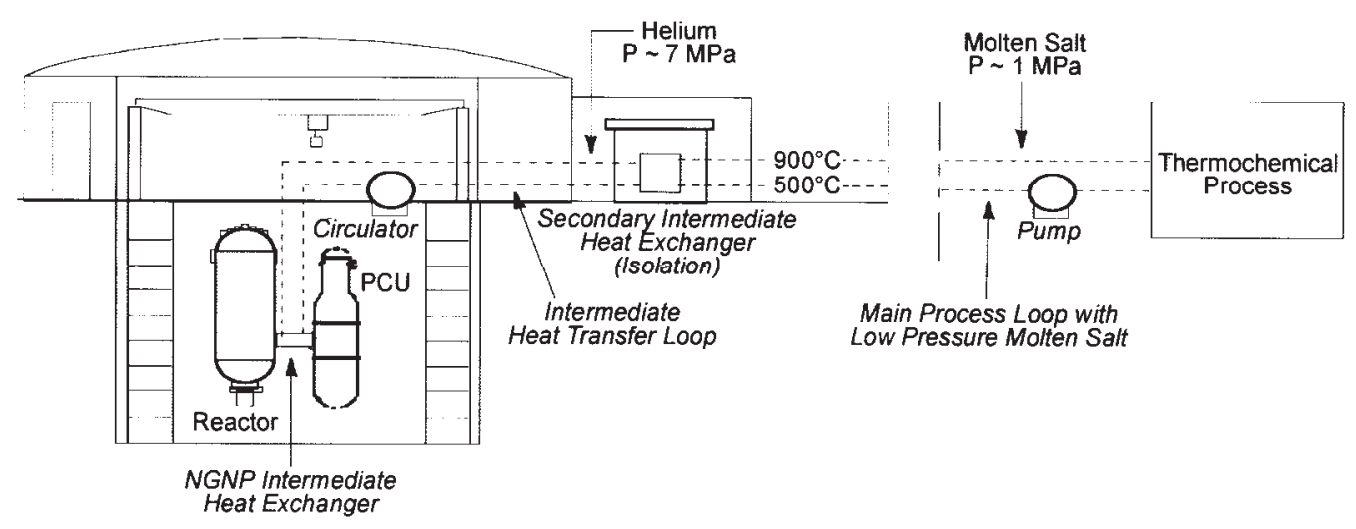

Figure 4. Direct cycle power conversion unit with intermediate heat transfer loop.

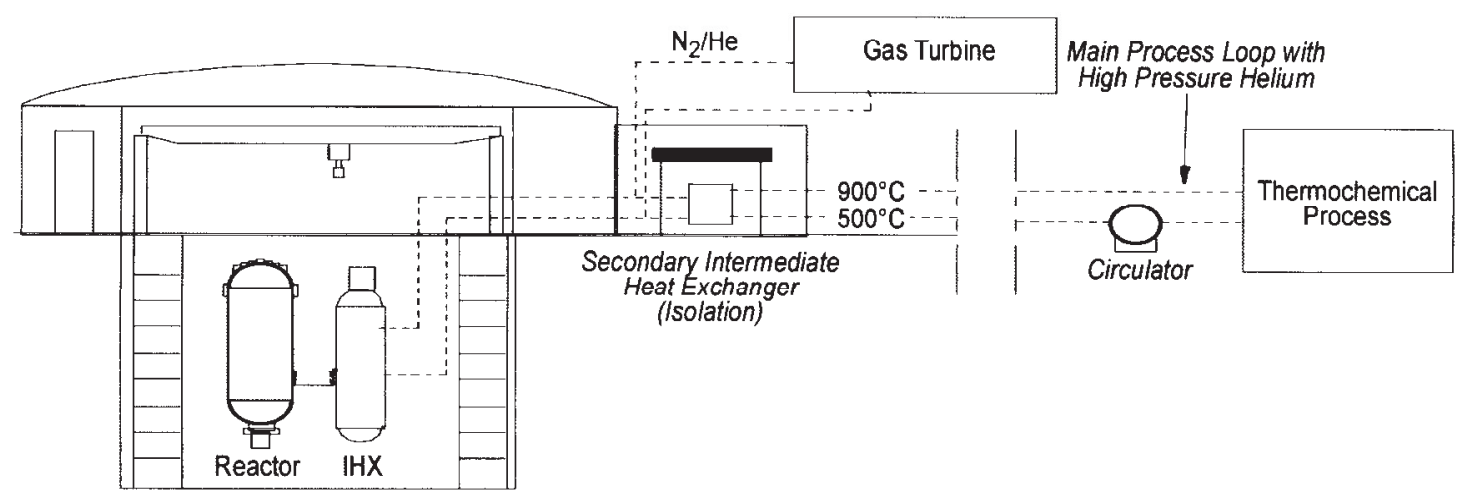

Figure 5. Indirect cycle power conversion unit with helium main heat transfer loop. 


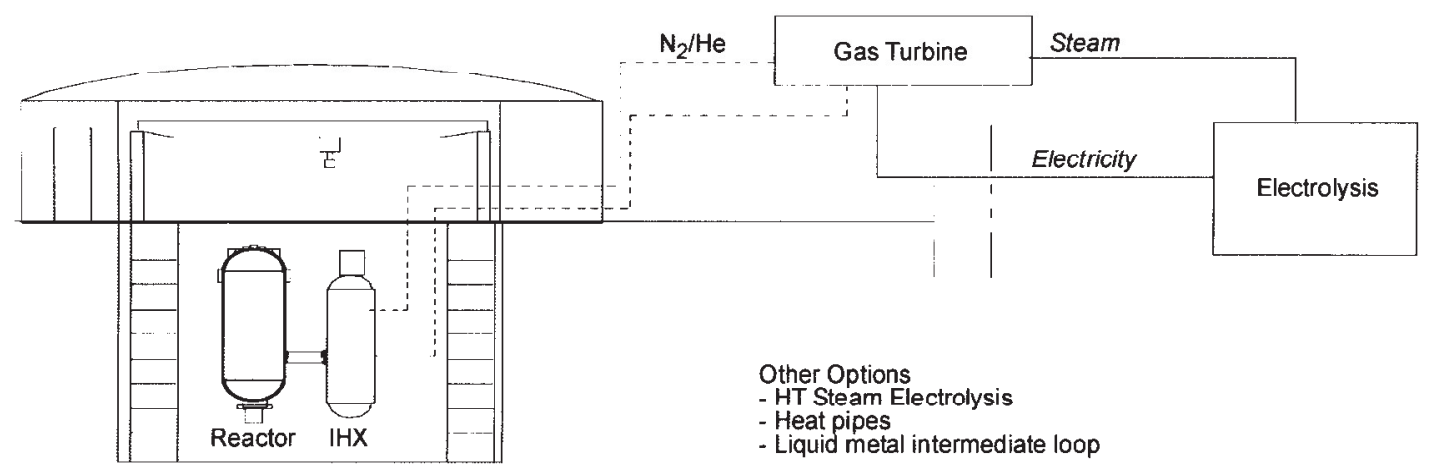

Figure 6. Indirect cycle power conversion unit with high-temperature electrolysis.

\subsection{Technical Considerations}

\subsubsection{Process Selection and Effect on NGNP Design and Schedule}

Technical Observation. Significant technical challenges remain in the development of any of the candidate hydrogen production processes in the NGNP program. These technical challenges are described in detail elsewhere, and include (1) hydrogen plant materials qualification, (2) development of an understanding of process chemistry that will be sufficient to lead to a robust and efficient system design, and (3) plant controls issues. The risks associated with materials qualification increase with temperature, particularly with regard to the secondary IHX, process heat exchangers, and heat transfer loops. The current project plans appear to have identified many key technical risk areas, but others may arise as work progresses. JAERI representatives reported that many of the challenges they faced over the last ten years did not become evident until laboratory systems were operational. Operation of a comparable laboratory system in the United States, ostensibly as part of the INERI effort, is still three to fours years away, leaving only about three years before pilot-plant decisions must be made. Accordingly, the schedule for the project is considered aggressive. Funding levels may be below those required for timely and successful completion of the work.

Associated Risk. The risk associated with the current nuclear hydrogen research and development plan is that it will not be completed in time to support the pilot plant decision in 2009. Therefore, key functions and requirements for the nuclear portion of NGNP may not be able to be finalized in time to support the overall NGNP schedule. These include (1) quantity and rate of heat to be transported, (2) need for an intermediate heat transfer loop to provide isolation between the nuclear and hydrogen production portions of the plant, (3) hydrogen production temperature requirements, (4) effect of loss of load to the hydrogen plant, and (5) effect of loss of reactor power. Each of the candidate processes (e.g., SI, HTE, hybrid processes) would impose different requirements on the NGNP, and hence affect the overall design as well as the design of critical components such as the NGNP IHX.

Recommendations. The ITRG recommends that consideration be given to the following:

- Continue to promote international cooperation, particularly with JAERI, so that a better understanding of the technical issues with the SI process is developed and appropriate lessons learned and technology incorporated into the INERI effort and other research and development efforts underway in the United States. This may permit an earlier narrowing of the number of processes being developed in parallel (there are currently about five candidate processes being considered) 
- Focus on sulfuric-acid decomposition as the common coupling step for the SI, Westinghouse, and sulfur-bromide (ISPRA) processes to reduce dependence on successful and timely SI process development.

- $\quad$ Explore the possibility of acquiring the detailed SI process experience from JAERI, including past experience with and data from the laboratory-scale system. This would be followed by continued cooperation and information exchanges in the bench-scale and pilot-plant studies to be conducted at JAERI through 2010.

- Explore the possibility of working with international organizations, such as JAERI, to share design work for the pilot plant. As noted above, JAERI is targeting deployment of an SI pilot-plant on a schedule that is slightly ahead of that envisioned for the NGNP.

- $\quad$ Ensure that adequate funding and resources are available to meet the research and development schedules for the candidate processes.

Technical Justification. More than 100 processes for generation of hydrogen by thermal or electrochemical means have been reported in the literature. Several independent, detailed reviews of candidate hydrogen production processes have been completed over the past five years. Essentially all of these studies, including those from the United States, Japan, and France, conclude that the SI cycle is a leading candidate for nuclear cogeneration of hydrogen generally, and for the NGNP specifically. Therefore, the current focus on the SI process as the thermochemical process of choice appears warranted, and cooperation with international organizations that have the best experience with the SI processes is justified. This is particularly true because, other than at JAERI, no laboratory-scale SI process systems have been in operation since the late 1980s. This may mean that startup times for new research initiatives in the United States are longer than planned.

In addition, based on presentations made to the ITRG, there is some uncertainty as to whether the HTE process is receiving sufficient research and development support to ensure a level of development that would support a pilot-plant decision by FY 2009.

Other processes, which have already undergone feasibility demonstration, such as the hybrid Westinghouse process or sulfur-bromine process, are considered promising enough to warrant parallel investigation and thereby reduce the overall NGNP project risk associated with development of the thermochemical hydrogen production processes. However, this will increase competition for resources if the NGNP project is not focused on large-scale demonstration of sulfuric-acid decomposition, which is common to all of these processes.

\subsubsection{Design and Materials}

Technical Observation. Materials qualification for a variety of hydrogen plant components is considered the single biggest uncertainty in the qualification of the hydrogen production process. While the materials issues associated with the SI process have been highlighted, any of the sulfur-based processes pose materials challenges because they share the requirement of high-temperature decomposition of sulfuric acid. This includes the Westinghouse hybrid process and the sulfur-bromine process. As materials issues are uncertain, so is the design of the critical hydrogen plant components, including heat exchangers, chemical reaction systems, hot ducts and pipes, and other plant components, such as valves and instruments.

Associated Risk. The risks associated with materials development and design include corrosion resistance, life prediction, inspection, and repair. Materials of construction for the SI reaction systems, particularly the high-temperature sulfuric acid reactor and the hydrogen-iodine reactor and separation 
system, have not been clearly defined. Candidate materials of construction include $\mathrm{SiC}$ composites, tantalum, tantalum alloys (W-Nb), or noble metals. Current laboratory-scale systems are constructed from glasses, which are not usable in an industrial-scale system. Risk will also increase with the operating temperatures.

Recommendations. The ITRG recommends the following:

- For reasons that are similar to those discussed with respect to lowering reactor outlet temperature for the nuclear portion of the NGNP (equipment life, materials behavior and qualification, licensing), consider a lower temperature for the hydrogen production facility. Figure 2 shows that only modest reductions in hydrogen production efficiency will occur by lowering the temperature to $900{ }^{\circ} \mathrm{C}$. Even lower temperatures are required for HTE or hybrid processes. Over time, it may be practical to increase the temperature of the plant to realize greater hydrogen production efficiencies. The overall risk associated with the development and qualification of materials will be reduced if the target core outlet temperature is reduced below $1000^{\circ} \mathrm{C}$.

Technical Justification. The designs and materials of construction of the NGNP IHX, any secondary IHXs used in the system, hot gas ducts, molten salt loops (if used), and the process plant heat exchangers (see Figures 3 through 6), have yet to be determined. All of the heat exchangers must exhibit high specific heat transfer area (up to $1000 \mathrm{~m}^{2} / \mathrm{m}^{3}$ ) and be able to operate at temperatures as high as $1000{ }^{\circ} \mathrm{C}$. Candidate designs include the Heatric Printed Circuit Heat Exchangers (PCHEs), plate-fin devices, prime surface recuperator-type designs, and possibly $\mathrm{C}-\mathrm{C}$ composite strip fin designs. Testing of PCHFs is being pursued by at least one vendor for helium-helium service. Use of helical shell and tube designs for helium-helium service applications may be possible, but the surface-area-per-unit-volume goals are unlikely to be met (HTTR uses such a design fabricated from Hastelloy XR). Other open issues include whether heat exchangers of the size required can be manufactured and how they would be inspected, serviced, and cleaned/decontaminated over the life of the plant. The specific Code requirements and Class 1 to Class 2 boundaries for the IHX are also not clear. Some needs may also exist for establishing accurate heat transfer data such as heat transfer coefficients. The JAERI Helium Engineering Demonstration Loop (HENDEL) operated in the early to mid 1990s to evaluate He heat transfer performance at up to $1000^{\circ} \mathrm{C}$. Data from this loop may contribute to the design of the IHX by providing experimentally determined heat transfer coefficients. Experience from HTTR is also likely to be valuable. Other valuable experience that should be factored into the NGNP development effort was obtained in Germany in the 1980s through the early 1990s. Research expenditures associated with the design of a process heat plant were reported to have been about $\$ 2$ billion. These efforts included testing of hot gas ducts and various heat exchanger designs.

\subsubsection{Method of Heat Transfer and Transport}

Technical Observation. It is not clear at this time whether helium or a molten salt is the preferred method of heat transport from the nuclear portion of the NGNP to the hydrogen production plant.

Associated Risk. Helium and molten salt both present technical challenges and therefore pose serious risks to the NGNP technical viability and schedule.

Recommendations. The ITRG offers the following recommendations:

- At this time, consider both helium and molten salt as potential candidates for the heat transfer medium between NGNP and the hydrogen production plant. 
- When considering molten salt alternatives, adopt the lessons learned from other industries, including (1) aluminum production, (2) glass works (3) high-temperature solar energy, (4) geothermal energy, (5) chemical processes, (6) aerospace, and (7) fusion research.

- Consider use of an intermediate heat transfer loop between the NGNP and the hydrogen production plant that will provide for additional isolation of the two plants.

- Encourage additional international cooperation including incorporating lessons learned from the JAERI HTTR program, prior HENDEL heat transfer experiments, and the work performed in Germany in the 1980 s in the design of process heat plants.

- Consider use of two boundaries between the nuclear plant and the hydrogen production facility. In this arrangement, an intermediate helium heat transfer loop at high pressure (greater than reactor system pressure) would be coupled to a second IHX that transfers heat to either a gas or molten salt loop. The gas or molten salt loop would be the primary method of energy transfer to the hydrogen production plant over long distances.

Technical Justification. As discussed earlicr, up to $50 \mathrm{MWt}$ from the NGNP will be available for hydrogen generation. Regardless of which process is used to produce hydrogen (all require energy input from $450-950^{\circ} \mathrm{C}$ ), efficient and reliable heat transfer from the NGNP to the hydrogen plant will be a requirement. For the SI process, three sections of the hydrogen plant require different temperatures (nominally $120^{\circ} \mathrm{C}, 900^{\circ} \mathrm{C}$, and $450^{\circ} \mathrm{C}$ ). Optimization of the arrangement of heat exchangers, intercoolers, and reboilers in the system will be a moderate challenge but does not appear to pose a high degree of risk.

Several means of transferring heat from the NGNP to the hydrogen production facility have been described. These range from the use of one intermediate heat exchanger (IHX) with helium as the working fluid to use of an intermediate heat transfer loop with an independent main heat transfer loop (essentially a tertiary loop). These approaches are shown in Figures 3 to 6 . The main tertiary heat transfer loop may use helium or molten salt as the working fluid.

Helium is the only practicable alternative for the intermediate loop if this is a design feature of the NGNP. Helium also offers advantages for the main heat transfer loop because of its casc of handling, inertness, and low cost. If an intermediate loop is not used, contamination from the secondary to primary side would be manageable if (1) the main process loop were operated at higher pressure than the primary circuit, and (2) the purity and moisture content of the main process loop could be maintained.

Candidate molten salts for the main process loop include $\mathrm{LiF}: \mathrm{Be}_{2}$ (Flibe), alkali fluorides, and fluoro-borates. Others will undoubtedly be identified as research and development continues. Molten salts offer several potential advantages over helium for the main process loop, specifically the potential operation at low pressure and use of smaller-diameter piping. Pumping costs will probably be lower than comparable costs for helium. Molten salts have low reactivity with air, low vapor pressure, and low electrical conductivity. Preliminary evaluations suggest that candidate salts are fairly inert to the chemical constituents of the SI process. Molten salts have good heat transfer properties in general, but may require more development in the design of heat exchangers as they provide their best heat transfer under turbulent conditions. This may require special considerations in the design of flow channels if plate-type or strip fin designs heat exchangers are used. Further, the melting point of the salts ranges from about $380-550{ }^{\circ} \mathrm{C}$, which would require main process loop features such as heat tracing, preheating capability, and large dump tanks in the event of loss of NGNP heat. These technical issues have been addressed but not solved.

Options for main process loop piping for either molten salts or helium include internally lined piping, pipe-in-pipe configurations, or unlined systems fabricated from higher-temperature alloys. The 
size of the piping required for the intermediate heat transfer loop also depends on the fluid chosen. For the $50 \mathrm{MWt}$ heat source from the NGNP, the piping diameter required for helium is not unreasonable, calculated to be approximately $45 \mathrm{~cm}\left(60 \mathrm{~m} / \mathrm{s}\right.$ velocity, $350^{\circ} \mathrm{C}$ temperature drop, $7 \mathrm{MPa}$ pressure $)$. But for a $600-\mathrm{MWt}$ hydrogen production facility, multiple large pipes may be required. A single pipe less than $25 \mathrm{~cm}$ in diameter would be sufficient with a molten salt for the NGNP, and a single pipe less than $1 \mathrm{~m}$ in diameter would be sufficient for a 600-MWt application.

\subsection{Collocation of the NGNP and the Hydrogen Production Plant}

\subsubsection{Issues Associated with External Events}

Technical Observation. Licensing of the NGNP will require evaluation of the potential for external events associated with the hydrogen plant, including (1) explosions, fires, and release of toxic gases, (2) control room habitability, and (3) missile generation. It is unclear that these issues have been addressed sufficiently to date, and therefore, they contribute to technical risk. Figure 7 illustrates the key issues related to licensing the NGNP with thermochemical hydrogen production.

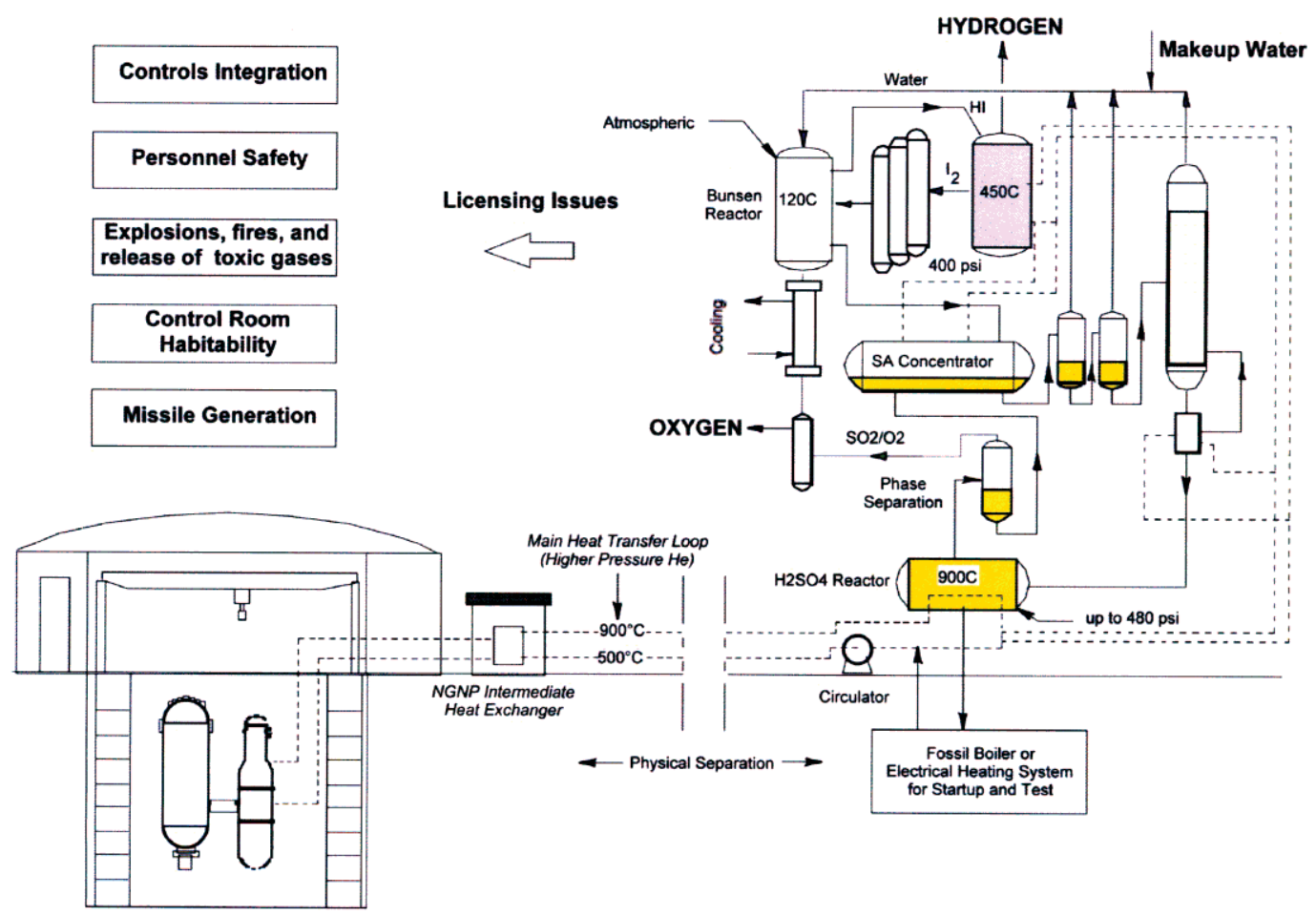

Figure 7. Key issues related to licensing NGNP with thermochemical hydrogen production.

Associated Risk. The primary risk is associated with an inability to license the NGNP because of unacceptable hazards posed by the hydrogen production facility. A secondary risk is that events at the hydrogen production facility could damage NGNP structures, systems, or components, corresponding to an investment risk.

Recommendations. The ITRG recommends that the criteria for siting the NGNP be defined early in the design effort and that the USNRC be involved in or be made aware of early design decisions related to the hydrogen production facility as they progress. These would include separation, isolation of systems, and compensatory measures to counter external events, such as use of berms. 
Technical Justification. As with any nuclear plant, the NGNP will be subject to licensing requirements, including General Design Criteria (GDC), such as GDC 4, Environmental and Dynamic Effects. Other licensing requirements will include the Site Criteria of 10 CFR 100. The Site Criteria include evaluation of any man-made hazards in the vicinity of the plant, including nearby industrial facilities. The hydrogen production facility would clearly qualify as a nearby industrial facility. Potential hazards that must be considered include missiles, shock waves, flammable vapor clouds, release of toxic or corrosive gases, or generation of missiles or incendiary fragments. For any of the hydrogen production processes being considered, each of these must be considered. Another consideration will be Control Room Habitability evaluations associated with toxic gas releases or gases that have a potential to act as an asphixiant (helium). Several of the gases present in the sulfur-based cycles (SI, Westinghouse hybrid, and sulfur-bromine), such as sulfur trioxide, are heavier than air and will require careful evaluation through plume analyses.

Based on current regulatory guidance, there appears to be no significant risk or issue with collocating the hydrogen plant with the NGNP. Preliminary evaluations provided to the ITRG suggest that the risk of collocating the nuclear and hydrogen production facilities is acceptably low in light of current regulations, and pose no greater challenge than those faced at current plants located adjacent to chemical process plants, pipelines, and major transportation corridors.

\subsubsection{Personnel Safety}

Technical Observation. Protection of plant personnel and the public is just as important as protection of the physical plant. The hydrogen production facility will include numerous chemical reactors, heat exchangers, valves, pumps, and piping systems operating at high temperature and pressure, many of which will contain toxic and/or corrosive materials.

Associated Risk. The risk is associated with inability to design a hydrogen production facility that will not pose undıe, risk to hydrogen plant workers, NGNP plant workers (if different), or the public.

Recommendations. The ITRG recommends that personnel safety be highlighted as an important functional requirement for the NGNP as a whole, and that specific focus on personnel safety be placed on the hydrogen production facility. $\Lambda$ ppropriate safety analysis, failure modes and effects analyscs, and probabilistic techniques should be used in the design of the hydrogen production facility to identify risk areas and potential consequences to personnel safety. The ITRG further recommends that as the NGNP and hydrogen plant designs progress, evolving codes and standards for hydrogen production, storage, and transport (through pipelines) be closely monitored and factored into the designs.

Technical Justification. The success of the NGNP could be severely compromised if events in the hydrogen production plant resulted in an injury to any site personnel. This would include any injury that occurs during construction, commissioning, or operation. The NGNP design and the design of the hydrogen production plant should both take safety into account, but this may be a greater challenge with the hydrogen plant, for the following reasons: (1) none of the hydrogen production processes have been demonstrated at any level greater than laboratory scale, so there is little industrial experience with the reliability and integrity of large-scale plant components, (2) scale-up of the processes may involve new challenges in the design of safety and protective devices, including fire suppression and local monitoring for chemical leaks, and (3) highly reliable instrumentation will be required for process monitoring and control, the existence of which has not been proven to date. The design and construction of the NGNP and certain features of the hydrogen production plant, such as the main heat transfer loop, may come under the auspices of the USNRC, but design of the hydrogen facility will also involve other regulatory agencies and as many as twenty other codes and standards. These include Department of Transportation (pipelines), International Electrotechnical Commission (electrical codes specific to hydrogen facilities), 
Environmental Protection Agency (environmental permitting), National Fire Protection Association (fire protection), and Underwriters Laboratories (equipment certitication). Currently, there are more than twenty organizations in the United States and overseas that are involved in the development of codes and standards for hydrogen production, distribution, and use. Many of these codes and standards are evolving. DOE is intimately involved in this work through its Hydrogen Codes and Standards Coordinating Committee.

\subsubsection{Process Control and Plant System Interactions}

Technical Observation. Normal operations, upsets, or unanticipated transients in either the NGNP or the hydrogen production plant must not compromise safe operation of the other portion of the plant. At present, these control and plant system interactions have not been well defined.

Associated Risk. The main risk is that operational changes or equipment failures in the hydrogen production plant could affect safe operation of NGNP. A secondary risk is that changes in the operations of the NGNP (power levels, electrical output) could affect safe operation of the hydrogen production facility.

Recommendations. The ITRG recommends that careful evaluations be performed of how the NGNP and the hydrogen production facility would interact, and that design features be incorporated into each that would mitigate or prevent undesirable interactions. Use of a common, integrated control system for the two portions of the plant (nuclear and hydrogen) is not desirable. It is considered preferable that the two systems be capable of being operated independently. This does not mean that a common control room is precluded as part of the design. Further, for the NGNP, the ITRG recommends a separate startup heat source for shakedown and commissioning of the hydrogen plant.

Technical Justification. Information presented to the ITRG suggests that integration of the nuclear plant with any of the candidate hydrogen production processes is likely to be achicvablc. For instance, the SI process is expected to shut down in a safe and smooth manner upon loss of heat from the NGNP. The same would be expected to be true for an HTE plant. Another possibility that has been suggested is to include a steam generator in the main heat transfer loop between NGNP and the hydrogen production plant to reject heat in the event of a trip in the hydrogen plant (this is the approach at H'I'IR). It has also been presented that if for any reason the hydrogen process shuts down while the reactor is operating at full power, the plant response is expected to be nearly the same as for a power conversion unit trip. The loss of load will initiate a reactor trip, and the large heat capacity of the core will limit any increase in fuel temperature.

While several of the candidate hydrogen production facilities are very complex, their complexity is actually no greater than that of many other chemical or petrochemical process plants. Nevertheless, these control and system interactions issues have only been preliminarily addressed. It is likely that more mature considerations of these issues have been completed at JAERI, a possibility that provides further motivation for international cooperation.

In the future, high-temperature reactors for production of hydrogen are not expected to require an initial startup heat source analogous to an auxiliary boiler at an LWR. The NGNP, however, will be a demonstration plant. It is possible that the startup of the reactor or the power conversion system could be delayed by startup problems. To avoid delay in shaking down the hydrogen processes, it will probably be useful to provide an auxiliary heater in the intermediate loop. The shakedown and commissioning of the hydrogen processes could thus proceed using heat from the auxiliary heater even if the reactor were not available. We would need approximately $20 \mathrm{MW}$ of heat to shake down the SI process effectively and perhaps $5 \mathrm{MW}$ of heat and $15 \mathrm{MW}$ of electricity to shake down the HTE process. 


\subsection{Hydrogen Quality and Purity}

\subsubsection{Technical Observation}

The viability of production of hydrogen from nuclear energy highly depends both upon ensuring a favorable production cost and upon product quality.

\subsubsection{Associated Risk}

The risk is that the hydrogen produced by the NGNP, or future high-temperature reactors operating to produce hydrogen cxclusively or in cogeneration mode, is of a quality or purity that does not meet market needs. Examples include (1) hydrogen that contains unacceptably high levels of tritium or other radiuactive contamination, (2) hydrogen that contains tramp chemical species (e.g., carbon, sulfur, or iodine species) that render it unacceptable for use in fuel cells, or (3) hydrogen that is uneconomical because less expensive, less pure hydrogen would meet customer needs, such as for reformulation of gasoline.

\subsubsection{Recommendation}

We recommend that provisions be considered in the NGNP design that would preclude any credible ingress of tritium or other radioactive contamination to the hydrogen product stream, including use of a higher-pressure intermediate heat transfer loop as opposed to a low-pressure heat transfer loop. Assumptions that heat exchangers will provide an adequate barrier between the primary circuit and the intermediate heat transfer loop do not adequately reflect the practical experience with heat exchangers (i.e., leakage should be anticipated). Further, even if the heat exchangers are assumed to be adequately leak-tight, the potential for tritium diffusion has to be evaluated and found to be acceptable. 


\section{MAJOR COMPONENTS}

\subsection{Introduction}

A review of the design, fabrication, and operation of the principal components of the prismatic gas-cooled reactor was conducted with the objective of identifying the major risks associated with each. Information reviewed included that provided by the two proponents of gas-cooled prismatic-core plants, as well as information provided by the Pebble Bed Modular Reactor project, much of which is applicable to the prismatic design. In addition, information was also obtained from background documents prepared by the INEEL for the NGNP.

In assessing risks, the ITRG has assumed that its recommendation will be followed, that the reactor outlet temperature for the NGNP will be reduced from $1000^{\circ} \mathrm{C}$ to $900{ }^{\circ} \mathrm{C}$. As discussed in the materials section of this report, the metallurgical risks of the $1000^{\circ} \mathrm{C}$ outlet temperature are unacceptably large. The risks assessed in this section do not include those associated with the development of the Power Conversion System or the hydrogen production plant, which are treated in other sections of this report.

\subsection{Assessment of Risks}

Results of the component risk assessment are summarized in Table 3 . The table identifies risks of several kinds: design risks, development risks, schedule risks, and licensing risks. Most of the risks can be mitigated by one or all of the following measures:

- Early development of a design meeting the requirements of the project

- $\quad$ Prototyping and testing of key components, including full-scale tests of rotating assemblies and seals

- Materials testing at elevated temperatures and in representative corrosive environments

- Early licensing initiatives to establish acceptable design and analysis rules

- A strong project organization, to coordinate and expedite the above activities.

Given timely and intelligent application of these mitigation measures, the risks identified in Table 3 do not, for the most part, threaten the success of the project. There are, however, two significant challenges:

1. Development of metallic materials capable of operating reliably in the $900-950{ }^{\circ} \mathrm{C}$ range for periods of 12 years or more. This development is particularly challenging for the intermediate heat exchanger. That metallic materials can operate in the $900-950{ }^{\circ} \mathrm{C}$ range is not at issue. It is not clear that lifetimes consistent with high plant availability and low replacement part costs can be achieved. Consequently, early project activity to address these risks is necessary; an early start will allow development of alternative materials and design approaches in the event the initial material selection or design approach fails.

2. Design of an intermediate heat exchanger in a code-acceptable configuration. As with the reactor vessel, an IHX can be configured so that, under normal operating conditions, the return helium cools the pressure-bearing vessel, maintaining it at a temperature below the creep range. Again under normal operating conditions, the pressure difference between primary and secondary gas circuits can be made small, so that, although the heat exchange metal at the hot end is in the creep range, the stress on the metal is low. However, under some upset conditions, the heat exchange 
metal must withstand full coolant pressure-a loss of secondary coolant, for example. Under these conditions, the acceptability of the tube material as a Class I pressure boundary is questionable. To address this issue, one indirect cycle proponent has proposed that the secondary circuit be made part of the primary pressure boundary, up to isolation valves in the inlet and outlet ducts. This approach may not solve the problem. The temperature of the outlet duct of the IHX secondary circuit will be in the $850^{\circ} \mathrm{C}$ range. Code qualifying a material as a Class I boundary at this temperature is not trivial. The hot gas isolation valves also need development.

Despite these challenges, however, the development of acceptable IHX and hot gas isolation valve designs must be undertaken, if the NGNP is to be capable of supplying process heat for hydrogen generation. 


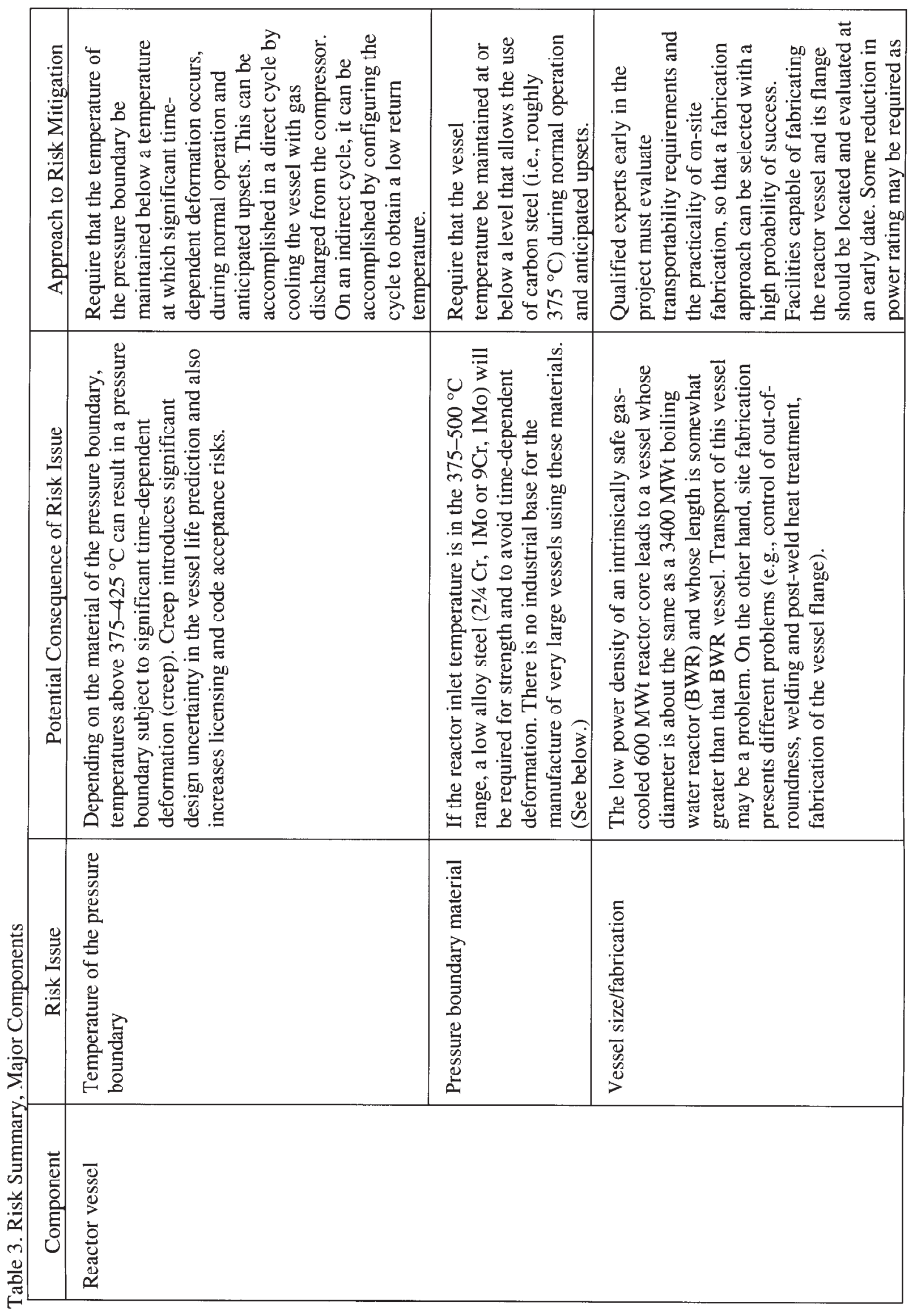




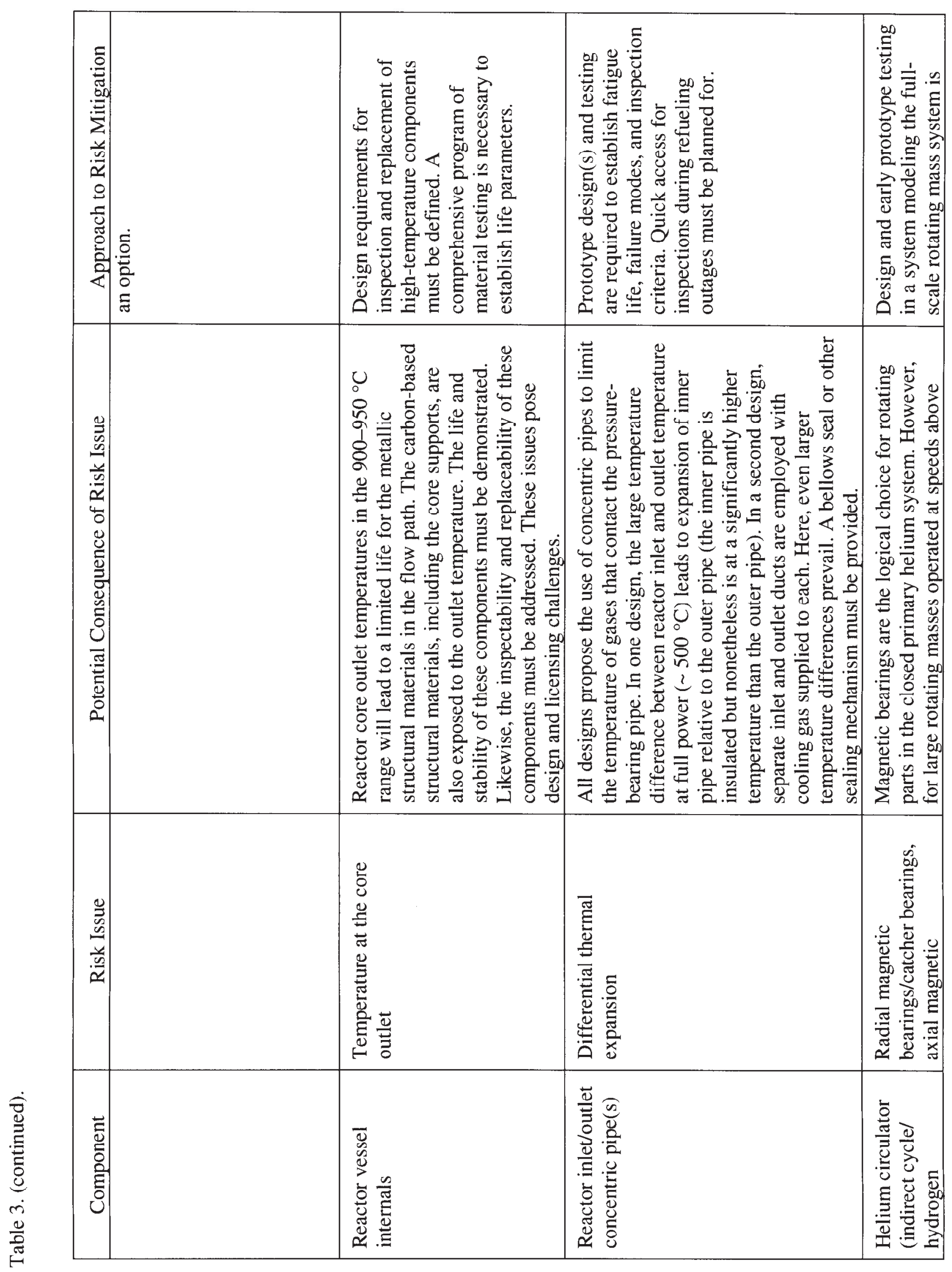




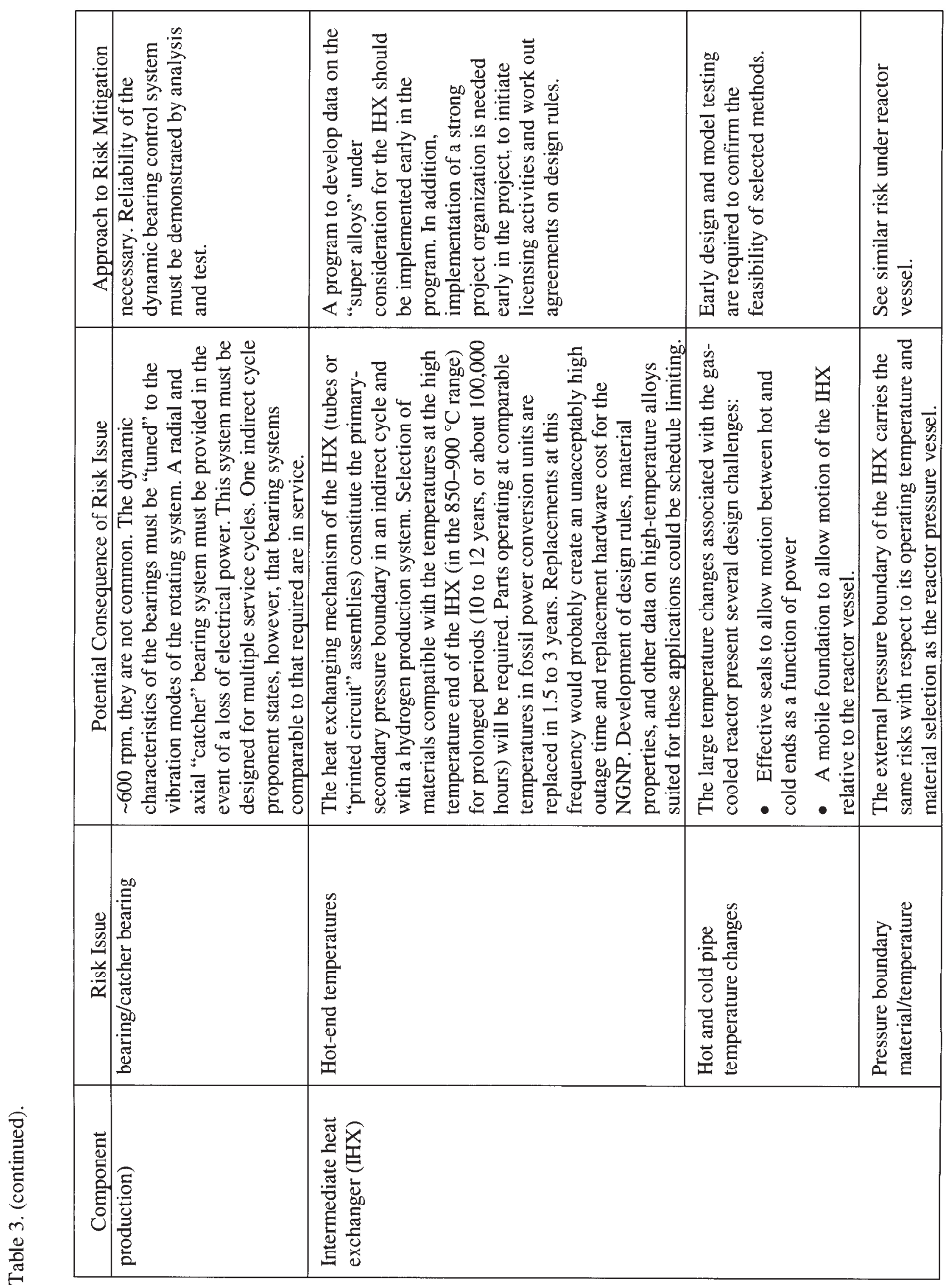




\begin{tabular}{|c|c|c|c|}
\hline 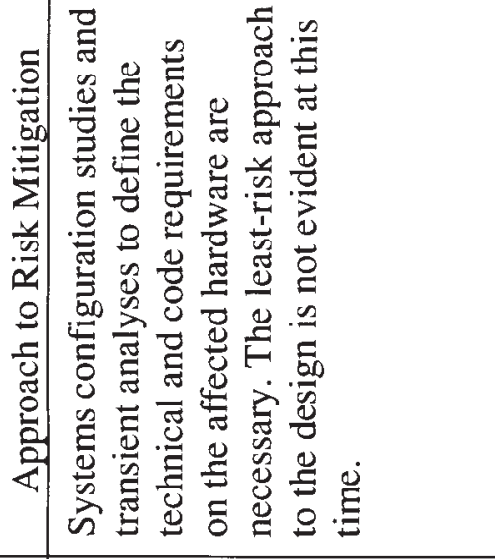 & 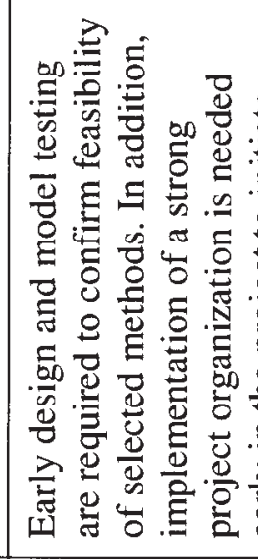 & 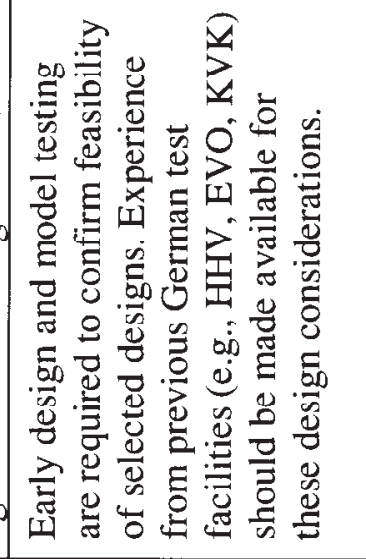 & 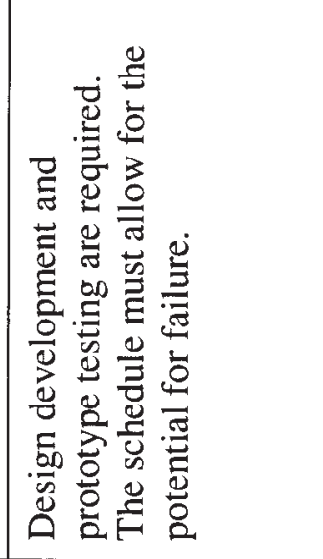 \\
\hline 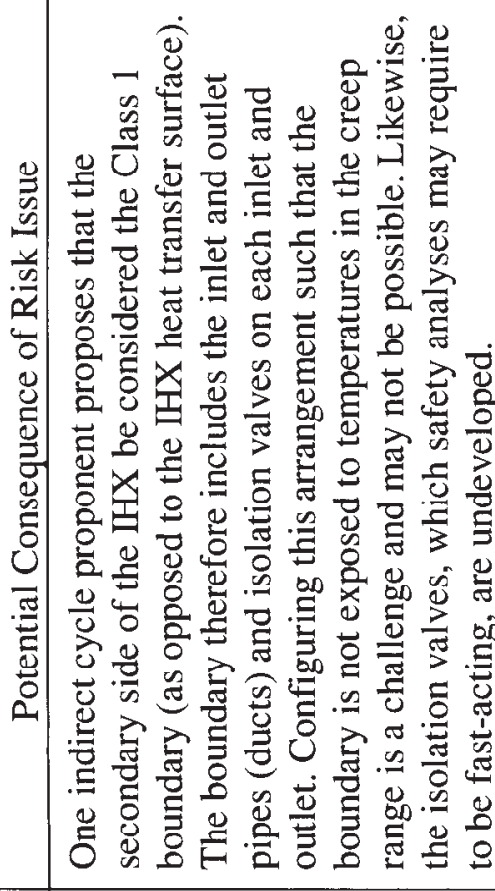 & 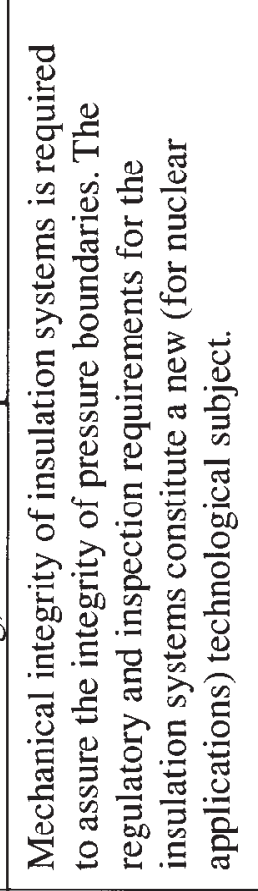 & 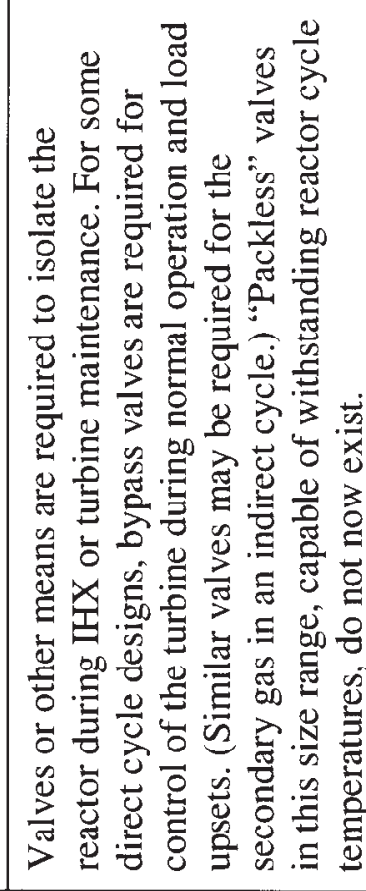 & 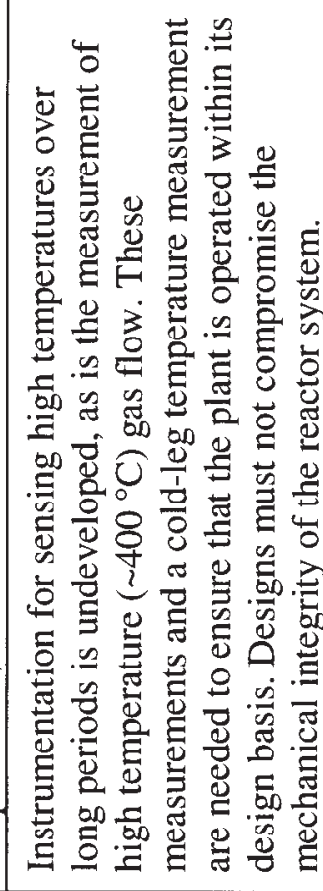 \\
\hline 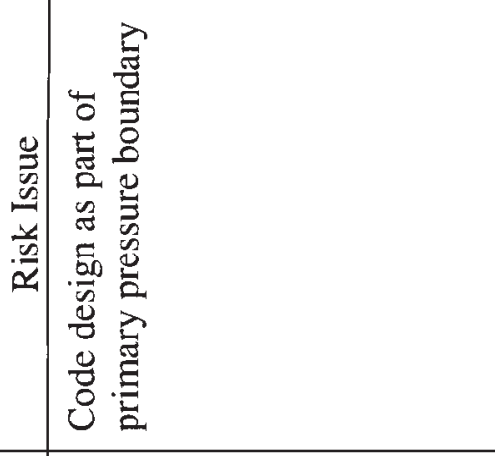 & 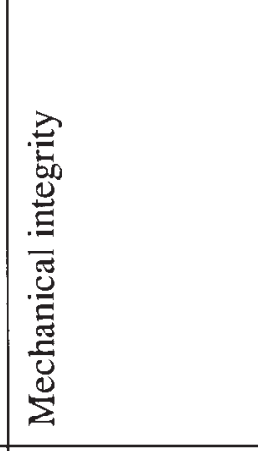 & 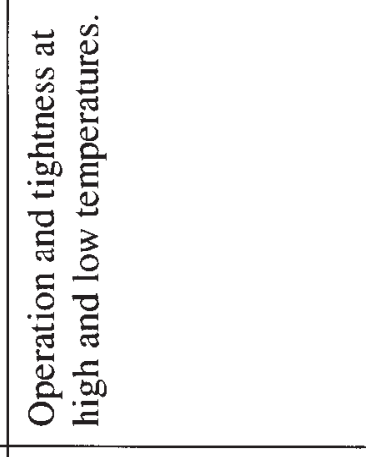 & 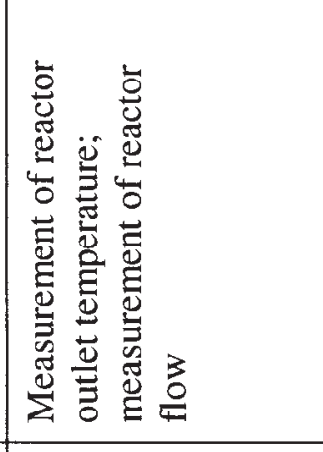 \\
\hline 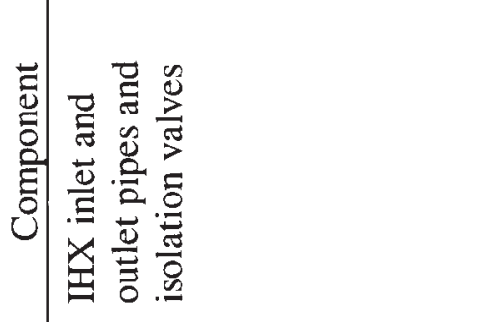 & 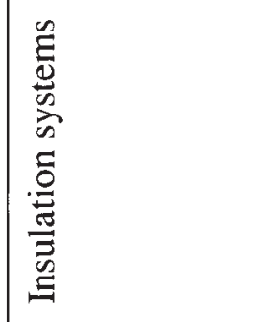 & 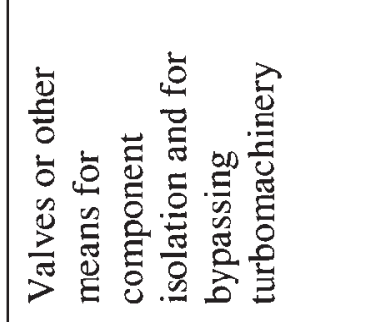 & 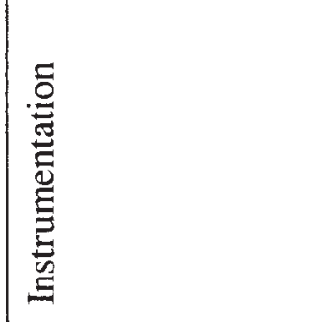 \\
\hline
\end{tabular}




\section{SYSTEM DESIGN}

A review of the design, fabrication, and operation of the principal systems and components of the prismatic gas-cooled reactor was conducted with the objective of identifying the major risks associated with each. Information reviewed included that provided hy the two proponents of gas-cooled prismaticcore plants, as well as information provided by the Pebble Bed Modular Reactor project, much of which is applicable to the prismatic design. In addition, information was also obtained from background documents prepared by the INEEL for the NGNP.

- The instrumentation of the NGNP requires special attention because of the high-temperature helium environment, especially any sensors that are exposed to the core outlet temperature. These sensors represent an important development risk. Hot-leg helium temperature measurement is difficult, and most sensors do not have an acceptable life under those service conditions. In the AVR none of the temperature sensors in the hot gas area survived, and the AVR used the heat balance to calculate the core outlet temperature. This method of determining the core outlet temperature would be even more difficult for a direct Brayton cycle.

The ITRG recommends that early development of sensors for determining the core outlet temperature be initiated. Alternatively, means must be developed either to ensure the ease of replacement of these sensors or to alleviate the need for these sensors.

- The plant control system of the NGNP requires early attention, because of the effect of coupling the two diverse processes (electricity generation and hydrogen production). The fact that there are two processes running simultaneously will complicate design of the control system, especially when there is an upset in one of the processes.

The ITRG recommends early investigation into the dynamic behavior of the NGNP during startup, shutdown, sudden loss of hydrogen production, and the loss of secondary coolant pressure.

- The thermal designs of various NGNP components (such as high-temperature primary coolant boundary penetrations, vessel support interfaces to the reactor building concrete, etc.) represent significant design challenges. The interface between high-temperature components and lowertemperature structures must be carefully examined to assure the integrity of the structure with lower temperature capability.

The ITRG recommends that early attention be given to design details of such critical components, including a survey of design solutions employed in past HTGRs worldwide.

- The uninsulated reactor vessel and the various large vessel supports will put a significant heat load on the ventilation and air-conditioning system and represent a significant design challenge. The reactor building ventilation and air-conditioning system will have an important function of maintaining the reactor building environment in an acceptable state to ensure the proper functioning of the plant monitoring instruments.

The ITRG recommends that early emphasis be given to the means of achieving an appropriate reactor building environment. 


\section{SAFETY AND LICENSING}

The following subsections summarize selected considerations regarding successfully achieving an acceptable safety basis and licensing the NGNP, including:

- Confinement concepts

- $\quad$ Licensing strategy

- Maintainability and inspectability.

\subsection{Decisions Relative to Confinement Versus Containment}

Accident dose consequences play an important role in establishing the overall design of the facility. The design features considered when calculating releases in the facilities include fuel form and configuration, reactor coolant system integrity, and building integrity. Many of the design features are driven by the performance of the fuel. Current LWRs contain the fuel in fuel rods, which are predicted to fail under certain severe accident scenarios. The reactor coolant systems are generally leak-tight and contain fission products from fuel that leaks during normal operations and accidents that do not result in failure of the piping or components. The final barrier to the release of fission products is the traditional containment. Currently operating reactors in the United States all limit post-accident releases to the environment of fission products that escape the fuel and reactor coolant system by capturing them in a leak-tight containment.

All of the proposed NGNP designs make reference to coated fuel particles, which show promise of greatly reducing the release of fission products during normal operations, expected transients, and designbasis accidents. Predictions and testing to date point to this improved performance. Much of this work has been done in the international scientific community. United States manufacturers have not, as yet, demonstrated the desired fuel performance, and the NGNP requires somewhat more aggressive performance than achieved for the previously manufactured foreign fuel. The NGNP reactor design proponents have done some evaluation of post-accident consequences. The results of their analyses show that the proposed designs meet the current NRC Regulations for offsite dose consequences. These evaluations are limited because they do not have the benefit of demonstrated robust fuel testing and performance programs. The proponents' evaluations are based on important assumptions related to source terms, release fractions, deposition, plateout, wash out, etc. These have not yet been verified by tests or experiments. These are planned, but results will not be available for several years. Consequently, there are uncertainties in the fuel performance and source term to be used. As noted elsewhere in this report, there are some issues relating to the performance of reactor coolant system materials at higher temperatures that may hring the coolant system integrity into question. Thus, the final harrier to releases is the building containing the reactor and related systems.

With increasing temperatures, graphite will undergo some oxidation (corrosion) by air. The reaction rates are first controlled by the chemical kinetics, then by the diffusion velocities, and finally by only the mass transfer of air (the limiting factor). Thus, the amount of air entering the core region after a depressurization and core heatup accident has to be reduced to avoid unacceptable corrosion of core structures and coated particles, with the subsequent release of fission products. Consequently, large breaks of the pressure boundary that would allow the free access of air (especially chimney effects) must be excluded or shown to have acceptable consequences. Further work is needed to understand and evaluate the different types of breaks and core internal processes that result in the ingress of air. For example, can air-cooling be tolerated as the ultimate decay heat removal process if it is assumed that the pressure boundary might fail because of potential turbine machinery missiles? 
Because of the uncertainties in the performance of the fuel and the coolant system at potentially very high temperatures, there are concerns relating to the release of post-accident fission products to the environment. Also, the unlimited ingress of air causes concerns. Filtration and isolation are desirable to provide additional margin in the form of reduced accidental releases to the environment due to uncertainties in the overall design and performance of the plant, especially the ability to limit air ingress and of the fuel to limit fission product releases. As noted, fuel tests to obtain more details of performance are planned for the future but are not yet available. Consequently, the ITRG concludes that the NGNP design should include some form of confinement of the post-accident environment to provide margin for those uncertainties. An LWR type of high-pressure leak-tight containment does not appear to be needed.

We conclude that following an accident, fission products and other radioactive materials need to pass through a structure that provides reasonable cleanup of the post-accident environment (e.g., filters) and the ability to isolate the structure to prevent excessive air in-leakage. This constitutes what the ITRG considers confinement.

The configuration of future commercially deployed units should take advantage of successful completion of the fuel development program or other fuel options (such as a fuel licensing program described in the Fuel Development section of this report), reduction of the maximum operating temperatures of the reactor coolant system materials, international reactor and fuel testing experience, and demonstration plant performance to provide verification of expected fuel behavior. Successful results could allow relaxation of the above-described confinement requirements at a future date.

\subsection{Licensing Strategy}

In discussion with the NGNP concept proponents, it was not clear that there is a licensing strategy developed to ensure licensing and schedule success. Although there have been communications with the $\mathrm{NRC}$ over the years dealing with new or unique designs, those communications have not been aimed at nor have they delivered important regulatory decisions. The NGNP is targeted at being operable in the 2017-2020 time frame. Discussions with the regulatory staff may change in the near future as the staff migrates to other jobs in other areas of responsibility or leaves the agency. Much effort needs to be under way to ensure a smooth licensing process with minimal schedule impacts.

The staff will want to translate its current set of Light Water Reactor requirements into those for the NGNP. This set of requirements has served the public well. Thus, the NRC General Design Criteria, Standard Review Plans, NUREG Requirements, Unresolved Safety Issues (USIs), and Generic Safety Issues (GSIs) will need review for specific applicability. For example, NGNP designs will need to be evaluated for potential nearby earthquake activity. There are several USIs/GSIs relating to the potential impacts of hydrogen storage on site. Many LWR requirements are clearly applicable.

The NRC typically develops its own analytical tools to provide for independent verification of facility performance. These tools usually address station performance during transients and accidents, including some source term work. In addition, system and equipment reliability data are needed for any probabilistic risk analyses (PRAs) that are performed. The licensees/designers are expected to submit a site-specific PRA with their application for a license. These studies are required by the Regulations to be completed no later than two years following the issuance of a Construction Permit to achieve improvements in the plant without excessively impacting the plant. Such details are not currently

available for the helium-cooled reactor concepts or the molten-salt-cooled reactor concept. The ITRG was informed that the PBMR concept has progressed to the point where the designers were beginning their Preliminary Safety Analyses, so they appear to be closer to having sufficient detail to perform a PRA. 
In many cases, the concepts that are being considered for the NGNP are "expanding" the regulatory boundaries. The suite of operating conditions, expected transients, and design bases events are not well defined. These evaluations are necessary for the regulators' understanding of the plant, as well as to provide a basis for their ability to reach a conclusion that there is no undue risk to the public health and safety or the environment. As noted above, current LWRs all provide for a leak-tight, high-pressure containment design. Currently licensed reactors are based on a Technical Information Document 14844 source term that has been specified in the regulations. Recent regulatory advances in phenomena understanding have allowed for the use of alternate source terms for LWRs. The proponents are suggesting using source terms for the NGNP that are mechanistically determined; however, the specific designs, equipment performance, and scenario evolution are likely to be substantially different from those in LWRs. Commercial VHTRs may have as many as four reactors that could be operated from one control room with only two licensed senior operators and a licensed supervisor. The direct cycle concepts being looked at for the NGNP include the potential operation of two reactors connected to one turbinegenerator. Thus, a turbine trip event could result in the shutdown of two reactors, probably by a limited crew from one control room. The NRC staff has not had to evaluate these considerations before.

As noted, the designs have not progressed to the point where there are significant details available on the performance characteristics of components, equipment, systems, or structures. Thus, it will be difficult to evaluate a PRA that requires some level of knowledge of the designs. There are many components that will be required to perform in high-temperature environments previously not considered in nuclear reactors in the United States.

The NRC needs to decide how the integrated risks from multiple modules on the same site should be considered from a Price-Anderson insurance perspective or from a "combined risk" perspective.

The Code of Federal Regulations for Nuclear Reactors includes Section 10CFR50.34. This scction discusses the requirements for the technical content of applications for a Construction Permit and supporting documentation contained in a Preliminary Safety Analysis Report (PSAR) along with the requirements for an Operating License and supporting documentation contained in the Final Safety Analysis Report (FSAR). Although many of the specific requirements in this section are for LWRs (such as requirements for a high-pressure coolant injection system and an automatic depressurization system), others are applicable to non-LWRs. Control of radioactive materials released from the facility and necessary reactor instrumentation and control systems are examples of requirements that are applicable to non-LWRs.

There are two levels of detail of these requirements. Because final reactor and facility designs are typically not available early in the process, the request for a construction permit will be supported by a PSAR. In addition to requiring preliminary design information and an evaluation of the performance of important Structures, Systems, and Components (SSCs), the PSAR requires identification of those items that require research and development $(R \& D)$ to confirm the adequacy of the design or to resolve any safety questions. A schedule for the R\&D is necessary to demonstrate that completion of the R\&D is consistent with completion of the construction of the facility. For example, current development of the TRISO fuel requires such an R\&D plan to be developed.

When the construction of the facility is nearing completion, an application for an Operating License with supporting FSAR can be submitted to the NRC for review. The FSAR must provide detailed analyses that show how the safety functions of the SSCs will be accomplished. In addition, a description and evaluation of the results of the R\&D efforts must demonstrate that the safety questions identified at the construction permit stage have been resolved. Plans and procedures for facility operation, maintenance, surveillance, and periodic testing must also be provided. Details of the TRISO fuel performance, including release fractions, must be available to conduct final analyses of the performance 
of the plant and safety systems. High-temperature materials performance characteristics during normal operations, transients, and accident conditions must be understood and found acceptable.

Because there are so few design details available, and the schedule for them is still years away, it is unlikely that they will be available in time to support a 10CFR Part 52 process for one-step licensing. One-step licensing requires the availability of final design details comparable to those that are traditionally available at the time a Final Safety Analysis Report (FSAR) was filed to support the request for an operating license. The FSAR was typically filed about two years before the plant was ready to hegin operation, when construction had been underway for a number of years, and final plant details and analyses were available. This level of information is not likely to be on hand when needed to support the proposed NGNP schedule. Thus, the first or demonstration NGNP should be licensed under 10CFR Part 50. At the time of the FSAR, the owner could concurrently apply for licensing the NGNP as a Certified Design under Part 52, because the design detail would be available then. Subsequent units would then be able to take advantage of the certified design, utilize the One-Step Licensing approach, and thus shorten the licensing process and its exposure to litigation.

The above discussion indicates the need for an overall strategy for addressing the licensing efforts to support the schedule.

We recommend that a strategy be expeditiously developed with the assistance of power generating companies that are the potential owners of the commercial application of the NGNP and have extensive experience with the NRC Licensing Process. Such a strategy should involve early and frequent involvement with the NRC. The Commissioners and Senior Management of the NRC should be briefed so that they understand the need for the NGNP project to support the national interest for hydrogen generation, the continuation of nuclear power as an energy option, and the development of new, more efficient and safer nuclear power plants. The early interactions should include briefings of the NRC on important key technical issues and the documentation of decisions by the regulator that will carry on beyond the availability of the current reviewers. The staff has a current Topical Reports process. That process addresses individual technical issues and provides documented NRC conclusions relative to those items. However, for the process to be applied, the NRC requires that there is generic applicability and a current utility sponsor as an expected user. This process could be modified to get decisions on specific technical issues that are outside the scope of current regulations, such as the potential use of one control room to operate up to four units. Thus, the owner must develop and implement a regulatory strategy to ensure that the licensing functional requirements are met, and commercial viability is not jeopardized.

\subsection{Maintainability and Inspectability}

One of the reasons that the current fleet of LWRs has achieved operational success with capacity factors above $90 \%$ is that major components are regularly inspected, and maintenance programs include predictive and preventive maintenance along with corrective maintenance. The attention to the plant equipment ensures that problems will usually be found before they cause failures, and the structures, systems, and components will perform as designed and evaluated.

In addition to the above-described features of the NGNP, there are other differences between the existing light water reactors and the proposed designs. As described by the proponents, the NGNP designs will be more compact, thus accessibility to equipment would be reduced, thus affecting maintainability. The significantly higher operating temperatures make inspections more difficult and potentially more hazardous. The reactor vessel contains a shutdown-cooling module located below the active core and core support structure. Unique inspection techniques will have to be developed if the core and related support structure are not removed for inspection and maintenance. There are graphite core support columns below the active core that could be adversely affected by air intrusion or potential flow-induced erosion. These, 
along with the metallic core support plate and metallic core support structure, will need inspection. The reactor pressure vessel head and the absorber (control) rod "standpipes" have to be protected against hot coolant convections (e.g., thermal striping) after a loss of forced helium circulation.

The upper parts of the reactor head are insulated to prevent those materials from exceeding their temperature limits. Inspection is needed to ensure insulation performance continues. Special process tooling and procedures will have to be developed to ensure the equipment performs as expected and analyzed. The concentric duct/pipe that connects the reactor vessel to the power conversion unit (PCU) or the intermediate heat exchanger also presents some unique inspection challenges.

The use of the Power Conversion Unit with a single shaft device that includes the electric generator, turbocompressors, multiple intercoolers, multiple recuperators, related piping, valves, and instrumentation results in a smaller "footprint" for the design. That footprint comes with a potential cost. The equipment is contained in a single large vessel. In order to work on much of the equipment, the entire long single shaft component would have to be removed. Thus, the higher temperatures and the need to remove major components to do routine inspections and maintenance makes these functions much more difficult. Because they may be harder to do and may entail a reactor shutdown of some length to accomplish, the tendency may be to postpone needed inspections and maintenance, providing an adequate technical basis exists.

The ITRG recommends that careful and specific consideration be given in the design process to how inspections and maintenance will be performed. Support from those utilities currently operating successful programs should be sought.

\subsection{Other Issues}

There are other issues that could adversely affect the licensing of the NGNP. These issues may impact the schedule while the reviews proceed through the regulatory process. Some are discusscd in more detail above, while others (such as the power conversion unit and other major equipment design) are addressed in other sections of this report.

Water ingress could add positive reactivity to the reactor, which could have deleterious effects on plant performance and response to accidents. Air ingress that could cause corrosion of the graphite core support structure has been previously discussed. High reactor core outlet temperatures are being considered. This can preclude the use of current materials and result in the need for unique or very special materials, some of which may need to be developed or are not readily available.

\subsection{Summary of Safety and Licensing Issues}

From a safety and licensing perspective, there are a number of potential problems that are risks to the schedule for startup of the NGNP, may decrease its commercial viability or acceptance by the Regulator or the public, or may take an inordinate amount of time and effort to resolve the technical issues. They have been discussed elsewhere in this section and are summarized here:

- A filtered confinement that limits air in-leakage is needed

- An overall strategy for licensing needs to be developed and implemented that includes early and frequent decision-making interactions

- $\quad$ Licensing of the NGNP should be done in accordance with 10CFR Part 50 with subsequent units licensed under 10CFR Part 52 
- Access for inspection and maintenance needs to be specifically included when the equipment and structures are designed

- A reduction in the prescribed maximum core outlet temperatures from $1000^{\circ} \mathrm{C}$ to approximately $900-950^{\circ} \mathrm{C}$ is recommended to allow the use of more proven materials (as discussed elsewhere)

- Use of a single-shaft power conversion unit presents a number of potential operational and maintenance challenges that there may be no real need to undertake at this time

- Use of an indirect cycle with the requisite intermediate heat exchanger for power conversion is recommended.

The issues discussed in this report section along with their respective recommendations should reduce uncertainty, provide a definitive increase in safety, and make the design easier to license on the proposed schedule. 


\section{REFERENCES}

1. J. M. Ryskamp, E. A. Harvego, S. T. Khericha, G. A. Beitel, and E. J. Gorski, Next Generation Nuclear Plant-High-Level Functions and Requirements, INEEL/EXT-03-01163, Idaho National Engineering and Environmental Laboratory, 2003

2. A Technology Roadmap for Generation IV Nuclear Energy Systems, GIF-002-00, Generation IV International Forum (2002), available from http://gif.inel.gov/roadmap/.

3. M. A. Feltus, et al., Technical Program Plan for the Advanced Gas Reactor Fuel Development and Qualification Program, ORNL/TM-2002/262, April 2003.

4. D. A. Petti, et al., Key Differences in the Fabrication, Irradiation and Safety Testing of U.S. and German TRISO-coated Particle Fuel and Their Implications on Fuel Performance, INEEL/EXT-02-00300, Idaho National Engineering and Environmental Laboratory, June 2002.

5. D. A. Petti, et al., Preliminary AGR Fuel Specification, Idaho National Engineering and Environmental Laboratory, EDF-4198, Rev. 0, September 25, 2003.

6. D. A. Petti, "Next Generation Nuclear Plant (NGNP) Fuel Development Needs: An Overview of the US Advanced Gas Reactor Fuel Development and Qualification Program," Idaho National Engineering and Environmental Laboratory, presented to the Independent Technical Review Group, Boston, January 14, 2004.

7. Next Generation Nuclear Plant Materials Selection and Qualification Program Plan, INEEL/EXT-03-01 128, Idaho National Engineering and Environmental Laboratory, November 7, 2003, p. vii. 


\section{BIBLIOGRAPHY}

\section{General Nuclear Power}

A Technology Roadmap for Generation IV Nuclear Energy Systems, GIF-002-00, Generation IV International Forum, 2002, http://gif.inel.gov/roadmap/.

H. A. Grunder, et al., six-laboratory letter to Spencer Abraham, Secretary, U.S. Department of Energy, "Nuclear Energy: Power for the $21^{\text {st }}$ Century, An Action Plan," April 30, 2003, http://nuclear.inel.gov/papers-presentations/6-lab-exec-sum.pdf.

T. McConnell, L. Long, et al., "A Roadmap to Deploy New Nuclear Power Plants in the United States by 2010," prepared for the U.S. Department of Energy, 2001, http://www.ne.doe.gov/nerac/ntdroadmapvolume1.pdf.

P. Sharp, et al., "The Future of Nuclear Power: An Interdisciplinary MIT Study," Massachusetts Institute of Technology, 2003.

\section{Next Generation Nuclear Plant}

P. E. MacDonald, et al., NGNP Preliminary Point Design-Results of the Initial Neutronics and ThermalHydraulics Assessments During FY-03, INEEL/EXT-03-00870, Rev. 1, Idaho National Engineering and Environmental Laboratory, 2003.

Next Generation Nuclear Plant Materials Selection and Qualification Program Plan, INEEL/EXT-03-01128, Idaho National Engineering and Environmental Laboratory, November 2003.

J. M. Ryskamp, E. A. Harvego, S. T. Khericha, G. A. Beitel, and E. J. Gorski, Next Generation Nuclear Plant-High-Level Functions and Requirements, INEEL/EXT-03-01163, Idaho National Engineering and Environmental Laboratory, 2003.

F. H. Southworth, et al., "The Next Generation Nuclear Plant (NGNP) Project-Preliminary Assessment of Two Possible Designs," $14^{\text {th }}$ Pacific Basin Nuclear Conference, Honolulu, Hawaii, March 21-25, 2004.

\section{Gas-Cooled Reactor Systems}

“Generation IV Roadmap: R\&D Scope Report for Gas-Cooled Reactor Systems," GIF-004-00, Generation IV International Forum (2002), http://gif.inel.gov/roadmap/.

"Generation IV Roadmap: Description of Candidate Gas-Cooled Reactor Systems Report," GIF-016-00, Generation IV International Forum (2002), http://gif.inel.gov/roadmap/.

G. Baccaglini, et al., "Very High Temperature Reactor (VHTR) Survey of Materials Research and Development Needs to Support Early Deployment," INEEL/EXT-03-00141, Idaho National Engineering and Environmental Laboratory (2003).

H. L. Brey, "The Evolution and Future Development of High Temperature Gas Cooled Reactor," GENES4/ANP2003, Sep. 15-19, 2003, Kyoto, Japan, corresponding author, Larrybrey@aol.com. 
H. L. Brey, "Development History of the Gas Turbine Modular High Temperature Reactor," consultant to EPRI, Larrybrey@aul.com.

J. H. Horlock, Advanced Gas Turbine Cycles, Elsevier Science Ltd, 2003.

K. Moormann, et al., "Oxidation Behavior of an HTR Fuel Element Matrix Graphite in Oxygen Compared to a Standard Nuclear Graphite," Nuclear Engineering Design, 2004, in press, Elsevier, available at www.sciencedirect.com.

\section{Pebble Bed Reactor Systems}

S. Ion, et al., "Pebble Bed Modular Reactor, The First Generation IV Reactor To Be Constructed," WNA 2003 PBMR Paper, http://www.world-nuclear.org/sym/2003/matzie.htıı.

A. Koster, et al., "PBMR: A Generation IV High Temperature Gas Cooled Reactor."

\section{Prismatic Reactor Systems}

"Current Status and Future Development of Modular High Temperature Gas Cooled Reactor Technology," IAEA-TECDOC-1 198, International Atomic Energy Agency, Fehruary 2001, http://www.iaea.org/inis/aws/htgr/abstracts/abst_gcr_review.html.

"Design and Evaluation of Heat Utilization Systems for the High Temperature Engineering Test Reactor," IAEA-TECDOC-1236, International Atomic Energy $\Lambda$ gency, http://www.iaea.org/inis/aws/htgr/abstracts/abst_heat.html.

"Gas Turbine Modular Helium Reactor (GT-MHR) Conceptual Design Description Report," Revision 1, Report 910720, GA Project Nu. 7658, General Atomics, San Diego, CA, July 1996, http://www.iaea.org/inis/aws/htgr/abstracts/abst_heat.html.

D. A. Copinger, et al., Fort Saint Vrain Gas Cooled Reactor Operational Experience, NUREG/CR-6839, ORNL/TM-2003/223, Oak Ridge National Laboratory, January 2004.

T. Iyoku, et al., "Graphite Oxidation Analysis Under Depressurization Accident for HTTR," Fuji Electric Co. Ltd., Tokyo 100, Japan, presented at The $1^{\text {st }}$ JSME/ASME Joint International Conference on Nuclear Engineering, November 4-7, 1991, Tokyo, Japan.

K. Kunitomi, et al., "Design and Development of Gas Turbine High Temperature Reactor 300 (GTHTR300)," GENES4/ANP2003, Sept. 15-19, 2003, Kyoto, Japan, Paper 1059.

K. Kunitomi, et al., "Depressurization Accident Analysis for the HTTR by the TAC-NC," Fnergy, Vol. 16, No. 1/2, pp. 471-480, 1991, Pergamon Press, http://www.iaea.org/inis/aws/htgr/abstracts/abst_389_26_2.html.

M. Labar, et al., "Gas Turbine-Modular Helium Reactor,” Nuclear News, October 2003.

M. Shindo, ct al., "Safcty Charactcristics of the High Tempcrature Engineering Test Reactor," Nuclear Engineering and Design, 132, North-Holland, Elsevier Science Publishers, 1991, pp. 39-45. 
T. Takeda, et al., "Study on the Passive Safe Technology for the Prevention of Air Ingress during the Primary-Pipe Rupture Accident of HTGR," Nuclear Engineering and Design, 200, Elsevier, 2000, pp. 251-259.

X. Yan, et al., "Cost and Performance Design Approach for GTHTR300 Power Conversion System," Nuclear Engineering and Design, 226, 35-1373, Elsevier, 2003, www.sciencedirect.com.

\section{Molten-Salt-Cooled Reactor Systems}

“Generation IV Roadmap: R\&D Scope Report for Nonclassical Reactor Systems," GIF-006-00, Gencration IV International Forum (2002), available from http://gif.inel.gov/roadmap/.

"Generation IV Roadmap: Description of Candidate Nonclassical Reactor Systems Report," GIF-018-00, Generation IV International Forum (2002), available from http://gif.inel.gov/roadmap/.

R. B. Briggs, “Tritium in Molten-Salt Reactors," Oak Ridge National Laboratory, Reactor Technology, Vol. 14, No. 4, Winter 1971-1972.

C. W. Forsberg, et al., "Molten-Salt-Cooled Advanced High-Temperature Reactor for Production of Hydrogen and Electricity," Nuclear Technology, Vol. 144, Dec. 2003.

C. W. Forsberg, et al., "Making Core Melt Accidents Impossible in a Large 2400-MW(t) Reactor," Oak Ridge National Laboratory.

C. Forsberg, et al., "Molten-Salt-Cooled Advanced High Temperature Reactor for Production of Hydrogen and Electricity," Nuclear Technology, Vol. 144, Dec. 2003.

D. F. Williams, et al., "Radiolysis Studies in Support of the Remediation of the Molten Salt Reactor Experiment," Oak Ridge National Laboratory, presented at the American Nuclear Society 1999 Winter Meeting, November 14-18, 1999, Long Beach, California.

\section{Particle Fuel}

EDF-4198, Rev. 0, Preliminary AGR Fuel Specification, Idaho National Engineering and Environmental Laboratory, September 25, 2003.

M. A. Feltus, et al., Technical Program Plan for the Advanced Gas Reactor Fuel Development and Qualification Program, ORNL/TM-2002/262, Oak Ridge National Laboratory, April 2003.

D. A. Petti, et al., Key Differences in the Fabrication, Irradiation and Safety Testing of U.S. and German TRISO-coated Particle Fuel and Their Implications on Fuel Performance,

INEEL/EXT-02-00300, Idaho National Engineering and Environmental Laboratory, June 2002.

D. A. Petti, et al., Preliminary AGR Fuel Specification, Idaho National Engineering and Environmental Laboratory, EDF-4198, Rev. 0, September 25, 2003.

K. Sawa and K. Minato, "Prediction of Fucl Performance and Fission Gas Release Behavior during Normal Operation of the High Temperature Engineering Test Reactor by JAERI and FZJ Modeling Approach," Journal of Nuclear Science and Technology, Vol. 38, No. 6, 2001, pp. 411-419. 
K. Sawa et al., "An Investigation of Irradiation Performance of High Burnup HTGR Fuel," Journal of Nuclear Science and Technology, Vol. 36, No. 9, 1999, pp. 781-791.

K. Sawa, et al., "Development of a Coated Fuel Particle Failure Model under High Burnup Irradiation," Journal of Nuclear Science and Technology, Vol. 33, No. 9, September 1996, pp. 712-720.

K. Sawa, et al., Fabrication of the First-Loading Fuel of the High Temperature Engineering Test Reactor," Journal of Nuclear Science and Technology, Vol. 36, No. 8, August 1999, pp. 683-690.

S. Ueta, et al., "Fuel and Fission Gas Behavior during Rise-to-Power Test of the High Temperature Engineering Test Reactor (HTTR)," Journal of Nuclear Science and Technology, Vol. 40, No. 9, September 2003, pp. 679-686.

\section{Hydrogen Generation Systems}

"Generation IV Roadmap: Crosscutting Energy Products R\&D Scope Report," GIF-008-00, Generation IV International Forum (2002), available at http://gif.inel.gov/roadmap/.

S. Goldstein et al., General Comments about the Efficiency of the Iodine-Sulfur Cycle Coupled to a High Temperature Gas Cooled Reactor," CEA/DEN/DPC-CEN, France.

E. F. Sproat III, et al., "Demonstrating the Nuclear Hydrogen Roadmap with the Pebble Bed Modular Reactor."

T. Takeda, et al., "Permeability of hydrogen and deuterium of Hastelloy XR," Journal of Nuclear Materials, 326, (2004) pp. 47-58, Elsevier, Available at www.sciencedirect.com.

T. Takeda, et al., "Counter-Permeation of Deuterium and Hydrogen Through Inconel 600," Nuclear Technology, Vol. 146, April 2004.

\section{ITRG Meeting Minutes—Limited Access Documents}

Minutes for NGNP ITRG Meeting held in Washington, DC on December 16-18, 2003, Rev. 1, February 12, 2004.

Minutes for NGNP I'IRG Meeting held in Boston, MA on January 14-16, 2004, Rev. 1, February 13, 2004.

Minutes for NGNP ITRG Meeting held in San Diego, California on February 24-26, 2004, Rev. 2, March 25, 2004.

\section{Gas-Cooled Reactors-Limited Access Documents}

"Assessment of GT-MHR Spent Fuel Characteristics and Repository Performance," PC-000502, Revision 0, March 2002, Sponsored by the United States Department of Energy.

"Issues Relaled to the Design, Construction, and Operation of GEN IV Very-High Temperature Reactors," Idaho National Engineering and Environmental Laboratory, December 11, 2003.

"Prismatic-Core Modular Thermal Reactor," Briefing Paper, Idaho National Engineering and Environmental Laboratory, December 11, 2003. 
"Pebble-Bed Reactor," Briefing Paper, Idaho National Engineering and Environmental Laboratory, December 11, 2003.

T. Burchell, et al., “AGR Fuel Compact Development Plan, Rev 5," Oak Ridge National Laboratory, July 23, 2003.

L. Loflin, "EPRI NMAC Maintainability Review of the International Gas-Turbine Modular Helium Reactor Power Conversion Unit,” Electric Power Research Institute 1001231, February 2001.

P. E. MacDonald, et al., "The Next Generation Nuclear Plant - Insights Gained from the INEEL Point Design Studies," Proceedings of ICAPP-04, Pittsburgh, PA, USA, June 13-17, 2004, Paper 4305 (preconference copy).

E. Rodwell, et al., "Evaluation of Materials Issues in the PBMR and GT-MHR," Electric Power Research Institute 1007505, November 2002.

E. Rodwcll, "Graphite for High-Temperature Reactors," Electric Power Rescarch Institute 1003013, August 2001.

E. Rodwell, "Auxiliary Bearings in Vertically Oriented Machines on Magnetic Bearings," Electric Power Research Institute 1003177, November 2001.

L. Sandell, "High Temperature Gas-Cooled Reactor for the Production of Hydrogen, An Assessment in Support of the Hydrogen Economy," Electric Power Research Institute 1007802, March 2003.

\section{Molten-Salt-Cooled Reactors-Limited Access Documents}

“Advanced High-Temperature Reactor (AHTR)," Briefing Paper, Idaho National Engineering and Environmental Laboratory, December 11, 2003.

"Assessment of the Molten Salt-Cooled Advanced High Temperature Reactor (AHTR) in Comparison to the Very High Temperature Reactor (VHTR)," Argonne National Laboratory, Draft v1, July 29, 2003.

C. W. Forsberg, et al., "Maximizing Temperatures of Delivered Heat from the Advanced HighTemperature Reactor," ICAPP '04, Topical Area 2, Session 2.021, Paper 4151, 2004 American Nuclear Society Annual Meeting, Pittsburgh, Pennsylvania, June 13-17, 2004 (pre-conference final paper dated March 15, 2004).

P. F. Peterson, et al., "Initial cost estimate for the Advanced High Temperature Reactor," Draft, Rev. D, January 22, 2004.

H. Zhao, et al., "A Reference 2400 MW(t) Power Conversion System Point Design for Molten-SaltCooled Fission and Fusion Energy Systems," U.C. Berkeley, Report UCBTH-03-002, Draft Rev. B, January 10, 2004.

\section{Presentations-Limited Access Documents}

\section{Washington DC Meeting, December 16-18, 2003}

P. MacDonald, Idaho National Engineering and Environmental Laboratory, "High Temperature Gas Cooled Reactors - History and Evolution." 
J. Ryskamp, Idaho National Engineering and Environmental Laboratory, "A Technology Roadmap for Generation IV Nuclear Energy Systems."

F. Southworth, Idaho National Engineering and Environmental Laboratory, "NGNP Project."

J. Ryskamp, Idaho National Engineering and Environmental Laboratory, "NGNP High-Level Functions and Requirements"

P. E. MacDonald, et al., "The Next Generation Nuclear Plant - Insights Gained from the INEEL Point Design Studies," Proceedings of ICAPP-04, Pittsburgh, PA, USA, June 13-17, 2004, Paper 4305 (preconference copy).

E. Hoffman, T. Taiwo, H. Khalil, Argonne National Laboratory, "Comparative Assessment of Molten Salt and Helium Gas Coolant Options for the NGNP."

J. Ryskamp, Idaho National Engineering and Environmental Laboratory, "Hydrogen Production from Nuclear Energy."

Unitcd Statcs International Team/General Atomics, "Modular Helium Reactor Based NGNP Design"

R. Matzie, Westinghouse/PBMR Pty LTD, "Pebble Bed Modular Reactor (PBMR).”

C. W. Forsberg, et al., "Maximizing Temperatures of Delivered Heat from the Advanced HighTemperature Reactor," ICAPP '04, Topical Area 2, Session 2.021, Paper 4151, 2004 American Nuclear Society Annual Meeting, Pittsburgh, Pennsylvania, June 13-17, 2004 (pre-conference final paper dated March 15, 2004)

Framatome ANP, "The Framatome ANP Next Generation Nuclear Plant" with text "Framatome ANP Indirect-Cycle Very High Temperature Reactor."

\section{Boston, Massachusetts Meeting - January 14-16, 2004}

L. Parme, United States International Team/General Atomics, "Safety and Licensing."

L. Parme, United States International Team/General Atomics, "Gas Turbine-Modular Helium Reactor Safety Approach."

D. Petti, Idaho National Engineering and Environmental Laboratory, "Molten Salt Corrosion and Safety."

D. Petti, Idaho National Engineering and Environmental Laboratory, "Next Generation Nuclear Plant (NGNP) Fuel Development Needs: An Overview of the US Advanced Gas Reactor Fuel Development and Qualification Program."

G. Baccaglini, United States International Team/General Atomics, "Design and Development of the Vertical Brayton Cycle Turbine and Associated Equipment."

G. Baccaglini, United States International Team/General Atomics, "Turbogenerator Design Development and Maintenance for the NGNP Prismatic Reactor."

M. LaBar, United States International Team/General Atomics, "Overview of the GT-MHR Russian Program." 
S. Melancon, Entergy, "NEW BUILD ECONOMIC\$ What do the Numbers Say?"

\section{San Diego, California Meeting -- February 24-26, 2004}

K. Schultz, United States International Team/General Atomics, "Hydrogen Production Alternatives."

C. McNeill, "Commercial Considerations for the Selection of Technology for the NGNP."

R. Varrin, Dominion Engineering, Inc., "Considerations for Hydrogen Production, Overview of Licensing and Technical Issues."

M. Ogawa, Japan Atomic Energy Research Institute (JAERI), "Research and Development of Hydrogen Production System with HTTR."

P. Venter, Pebble Bed Modular Reactor and M. Umaya, Mitsubishi Heavy Industries, "PBMR Power Conversion Unit."

D. Matzner, Pebble Bed Modular Reactor, "PBMR Reactor Presentation."

S. Caspersson, E. Lahoda, Westinghouse Science and Technology Center, "Westinghouse Process for Hydrogen Production, Coupled to the PBMR."

D. Matzner, Pebble Bed Modular Reactor, "Advanced PBMR Capabilities."

K. Sawa, S. Kato, K. Nishimura, Japan Atomic Energy Research Institute, "Present Status of HTTR Fuel Development Status" and "HTR Fuel Fabrication in Nuclear Fuel Industries, Ltd."

C. Forsberg, Oak Ridge National Laboratory, “Alternative Heat Transport Systems for High-Temperature Heat."

C. Forsberg, Oak Ridge National Laboratory and P. Pickard, Sandia National Laboratory, "The Advanced High-Temperature Reactor."

C. Forsberg, Oak Ridge National Laboratory, "AHTR Summary of Written Replies to the ITRG and Decay Heat Removal."

A. Shenoy, General Atomics, "Fort St. Vrain Lessons Learned."

W. Von Lensa, H. Chi, “Former European HTR Concepts and Large Experimental Facilities.”

H. Chi, "THTR Operating Experience."

O. Baba, "Experience of JAERI in Constructing HTTR."

R. Ballinger, "Surmounting the $1000^{\circ} \mathrm{C}$ Barrier and Beyond."

\section{Backup Slides not Presented}

S. Caspersson, Westinghouse Electric Co., "PBMR Pebble (PBR) Concept Advantages."

L. Parme, United States International Team/General Atomics, "Radionuclide Containment in Modular Gas-Cooled Reactors." 


\section{Appendix A - Achieving a Reactor Outlet Temperature of $1000^{\circ} \mathrm{C}-$ An Approach for Further Developing the NGNP}

\section{A.1. INTRODUCTION}

Based on review of the NGNP program, the ITRG concludes that there are materials development risks at a reactor outlet temperature of $1000^{\circ} \mathrm{C}$ that make it impractical to achieve an operational date of 2020. In particular, the achievement of a gas outlet temperature of $1000^{\circ} \mathrm{C}$ places impractical requirements for materials development in the areas of the intermediate heat exchanger, hot pipe, turbine inlet components (e.g., first-stage blades, disk, and manifold), and some in-core metallic materials, depending on the particular concept.

The INEEL requested the ITRG to describe a possible approach for the NGNP to achieve a reactor outlet temperature of $1000^{\circ} \mathrm{C}$. Conceptually, as described further below, this could be achieved following successful demonstration of NGNP at metal temperatures of $900{ }^{\circ} \mathrm{C}$ or less. However, consistent with the observations and conclusions summarized earlier in this report, the ITRG considers that the need to achieve higher outlet temperatures in a gas-cooled reactor must be justified (e.g., on an economic basis) before embarking on the extensive research and development program requiring many years and extensive resources. Lacking this justification, the ITRG does not recommend attempting to achieve a gas outlet temperature of $1000{ }^{\circ} \mathrm{C}$ for the NGNP.

The bases for the ITRG's observations and recommendations elsewhere in this report include technical and programmatic concerns based on considerations of risk that are judged not resolvable on the planned schedule for NGNP. Key schedule items affecting technical risks were identified as those associated with

- $\quad$ High-temperature materials development

- Advanced pressure vessel steel qualification

- $\quad$ Codes \& standards

- The intermediate heat exchanger development.

Selection of the technology and design configuration for the NGNP must consider both the cost and risk profiles to ensure that the demonstration plant establishes a sound foundation for future commercial deployments. If the technology stretch is excessive, e.g., from a materials development standpoint, the NGNP may become solely an exercise in research and development, and fail to accomplish the high-level functions and requirements describing its broader mission. The NGNP challenge is to achieve a significant advancement in nuclear technology while at the same time setting the stage for deployment of the new technology in the commercial sector soon after 2020. Nevertheless, in the interest of seeking higher efficiency of electricity and hydrogen production, an approach is presented here for developing the NGNP to achieve an outlet temperature of $1000^{\circ} \mathrm{C}$ after its objectives have been met at $900{ }^{\circ} \mathrm{C}$.

For purposes of this discussion, the ITRG suggests the following practical success criteria:

1. The plant must work as advertised. That is, the plant must generate electricity reliably and safely and, at the same time, must be capable of supplying heat to a hydrogen generation process.

2. The plant must be commercially attractive for the industry. 
3. The plant must eventually be capable of $1000^{\circ} \mathrm{C}$ gas outlet temperature without wholesale replacement of Class I components. That is, there must be an uprate path that is financially and technically achievable within the existing plant envelope.

\section{A.2. A POSSIBLE APPROACH}

A possible approach with the highest probability of success as defined above will be to take a phased approach to the development process.

\section{A.2.1. Phase I: Initial Operation}

The NGNP would begin operation with a gas outlet temperature of $900^{\circ} \mathrm{C}$. With this gas outlet temperature, the initial plant could be built using existing materials for key limiting components, including the core barrel, hot gas duct liner, and high-pressure turbine materials. The intermediate heat exchanger, for an indirect cycle plant, and the hydrogen process interface heat exchanger for the direct cycle, could also be built with existing materials, although code qualification would be required. The Class I boundary material could be a 508/533 class material, and the pressure boundary would be cooled to keep the metal temperatures within ASME Code allowables while not requiring use of the hightemperature code cases. With this initial plant, there would be minimal code and standards qualification issues.

In the case of the indirect cycle, the IHX would be constructed in modular form, with the expectation that individual modules would be periodically replaced. It is recognized that the replacement period for IHX modules would probably be much less than the 60-year plant life. The design with the highest probability of success would be one in which the Class I boundary would include the "shell" of the heat exchanger and secondary gas exit piping up and including isolation valves. The primary/secondary tubing interface would be outside of the Class I boundary and designed in accordance with Section VIII of the ASME Code. The number of materials qualified for use in Section VIII is larger that those qualified for Section III, and the qualification process for new materials is less stringent. However, in any design at these temperatures, the allowable stresses for the IHX material will be extremely low-on the order of $10-15 \mathrm{MPa}$. Therefore, in the best of scenarios, it is likely that great care will be required to limit the stress in the material.

In the case of the direct cycle, as with the indirect cycle, the interface heat exchanger would be modular in design and replaceable. The Class I boundary would, again, consist of the heat exchanger shell and exit piping up to and including isolation valves.

The initial fuel form for the NGNP would be TRISO $\mathrm{UO}_{2}$ coated-particle fuel. The international experience base for this type of fuel is extensive. $\mathrm{UO}_{2}$-based fuel has the highest probability of being available on the NGNP time schedule. This type of fuel is currently being used for the HTTR in Japan and the HTR-10 in China, and will be the fuel of choice for the PBMR in South Africa. For anticipated maximum fuel temperatures up to and including those that would exist for a gas outlet temperature of $1000^{\circ} \mathrm{C}$, this fuel type can be expected to perform adequately as long as the discharge burnup is limited to the existing experience base. Use of $\mathrm{UO}_{2}$-based fuel for the initial plant will allow for a decoupling of the UCO base fuel development program from the NGNP construction schedule.

\section{A.2.2. Phase II: Plant Up-rate}

As a part of the development process, and in parallel with the initial construction, a materials development and qualification program would be initiated, the purpose of which would be to produce higher-temperature replacement materials for those components that, when changed out, would allow for 
an increase in gas outlet temperature to $1000^{\circ} \mathrm{C}$. In Phase II, these components would be replaced and the gas outlet temperature increased. The appropriate changes and/or development of new codes and standards will also have to take place, and the necessary changes to the operating license obtained.

\section{A.2.3. Intermediate Heat Exchanger}

The functions and requirements make use of some form of interface heat exchanger mandatory, either as the intermediate heat exchanger in an indirect-cycle plant or as the interface between the primary helium loop and the hydrogen production facility for both the indirect- and direct-cycle plants. The difference between the indirect- and direct-cycle plants, with regard to the IHX, is simply a matter of size.

\section{A.2.4. Direct Cycle Plant} materials:

For the direct cycle, the following components would be replaced with the following suggested

1. The hot duct liner would be replaced by carbon-fiber composite (CFC) materials.

2. The high-pressure turbine blades would be replaced with either ceramic or CFC materials.

3. The high-pressure turbine disks would also be replaced. It is likely that an integral blade/disk configuration would be needed for blade and disk replacement.

4. The in-core components that may have been metallic (depending on design) would be replaced with CFC materials.

5. The hydrogen-process heat exchanger material would be replaced with a higher-temperature material or possibly a new design heat exchanger altogether if one becomes available.

The up-rate to Phase II will require a step change in the technology required for some core components, for the high-pressure turbine, for the IHX and other heat exchangers seeing similar conditions. Based on discussions with the concept proponents and potential vendors, the ITRG judges that the material development time for this equipment would approach 15 years, with the carbon-carbon composite turbine blade/disk development effort being the limiting technology.

In the case of the turbine, blade cooling will not be an option as would be the case for an open cycle gas turbine operating with air as the gas. The thermal properties of helium result in thermal shock being an issue with metallic blade materials when cooled by helium. As a result of this, a transition to $\mathrm{CFC}$ materials will be required. The transition from metallic to CFC or other composite material will require a very large and time consuming development effort in the areas of fabrication and properties assurance for the turbine components. It is likely that the turbine blades and disk would be fabricated as a single unit. The team had discussions with MHI, the supplier of the PBMR system turbo-machinery, regarding the time that would be required for the development of CFC-based hot sections. They estimated that a 15-year development program would be required. In addition, there are currently no ASME Code standards for CFCs. Radiation damage data for these materials are also very incomplete, and the development of the required data will be a significant effort.

\section{A.2.5. Indirect Cycle}

In the case of the indirect cycle, it is highly unlikely that a metallic material will become available that will not require replacement of the IIIX at least once, and probably more than once, during the plant 
life, even for an operating temperature limited to $900^{\circ} \mathrm{C}$. At $1000^{\circ} \mathrm{C}$, it is not even clear that for the higher temperature a metallic material will become available on any reasonable time scale, or at all. Use of a metallic material for operating at $1000^{\circ} \mathrm{C}$ is more likely to be practically unachievable. Thus, the IHX will become the limiting component in the up-rate for the indirect cycle, as well as for the hydrogen interface in the direct cycle. This is discussed further below.

In the case of the fuel, as pointed out above, there is no fuel-related limitation to the increase in gas outlet temperature from $900{ }^{\circ} \mathrm{C}$ to $1000{ }^{\circ} \mathrm{C}$.

The increase in gas outlet temperature will call for an increase in the reactor inlet temperature. This will result in a potential increase in pressure vessel temperature to lcvels above the current code allowable. However, it is believed that, in the case of 508/533 steels, the ASME Code could be changed to allow for this temperature increase.

\section{A.2.6. Alternative Pressure Vessel Material}

The suggested path forward calls for use of 508/533 class steels for the irreplaceable pressure boundary. Use of 508/533 class materials will allow the program to stay within the existing radiation damage and other property database. This will eliminate the requirement for the qualification of a new material that would put the schedule at risk and greatly increase cost. Along with this choice of material goes the requirement that time dependent deformation not be allowed in the irreplaceable Class I boundary components. From a reactor pressure vessel standpoint, it is the ITRG's judgment that a $1000{ }^{\circ} \mathrm{C}$ gas outlet temperature can be achieved, albeit with some penalty in design flexibility without a change to a more advanced material for the pressure vessel. If changes to the ASME Code can be justified to allow for higher average metal temperatures, then much, if not all, of the reduction in flexibility will be recouped.

In spite of the valid arguments above, the ability to allow higher-pressure boundary temperatures does add flexibility. It is possible that the 9 Cr class of steels could be qualified in time for use in NGNP Phase I. Qualification of these materials would include an extensive development program in the areas of fabrication, welding, and inspection, as well as development of the necessary irradiation data. If this class of materials were to be available, then their use should be considered. However, this is a significant risk. As has been stated in the body of the report, even if these materials were to be available, time-dependent behavior should not be allowed.

\section{A.2.7. Heat Exchanger Issues: Implications for the Indirect Cycle at $1000^{\circ} \mathrm{C}$}

The IHX is the most critical component for the indirect cycle. As a practical matter, the requirement for an interface heat exchanger for the hydrogen plant makes the two cycles similar from a materials standpoint for this application. The implications for this cycle are discussed further below. While only a few materials are available for $900^{\circ} \mathrm{C}$ operation, there may be no metallic materials at all that could operate at $1000^{\circ} \mathrm{C}$ with any reasonable life expectancy in NGNP conditions. The most commonly identified materials, Incoloy 617 , Hastelloy X, and $\mathrm{HX}$, are not approved for $900{ }^{\circ} \mathrm{C}$ service, and their allowable stresses for $900^{\circ} \mathrm{C}$ service are extremely low. Thus, any heat exchanger design will require allowance for periodic replacement of the hot section core of the unit at $900{ }^{\circ} \mathrm{C}$ operation. The HTTR intermediate heat exchanger has a design life of 10 years for operation at $950{ }^{\circ} \mathrm{C}$. None of the above-mentioned materials are qualified for service at $1000^{\circ} \mathrm{C}$. At this temperature and above, the only metallic materials that may be suitable would be the oxide dispersion strengthened (ODS) or refractory materials. 
A considerable effort is underway at Oak Ridge National Laboratory and other places to develop this class of materials, and there are a number of commercially available ODS alloys, including Incoloy MA 956 and MA 958. These materials are solid solution alloys that are strengthened by the inclusion of a dispersion of fine yitria $\left(\mathrm{Y}_{2} \mathrm{O}_{3}\right)$ particles in the matrix. The addition of ODS-yitria results in a highly creep-resistant material that shows significant creep strength at temperatures approaching the incipient melting point of the matrix composition. However, there are significant fabrication and welding problems related to the use of ODS materials. Products fabricated using ODS materials have been limited to very simple shapes and limited in size. ODS materials are produced using powder processing and hot isostatic pressing (HIP) techniques as opposed to more conventional melting practice. A significant increase in size beyond current industrial practice would have to be achieved before these materials could be used for the NGNP. Lastly, and most critical for the use in the NGNP, are difficulties associated with joining of ODS materials. The welding process often results in the removal of the dispersion particles from the material. Welding thus destroys the ODS structure upon which its superior creep strength is based. Once again, work is under way at the national laboratories to develop suitable joining techniques. However, the qualification of these techniques, if that can be identified, will take considerable time and cost. Decreases in ductility at lower temperatures pose additional problems. The use of refractory materials would also require a significant increase in development cost and time. While refractory materials have been used for high temperature heat exchangers in the chemical industry, these applications have been for small components.

Based on the above discussion, it was not clear to the ITRG that a metallic nickel-base superalloy material will ever be practical for IHX service at $1000^{\circ} \mathrm{C}$. The only other metallic materials that exhibit the required high-temperature strength would then be the refractory alloys. However, the difficulties associated with production, fabrication, not to mention material availability, will probably make use of these materials impractical.

In the long term, developments in the area of ceramic ( $\mathrm{SiC}, \mathrm{SiC}-\mathrm{SiC}$ composites) and carbon-based (carbon-fiber composite) materials for heat exchanger applications show promise. There is a significant and growing use of $\mathrm{CFC}$ and $\mathrm{SiC}$-based composite for high-temperature and corrosion-resistant applications. CFCs have been, and are being, used in other industries including military and commercial aircraft and chemical. For these classes of materials, the $1000{ }^{\circ} \mathrm{C}$ operating temperature is well below the upper limits. These materials also have the advantage that they are, in many cases, highly corrosion resistant to environments that may be required for thermochemical water splitting. However, the problems associated with joining, achievement of gas tightness, mechanical properties, and other issues must be solved before they can be considered as viable candidates for large-scale NGNP applications where standards for use will be much more stringent.

The availability of materials for service at $900{ }^{\circ} \mathrm{C}$ may make the use of the indirect cycle at $900{ }^{\circ} \mathrm{C}$ a viable alternative. However, replacement of this component at least once, and probably several times during plant life is highly probable. However, given that the likelihood of the availability of a material for IHX service at $1000^{\circ} \mathrm{C}$ is very low on any reasonable time frame, one must question the viability of employing the indirect cycle at $1000^{\circ} \mathrm{C}$ for the NGNP now and in the near-to-medium future. Thus, from a materials standpoint, operation at $1000^{\circ} \mathrm{C}$ or higher favors the use of the direct cycle.

The potential unavailability of a heat exchanger for operation in the $1000{ }^{\circ} \mathrm{C}$ range also has implications for the hydrogen production application. Current NGNP requirements are for a 50-MW hydrogen production capability. 


\section{A.2.8. Is the $1000{ }^{\circ} \mathrm{C}$ Gas Outlet Temperature Needed?}

The need for a $1000{ }^{\circ} \mathrm{C}$ gas outlet temperature for efficient electricity production is questionable. Furthermore, it is also not clear that this temperature is needed for the demonstration of thermochemical water splitting process (SI or other) to produce hydrogen. The current SI-based processes can operate with a minimum temperature of $800^{\circ} \mathrm{C}$ with only slightly degraded efficiency. Improvements in the SI-based processes (e.g., the application of membrane technology to drive the high-temperature reactions to completion at lower temperatures) and/or the use of high-temperature electrolysis would allow for a significant reduction in the needed temperature of heat supplied for hydrogen generation. It is thus prudent to consider whether the development costs and time for increasing the gas outlet temperature are justified.

\section{A.3. CONCLUSIONS}

\section{A.3.1. Possible Approach}

The following approach could be considered.

1. The initial NGNP should use a gas outlet temperature consistent with maintaining maximum metal temperatures at or below $900^{\circ} \mathrm{C}$ but with the anticipation that temperature-limiting components be designed to be replaced. These components include
a. Hot duct liner
b. HP Turbine in structure
c. HP turbine blades and disks
d. The intermediate heat exchanger
e. Metallic core structural components where necessary.

2. The irreplaceable Class I boundary material should be 508/533 steel, and the temperature of this boundary should be limited in accordance with current ASME Code restrictions.

3. The necessary materials and fuel development work should be initiated to produce higher temperature capability for the temperature-limiting components. This development should be in parallel with, and not interfere with, the development work necessary to support initial operations of the NGNP at lower temperatures by 2020 . This could involve a change of materials from metallic to carbon-fiber composites for these components.

4. A focused effort should be implemented in the area of heat exchanger development.

5. Necessary ASME Code development should be conducted in parallel with materials development:
a. Increase in code allowable temperature for 508/533 steels
b. If advanced steels are available on a suitable time scale, with code qualification, they should be substituted for the $508 / 533$ stecl
c. CFC standards
d. Graphite standards
e. 60-year life. 
6. Upon completion of the necessary development, the affected components should be replaced and the gas outlet temperature can be increased to $1000^{\circ} \mathrm{C}$.

\section{A.3.2. Direct versus Indirect Cycle}

The implementation of the indirect cycle will require that a heat exchanger be developed for the transfer of heat. The same heat exchanger technology would be used as the interface between the nuclear system and the hydrogen production process. However, in the case of the NGNP, the hydrogen production process will require a smaller component (by approximately a factor of eight). For a gas outlet temperature of $900^{\circ} \mathrm{C}$, there is high probability that heat exchanger technology will be available in time for deployment. However, for the $100{ }^{\circ} \mathrm{C}$ gas outlet temperature, while there are technologies that are promising in the longer run, it is unlikely that technology will be available on a time scale consistent with the development process for other key components critical to the up-rate in temperature. For this reason the ITRG concludes the following, from a materials standpoint:

1. The use of either a direct or indirect cycle is a viable option for operation at $900{ }^{\circ} \mathrm{C}$.

2. The probability of developing heat exchanger technology for $1000^{\circ} \mathrm{C}$ operation on a reasonable time scale is highly improbable, and the use of a metallic material is probably impractical.

Given (2), the direct cycle may be the only viable cycle for the NGNP if a $1000{ }^{\circ} \mathrm{C}$ gas outlet temperature is ultimately required. This approach does not support hydrogen production by use of high temperature process energy from the NGNP.

The implications of the ahove conclusions are that the generation of hydrogen with a gas temperature of $1000^{\circ} \mathrm{C}$, requiring a heat exchanger to operate at this temperature, is a remote possibility. Thus, the requirement for hydrogen generation will preclude, in all likelihood, operating at $1000{ }^{\circ} \mathrm{C}$. In short, with operation at $900{ }^{\circ} \mathrm{C}$, both the direct and indirect cycles are viable options with the generation of hydrogen. If a reactor outlet temperature of $1000^{\circ} \mathrm{C}$ is required, then the direct cycle is the only option, and hydrogen generation will only be viable if the temperature in the heat exchanger can be limited to $900^{\circ} \mathrm{C}$.

\section{A.3.3. Further Consideration: PV Steel Material Choice}

There would be significant advantages to the longer-term development of the technology if advanced pressure vessel steels could be deployed in Phase I of the NGNP implementation. However, the ITRG judges the risk involved for the qualification of these materials for the schedule specified to be too great. Time-dependent deformation would still not be allowed for the design.

\section{A.3.4. Beyond the Initial NGNP Demonstration}

The possible development approach outlined above allows for future more significant increases in gas outlet temperature. As discussed, increases in outlet temperature above even $900{ }^{\circ} \mathrm{C}$ are not necessary for hydrogen production. Ilowever, increased outlet temperatures would improve the thermal efficiency and, by the nature of the Brayton cycle, reduce the size of a plant for a given power. Higher temperatures would allow an increase in power generated while maintaining pressure vessel size within the capability of manufacturing facilities. Aside from pressure vessel steel material considerations, which could be adequately addressed by design and qualification of more advanced materials, the materials development effort for the $1000^{\circ} \mathrm{C}$ up-rate will result in materials, CFCs in particular, and fabrication technology to enable their use, that are capable of much higher temperatures-in the $>1500{ }^{\circ} \mathrm{C}$ range. At this point, the fuel becomes the limiting technology. Current TRISO fuel technology limits the gas outlet temperatures to about $1200^{\circ} \mathrm{C}$. Advanced fuel development, ZrC-based as an example, could remove this restriction. If 
this were possible, then gas outlet temperatures exceeding $1200^{\circ} \mathrm{C}$ are feasible. If heat exchanger technology based also on ceramic composites becomes available, then higher process heat applications would be possible.

Consistent with the observations and conclusions summarized earlier in this report, the ITRG considers that the need to achieve higher outlet temperatures in a gas-cooled reactor must be justified (e.g., on an economic basis) before embarking on the extensive research and development program requiring many years and extensive resources. Lacking this justification, the ITRG does not recommend attempting to achieve a gas outlet temperature of $1000^{\circ} \mathrm{C}$ for the NGNP. 


\section{Distribution}

\section{TRANSMITTAL OF THE INDEPENDENT TECHNOLOGY REVIEW GROUP REPORT}

A copy of the report entitled "Design Features and Technology Uncertainties for the Next Generation Nuclear Plant," INEEL/EXT-04-01816, authored by the Independent Technology Review Group (ITRG), is attached for your use. Dr. John Ryskamp and I thank the ITRG members and advisors for your effort producing this report. The U.S. DOE has noted your recommendations and observations. We hope that the report will help guide a successful NGNP demonstration in the next decade.

The U.S. DOE has authorized the report to be released to the public via paper copy upon request. Anyone seeking a copy of the report may contact me (1-208-526-3288, pem@inel.gov) or Trevor Cook (1-301-903-7046, trevor.cook@hq.doe.gov). Once again, we greatly appreciate your hard work.

Sincerely,

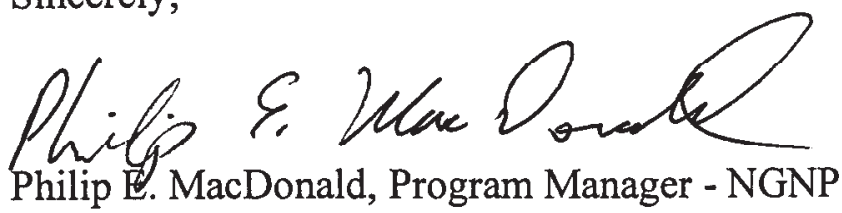

Advanced Nuclear Energy

Enclosure

Distribution

Mr. Osamu Baba, Oarai-JAERI

Prof. Ron Ballinger, MIT

Robert S. Brodsky, NPT, Inc.

Hans Chi, Consultatnt

Dennis Crutchfield, Consultant

Herb Estrada, Consultant

Jean-Claude Garnier, CEA/DEN/Cadarache

Gerald M. Gordon, Consultant

Jeff Hedges, Chevron Texaco

Phil Hildebrandt, EMT, Inc.

Richard R. Hobbins, Consultant

S, Kato, NFI

Dan Keuter, Entergy Nuclear

Marilyn C. Kray, Exelon

Dr. Werner von Lensa, ISRRT 
Distribution

August 30, 2004

CCN 51933

Page 2

Philippe Martin, CEA/DEN/Cadarache

Steve Melancon, Entergy Nuclear

K. Nishimura, NFI

M. Ogawa, JAERI

K. Sawa, JAERI

Christian Simon, Universite P\&M Curie

Henry Stone, Consultant

A. Tang, Chevron Texaco

M. Umaya, MHI Takasago Works

Dr. Robert D. Varrin, Dominion Engineering

cc: T. Cook, USDOE (10)

S. S. Crawford, INEEL, MS 3810 (w/o Enc.)

P. H. Divjak, INEEL, MS 3898

M. Feltus, USDOE

C. Fineman, DOE-ID, MS 1235

P. K. Kearns, INEEL, MS 3898

W. N. Sato, DOE-ID, MS 1203

R. Verslius, USDOE 